\title{
UNDERSTANDING THE DECLINE OF ACADEMIC INDICATORS FOR STUDENTS WITH DISABILITIES AT A RURAL MIDDLE SCHOOL
}

\author{
A Capstone Project \\ Presented to \\ The Faculty of the Curry School of Education \\ University of Virginia \\ In Partial Fulfillment \\ of the Requirements for the Degree \\ Doctor of Education \\ by \\ Bethany A.W. Hunter, B.S., M.Ed. \\ August 2017
}


(C) Copyright by

Bethany A.W. Hunter

All Rights Reserved

2017 


\section{EXECUTIVE SUMMARY}

Policymakers and advocates of Students With Disabilities (SWD) have worked together for decades to ensure SWD not only have access to public education, but also have equal opportunities within public education. These policies do not determine the specific criteria for a learning environment that serves SWD, only requiring students to be placed in the Least Restrictive Environment (LRE). Educational researchers have highly recommended collaborative instruction, where general educators and special educators work together in the classroom (Austin, 2001; Dahlberg \& Hoover, 2003; Magiera \& Zigmond, 2005). Given the high-stakes testing environment and the expectation that all students, including SWD, pass multiple curriculum tests in order to graduate, it is crucial that schools understand the impact of different instructional environments on SWD, giving them the greatest chance for success.

This study examines different models of delivery in serving SWD in a LRE and describes one rural school's approach to delivering instruction over a five-year period. Measures of student achievement, attendance, and discipline data from three groups of SWD were used to explore the impact of collaborative instruction. Additionally, 18 teachers responded to a survey reporting on the presence of criteria related to leadership, organizational structures, and professional development during the implementation of collaborative instruction. Six teachers responded to interview questions elaborating on the same criteria. 
Findings from this study showed the presence of two out of three criteria for optimal implementation of collaborative education. Survey respondents and interviewees reported supportive leadership and organizational structures were present to support collaborative instruction. Teachers also reported professional development supporting collaborative education was lacking. Despite the presence of supportive leadership and organizational structures, student achievement, measured by SOL pass rates in English, writing, and math, declined from 2011 to 2016. Attendance rates and discipline rates, however, did improve during this time.

Key findings resulted in the following recommendations for future implementation of collaborative instruction:

- Provide professional development opportunities targeted to teachers who have collaborative classrooms, including training specific to: the different models of collaborative instruction, classroom management for SWD, and collaborative consultation skills.

- Provide more feedback to collaborative instructors, especially general educators, to help them improve their instruction for SWD and their relationships with co-teaching partners.

- Provide teachers with the opportunity to volunteer to teach collaborative classes, rather than assigning collaboration without consulting the teacher.

- Provide extra time for collaborative teachers to plan together, either allowing them to have a common planning time, or reducing some of their other nonclassroom responsibilities (like after-school or lunch duties). 


\author{
Department of Leadership, Foundations, and Policy \\ Curry School of Education \\ University of Virginia \\ Charlottesville, Virginia
}

\begin{abstract}
APPROVAL OF THE CAPSTONE PROJECT
This capstone project, Understanding the Decline of Academic Indicators for Students With Disabilities at a Rural Middle School, has been approved by the Graduate Faculty of the Curry School of Education in partial fulfillment of the requirements for the degree of Doctor of Education.
\end{abstract}

Pamela D. Tucker, Ed.D.

Daniel W. Player, Ph.D.

Michael J. Kennedy, Ph.D. 


\section{DEDICATION}

I would like to dedicate this work to the many students who have passed through my classroom door, the students who are to come, and the teachers and administrators committed to their academic and personal success. 


\section{ACKOWLEDGEMENTS}

First, I would like to thank my parents, M. Reginald and Lucianne Warren, for always expecting me to achieve great things and setting a good example along the way. Thanks for not letting me give up.

I would also like to acknowledge and give thanks to my husband, Matthew Hunter, for supporting my educational goals and inspiring me to be a better student, teacher, mother, and wife.

Thank you, Janice Marston, for your friendship, mentorship, and much-needed encouragement throughout this process.

Many thanks to the group of ladies who supported and encouraged me through years of classes and writing: Dr. Mandy Hester, Wendy Fisher, Dr. Angela Thompson, Dr. Leslie Hackworth, Dr. Melissa Morgan, Terri Perkins, Dr. Tammy Donahue, and Ashley Houff.

Thanks especially to the professors of our cohort: Dr. Sara Dexter, Dr. Daniel Duke, Dr. James Esposito, Dr. Mark Hampton, and Dr. Michelle Young. I appreciate the added special education expertise from Dr. Michael Kennedy. I could not have completed this project without the patience, encouragement, and understanding of Dr. Pamela Tucker. Thank you for all your support. 
TABLE OF CONTENTS

DEDICATION

ACKNOWLEDGEMENTS ................................................................................ vii

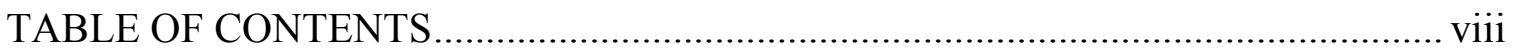

LIST OF TABLES

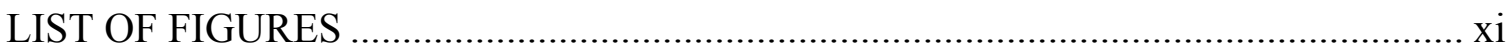

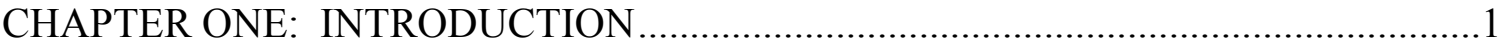

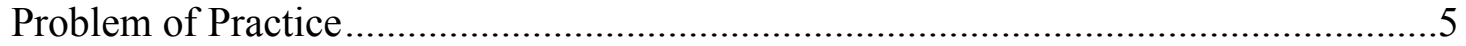

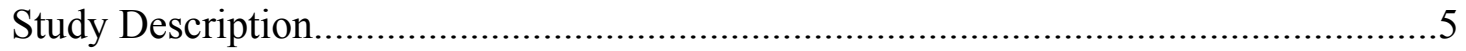

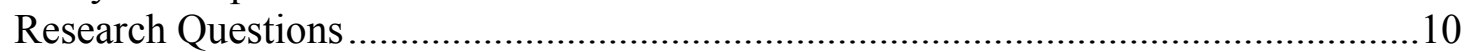

CHAPTER TWO: EDUCATING STUDENTS WITH DISABILITIES ........................11

Legal Context for Educating Students With Disabilities ..............................................11

Spectrum of Educational Settings for Students With Disabilities .................................15

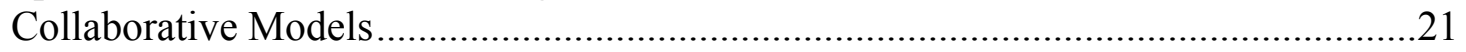

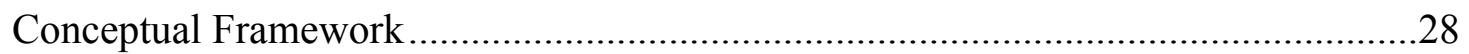

Conditions for Strong Collaborative Teams ...................................................29

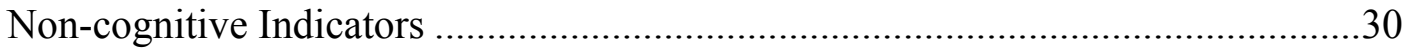

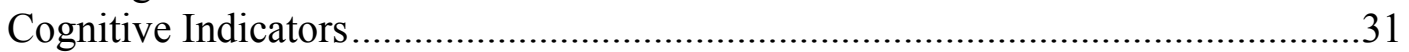

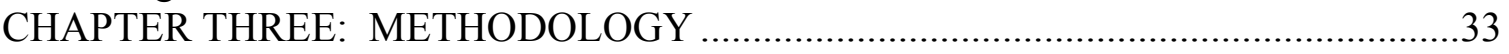

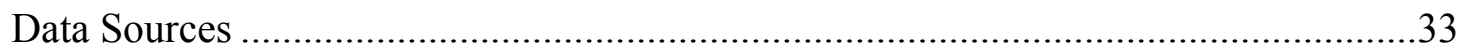

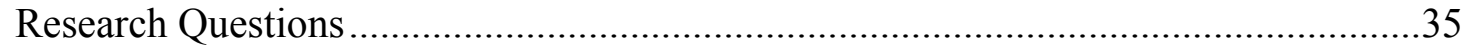

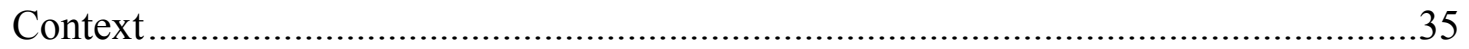

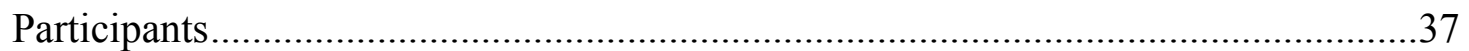

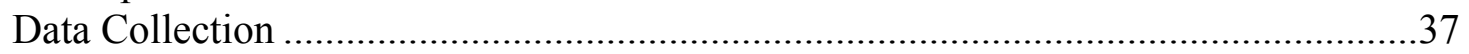

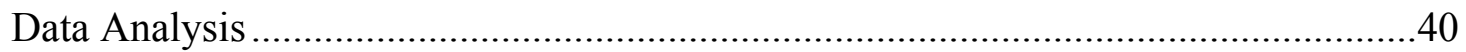

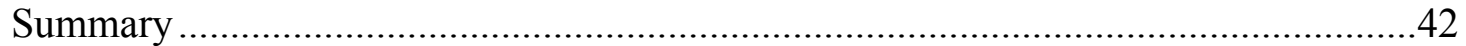

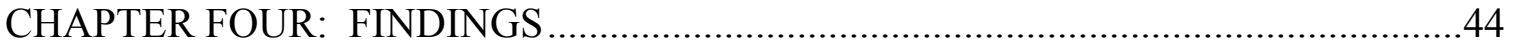

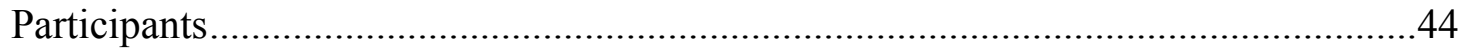

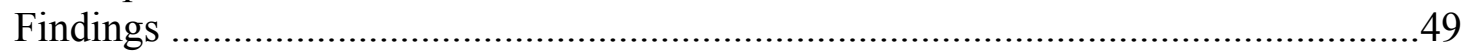

Research Question 1 ..................................................................................49

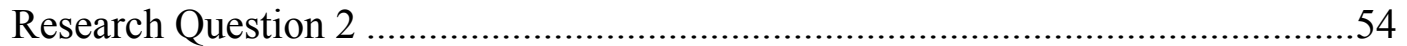

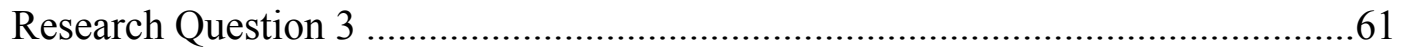

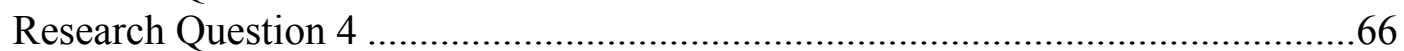

CHAPTER FIVE: DISCUSSION AND ACTION COMMUNICATIONS.......................70

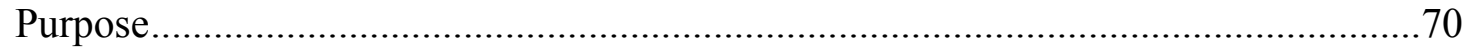

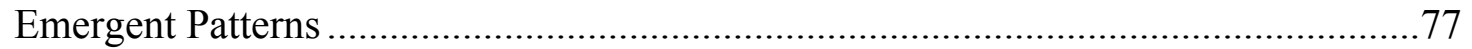

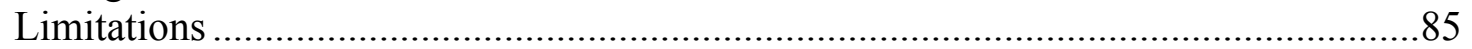




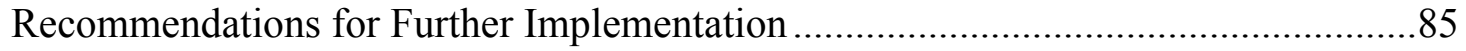

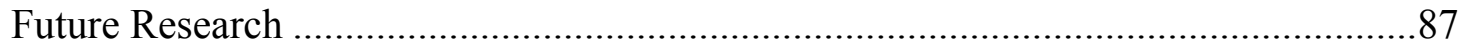

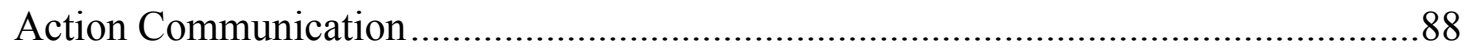

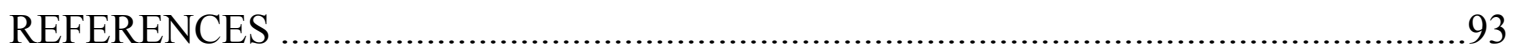

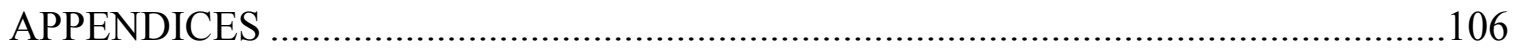

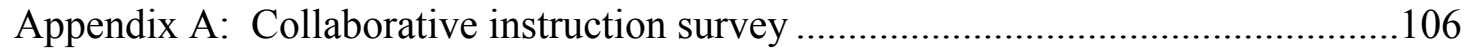

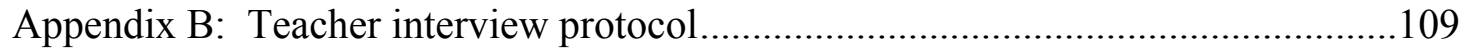

Appendix C: Initial e-mail to potential interviewees ..............................................112

Appendix D: Transcript of after-school faculty meeting address .............................113

Appendix E: Procedures for data collection .................................................... 114 


\section{LIST OF TABLES}

TABLE

Page

1. Pass rates for SWD at Central Middle School on VA SOL assessments .....................9

2. SOL pass rates and discipline data for Central Middle School .................................36

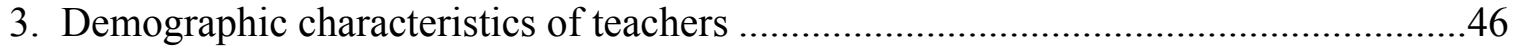

4. Teacher perceptions of leadership and administrative support...................................56

5. Teacher perceptions of organizational structures supporting collaborative

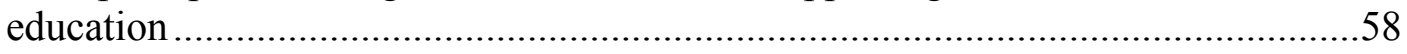

6. Teacher perceptions of professional development supporting collaborative

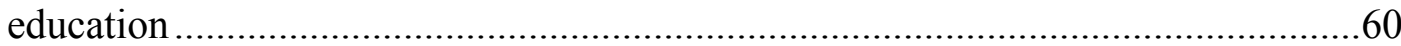




\section{LIST OF FIGURES}

FIGURE

Page

1. Classroom configuration for Full Content Collaboration (2011-2012) .........................7

2. Classroom configuration for Math/English Collaboration

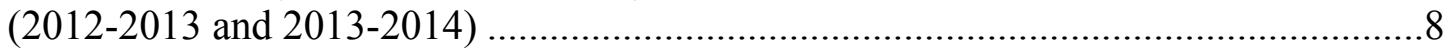

3. Conceptual framework for studying the instruction of Students With Disabilities ......30

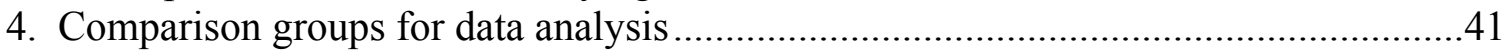

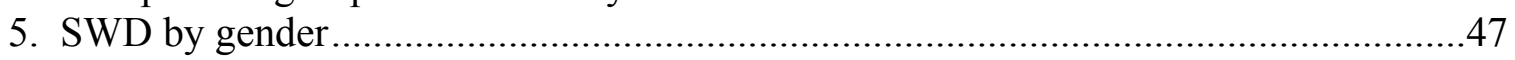

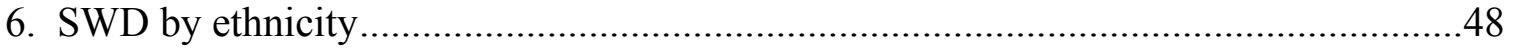

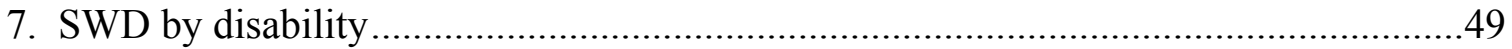

8. Cohort A English pass rates compared to overall pass rates ....................................62

9. Cohort B English pass rates compared to overall pass rates.....................................63

10. Cohort $\mathrm{C}$ English pass rates compared to overall pass rates....................................63

11. Writing pass rates for SWD compared to overall pass rates....................................64

12. Cohort A math pass rates compared to overall pass rates......................................65

13. Cohort $B$ math pass rates compared to overall pass rates ........................................65

14. Cohort $\mathrm{C}$ math pass rates compared to overall pass rates .......................................66

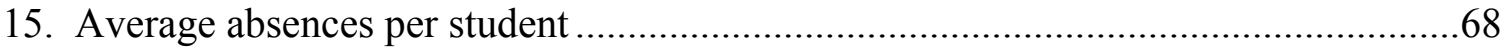

16. Total number of discipline offenses in each school year ........................................69 


\section{CHAPTER ONE: INTRODUCTION}

Students With Disabilities (SWD) are an identified portion of the student population who are served by public and private educational institutions throughout the United States. Although SWD face academic challenges that are different from general education students, all students have the right to an education that will prepare them to be successful members of society. SWD comprise a portion of the population that previously has gained access to educational services without meeting the same academic requirements as the general population. However, these students are an integral part of the community and economy. Legislation over the last forty years has ensured an education that is responsive to their needs, but there is a great deal of variation in how services are delivered without adequate research on the relative merits of these delivery models (Austin, 2001; Bauwens, Hourcade, \& Friend, 1989; Vaughn, Schumm \& Arguelles, 1997). The purpose of this study was to identify how the learning environment changed for SWD in one rural middle school from 2011 to 2016 and to identify patterns of student achievement as well as non-cognitive indicators during that time.

Since the passage of Public Law 94-142 (PL94-142), known as the Education for All Handicapped Children Act of 1975, children identified with various handicaps have been placed in special classrooms under the instruction of special education teachers. First enacted as law in 1990 and amended in 2004, the Individuals with Disabilities Education Improvement Act required the Least Restrictive Environment (LRE) be 
determined for special education students on an individual basis. Identification and placement of students may vary from state to state, but all states must comply with IDEIA in order to receive federal funds.

One consistent requirement placed upon school divisions by federal law is the provision of an Individualized Education Plan (IEP) for every student identified with a disability (VDOE, 2010). The IEP delineates the specific accommodations for each student and reinforces placement in the LRE (VDOE, 2010). In order to respond to the federal law and the individualized needs of SWD, school divisions adopted various models of instruction. Certain models quickly became remedies for the LRE placement, such as placement in a self-contained classroom with other students with similar disabilities.

Since 2002, the Elementary and Secondary Education Act, more commonly known as No Child Left Behind, required states to use standardized tests as a way to hold students and teachers accountable for academic standards. The most recent authorization of the Elementary and Secondary Education Act, the Every Student Succeeds Act (ESSA, 2015), reduces the burden of testing while holding all students accountable to high academic standards and maintaining annual reports for parents and students. The majority of the data in this study was collected before ESSA was signed. As a result of the high-stakes testing imposed by the previous version of ESEA, No Child Left Behind (2002), most SWD at Central Middle School were collectively moved into regular education classrooms so they would be better prepared for the format and rigor of the state tests. By eliminating the self-contained classroom, the division contracted the LRE continuum offered within the county. 
According to the Individuals with Disabilities Education Improvement Act Amendments of 2004 (IDEIA), federal law requires that Students With Disabilities (SWD) have access to the same quality education as their non-disabled peers (PL 105-17, IDEIA, U.S. Department of Education, 2004). In the United States, SWD make up about thirteen percent of students enrolled in public schools according to the Department of Education's National Center for Educational Statistics (USDOE, NCES, 2016).

Likewise, SWD enrollment in Virginia is just under thirteen percent (USDOE, 2016). According to school officials, SWD comprise about eleven percent of total student enrollment in Central Public Schools, and at Central Middle School, the percentage is less, around eight percent (B. Haught, personal communication, October 18, 2013).

Students With Disabilities make up a significant portion of students in the general education classroom, and their academic achievement is assessed in the same way according to the Virginia Department of Education (VDOE, 2010). In order for these students to be successful, schools must determine how to most effectively serve SWD in the LRE. With the signing of No Child Left Behind (NCLB) and reauthorization of the Elementary and Secondary Education Act (ESEA) in 2002, states began implementing accountability measures for the achievement of all students. To comply with NCLB, the Virginia Department of Education (VDOE) called for standardized testing to measure student achievement based on the Standards of Learning (SOL). The SOLs provide a basic framework of knowledge and skills students should master in order to make progress in school. VDOE provides standards for all required subjects and many elective subjects at every grade level in the Virginia public school system. Students take the Standards of Learning Tests for selected subjects beginning in third grade and ending in 
high school. While the Every Student Succeeds Act (ESSA, 2015) reduces the amount of testing required, students in Virginia continue to take seventeen SOL tests between third grade and eighth grade in addition to the tests they must complete in high school.

Students are required to pass six End-Of-Course (EOC) tests, including math, reading, and writing, in order to earn a standard diploma; students must pass nine EOC tests to earn an advanced diploma (VDOE, 2012).

In addition to individual student achievement, public schools in Virginia must show overall student progress on the SOL tests, as well as progress among each of the three Gap Groups: groups of students defined by ethnicity, disability, socioeconomic status, or native language. Gap Group 1 consists of Students with Disabilities, English Language Learners, and Economically Disadvantaged Students (unduplicated). Gap Group 2 are Black Students, and Gap Group 3 are Hispanic Students. Each gap group must achieve state-specified minimum gains on the SOL tests in order for the schools to meet accreditation standards. The scores for each gap group affect the overall pass rates as well as each school division's ability to meet Annual Measurable Objectives (AMO) set forth by the state. Pass rates of SWD directly impact the pass rates for Gap Group 1, and therefore, annual outcomes for the school and the division.

In further efforts to meet NCLB requirements, the division must provide SWD with an education in the Least Restrictive Environment (LRE), the educational placement where SWD can receive an education most like their non-disabled peers, to the extent their disabilities allow. In compliance with IDEIA (PL 105-17), schools have implemented special education instruction using a variety of delivery models, including self-contained instruction, collaborative instruction, and full inclusion instruction. 


\section{Problem of Practice}

The problem of practice addressed by this study was how to serve SWD most effectively in the LRE. The study explored how one school system delivered instruction for this population over a five-year period using collaborative models of instruction. SWD will face many of the same challenges when they leave school that students in the general education population will face. Until the achievement of SWD began to be measured by the same accountability standards, many were receiving an education unequal to that of their non-disabled peers (Thurlow \& Wiley, 2004). Because SWD are now held to the same standards as the general education population, schools are making serious efforts to provide SWD with an equally rigorous curriculum using instructional models that support the students' academic success.

\section{Study Description}

This study focused on student achievement and various non-cognitive indicators of SWD who received collaborative instruction at the middle level in one particular school division. The school division serves about 2,300 students in one primary school, one elementary school, one middle school, one high school, and one alternative education center. The middle school enrolls approximately 550 students in grades six through eight. The population includes general education students as well as students with lowincidence and moderate learning disabilities (e.g. math or reading disabilities, highfunctioning autism or Asperger's disease, emotional or behavior disorders, communication disorders, or other health impairments). Various instructional models have been implemented by the school administration and teachers to meet local, state, and national requirements for educating SWD. 
In the past decade, instruction for SWD has shifted from self-contained instruction to full inclusion to reflect changes in state and division policy as well as a reduction in resources provided for special education. At the state level, until 2010, most SWD were able to qualify for alternative assessments in lieu of the state standardized tests. In April 2010, the Virginia Superintendent of Public Instruction released a memo stating many of the alternative assessments would be "phased out" (VDOE, 2010). In anticipation of this change, the division leadership chose to eliminate alternative testing after 2010, except for students with more severe disabilities (e.g. severe Autism, blindness, deafness, intellectual disability). To better prepare students for state SOL tests, division leaders opted for most SWD to attend regular education classes instead of the previously self-contained classes where they received most of their instruction (B. Haught, personal communication, October 18, 2013).

Special education teachers were assigned to work with regular education teachers in a collaborative model to support SWD in the regular education classrooms. Central Middle School has implemented two iterations of collaborative instruction in recent years. Neither approach has been evaluated to determine fidelity of implementation or the impact on students' learning and behavior. The transition to inclusive education occurred over time. In the fall of 2009, SWD who had previously attended self-contained (SWD only) classes with a special educator, attended science and social studies classes with their non-disabled peers, where a special educator assisted students and teachers for thirty minutes of a sixty-minute class period. Students continued to receive math and English instruction with a special educator in a self-contained classroom consisting of only SWD. The following year, in the Fall of 2010, division leadership implemented the 
first collaborative instructional model considered in this study, Full Content Collaboration. In the Full Content Collaboration design, fifteen to twenty SWD in each grade level traveled to all four core classes (math, English, science, and social studies) as a cohort with the special educator assigned to that grade level. In this model, they joined five to ten general education students and a general educator as depicted in Figure 1.

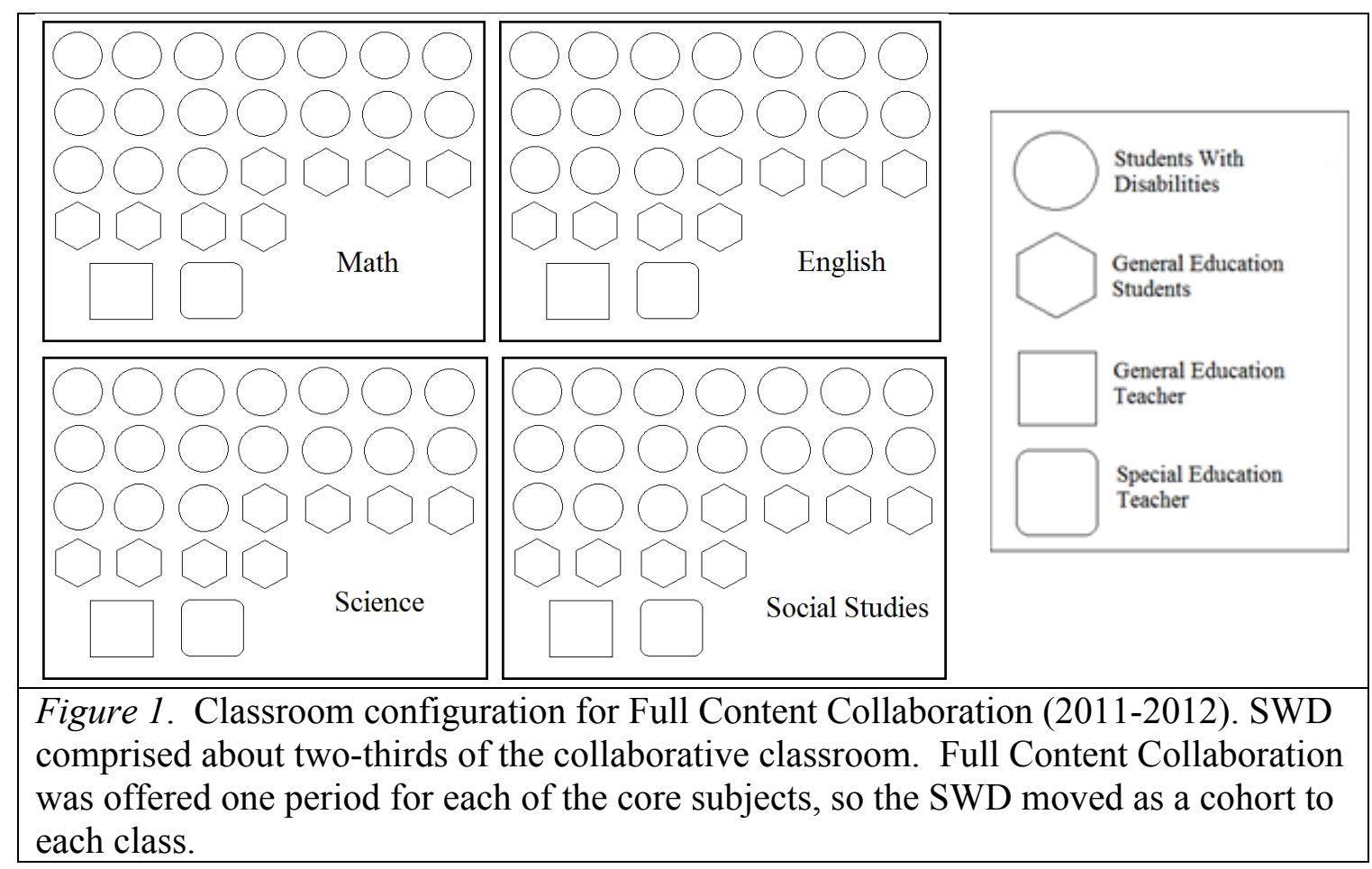

This model was implemented through the Spring of 2012, lasting two full school years. In the Fall of 2012, with teacher recommendations, the division leadership altered the collaborative instructional model to decrease the number of SWD in each classroom. The Math/English Collaboration design consisted of SWD having access to one of two collaborative math classes and one of two collaborative English classes. SWD were dispersed into science and social studies classes evenly where they did not have the support of a special educator in the classroom, but were provided classroom and testing 
accommodations according to each of their Individualized Education Plans (IEPs). See Figure 2 for a depiction of this model.

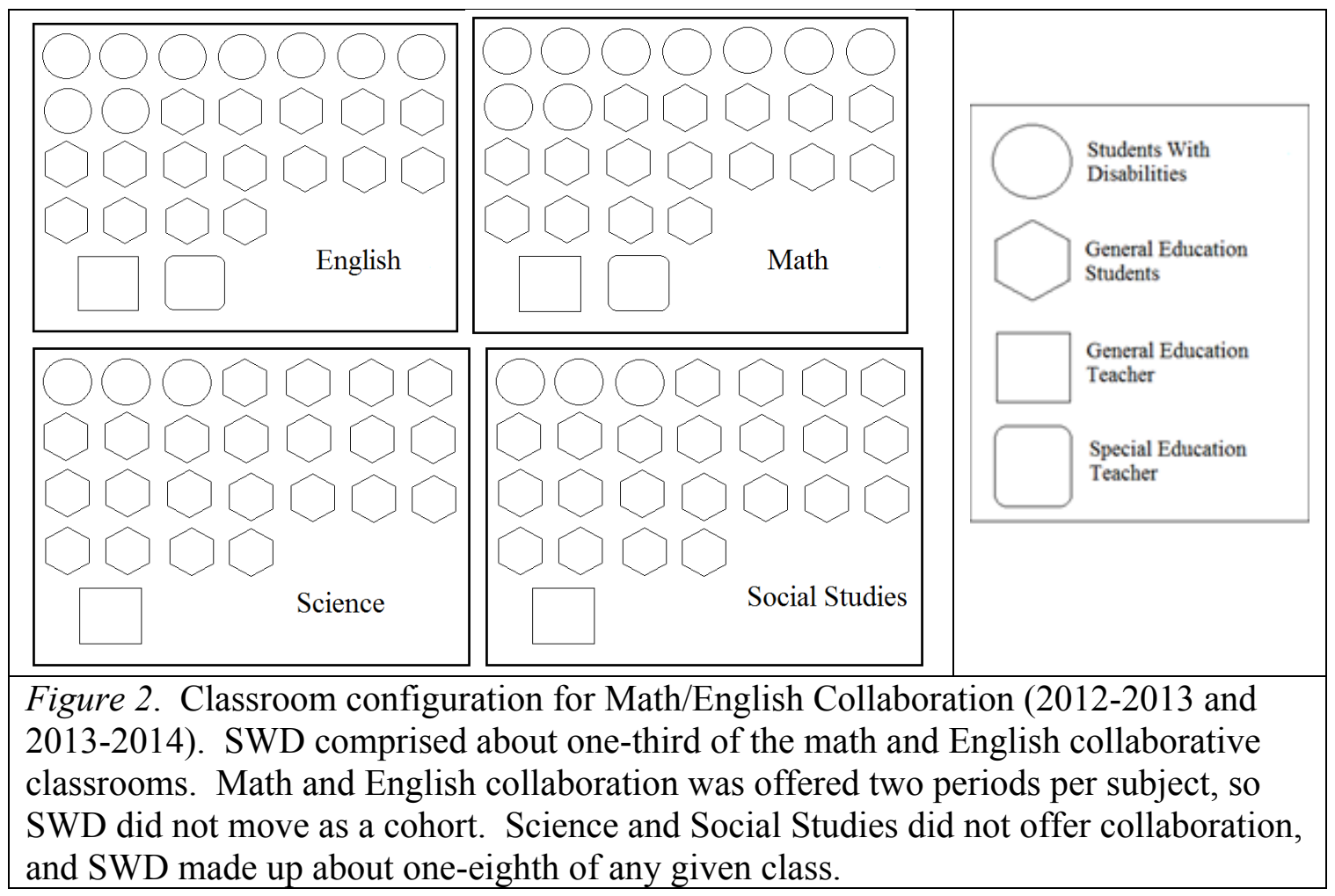

According to data from the Virginia Department of Education, the pass rates for SWD on the state tests have declined in math and English since the implementation of both collaborative models at Central Middle School as indicated in Table 1. Part of this study analyzed state SOL pass rates and student SOL scores from the most recent iteration of Math/English Collaboration to determine the changes in pass rates for math and/or English. Decreasing pass rates among SWD would place the school at risk of losing state accreditation, becoming a "turnaround" school, and making it subject to state sanctions. 
Table 1

Pass Rates for SWD at Central Middle School on VA SOL Assessments

\begin{tabular}{lcccccccc}
\hline Subject Area & 2009 & 2010 & 2011 & 2012 & 2013 & 2014 & 2015 & 2016 \\
\hline English & 80 & 79 & 44 & 40 & 39 & 37 & 32 & 52 \\
Math & $\mathrm{X}$ & 86 & 31 & 17 & 33 & 36 & 41 & 49 \\
Writing & $\mathrm{X}$ & $\mathrm{X}$ & 59 & 76 & 19 & 8 & 35 & 17 \\
History & 46 & 71 & 55 & 67 & 41 & 44 & 50 & 43 \\
Science & $\mathrm{X}$ & 53 & 80 & 88 & 25 & 23 & 33 & 31
\end{tabular}

Note. Writing and Science SOL tests are only administered at the end of the $8^{\text {th }}$ grade year. Tests are cumulative, including content from $6^{\text {th }}, 7^{\text {th }}$, and $8^{\text {th }}$ grade SOLs. Some early data are unavailable. (VDOE, 2016)

Student achievement on standardized tests is only one indicator of student success in school. Other outcome measures that are relevant for evaluating the impact of program delivery are attendance and general behavior. Researchers have reported the positive impact of high levels of student engagement on increased student achievement (Akey, 2006; Garcia-Reid, Reid, \& Peterson, 2005; Heller, Calderon, \& Medrich, 2003). Finn (1989) defined engagement in school based on levels of student attendance and participation as well as student behavior. This study identified characteristics of the collaborative instruction environment and patterns of cognitive and non-cognitive indicators among SWD at Central Middle School. In addition to student outcomes, data were gathered on teacher perceptions of the collaborative instruction environment and how changes in the environment may have affected students. 


\section{Research Questions}

This study collected and analyzed data to answer the following research questions:

1. How did the Collaborative Instruction environment change in the identified school from Fall 2011 to Spring 2016?

2. What were the teachers' perceptions of the Collaborative Instruction environment from 2011-2016?

3. What patterns of SWD achievement emerged from 2011-2016?

4. What patterns emerged among non-cognitive indicators for SWD from 2011-2016?

Student achievement data were collected from one source, the Central High School guidance department, where students in this study were enrolled. The researcher also collected data from teachers using interview and survey methodology to identify possible changes in the collaborative instruction environment. This study was intended to provide Central Public Schools, particularly the middle school, with a systematic review of the evidence on its implementation of two collaborative models in order to make more informed decisions about meeting the needs of the SWD, improving state test scores, and helping Central Middle School meet its Annual Measurable Objectives. 


\section{CHAPTER TWO: EDUCATING STUDENTS WITH DISABILITIES}

Equal educational opportunities for all students, regardless of race, ethnicity, or disability have been established through statute and case law. Legislators do not stipulate the type of educational setting for SWD, only that SWD must be offered instruction in the LRE. State departments of education and school divisions have created a spectrum of educational settings that meet the wide array of academic needs among SWD.

Collaborative instruction in the regular classroom, where general educators and special educators work together to meet the academic needs of SWD, is highly recommended by researchers (Austin, 2001; Dahlberg \& Hoover, 2003; Magiera \& Zigmond, 2005).

Although there are challenges to developing effective collaborative instruction, there are three major clusters of conditions for optimal implementation: supportive leadership, organizational structures, and professional development.

\section{Legal Context for Educating Students with Disabilities}

Since the 1970s, both policymakers and advocates of Students With Disabilities (SWD) have worked together to implement laws to ensure SWD not only have access to public education, but also receive the same educational opportunities as their nondisabled peers. Additionally, the United States Supreme Court has ruled repeatedly in favor of SWD, reinforcing existing laws that provide free and appropriate public education for all students, including SWD (Daniel R.R. v. State Board of Education, 1989; PARC v. Pennsylvania, 1972; Rafael Oberti v. Clementon School District, 1992; 
Roncker v. Walter, 1983; Sacramento Unified School District v. Rachel H., 1992).

Congress has reaffirmed that the education of SWD should take place in the Least Restrictive Environment (IDEIA, 2004).

Legislation defining educational opportunities. Until the 1970s, public schools were not required to enroll Students With Disabilities. In 1972, the Supreme Court ruled in favor of access to public education for all students in PARC vs. Pennsylvania, leading to the passage of the Education for All Handicapped Children Act (EHA) in 1975 (PL 94142). The EHA required all public schools that accepted federal funds to provide equal access for SWD. Since then, the law has been amended, and is now known as the Individuals with Disabilities Education Improvement Act (IDEIA) (PL 105-17), most recently reauthorized in 2004. The EHA granted all children access to public education, regardless of disability, while the IDEIA requires schools to provide individualized or special education for children with qualifying disabilities. According to IDEIA, each SWD must have an Individualized Education Program (IEP) listing the environmental and academic accommodations the student needs in order to be successful in the public school setting. The IDEIA also mandates that SWD are educated in the Least Restrictive Environment (LRE), the setting that is most like that of peers without disabilities as long as their academic goals can be met in that setting (USDOE, IDEIA, 2004). Since the implementation of EHA in 1975, schools across the country have adopted various policies, programs, and practices to meet the needs of SWD.

Court cases defining educational opportunities. Equal access to public education has a long legal history. Earlier antidiscrimination cases focused on classification of students by race, which then became the foundation for later cases 
regarding disabilities, gender, and language (Brown v. Board of Education, 1954;

McLaurin v. Oklahoma State Regents; 1950; Missouri ex rel. Gaines v. Canada, 1938). Even before Brown v. The Board of Education (1954), the United States Supreme Court heard cases regarding equity in public education. In Missouri ex rel. Gaines v. Canada (1938), although the Supreme Court held that not admitting a negro student to the state university was acceptable under the Fourteenth Amendment, the Court ruled that the state must separately offer the same opportunities to white and negro university students. Later, in McLaurin v. Oklahoma State Regents (1950), the Supreme Court ruled that the appellant, having been admitted to a state supported graduate school, must receive the same treatment at the hands of the state as students of other races.

The groundwork on equal access established in higher education was then used to address inequities in K-12 education. In a case argued in December 1952, the Supreme Court decided racial segregation in the public schools in the District of Columbia was a denial of due process of law guaranteed to all by the Fifth Amendment (Bolling $v$. Sharpe, 1954). The decision of Bolling v. Sharpe (1954) was not handed down until May 1954, and cited Brown v. The Board of Education (1954), claiming if "separate but equal" was not constitutional for the states, it was not constitutional for the federal government. Because the Bolling v. Sharpe (1954) case involved education in the District of Columbia, it was subject to the "equal protection" provision under the Fifth Amendment that applies to the federal government.

Earlier in 1954, the United States Supreme Court handed down the landmark decision in Brown v. The Board of Education. In this case, the Court declared state laws establishing separate public schools for black and white students were unconstitutional. 
The Court's decision stated that "separate educational facilities are inherently unequal" (Brown v. Board of Education, 1954). This ruling paved the way for SWD who were not receiving equal access to public education.

Nearly two decades later, in PARC v. Pennsylvania (1972), the Court ruled that because the state offers free education to students without disabilities, the state cannot deny students with mental retardation the same right. This decision influenced the passage of the Education for All Handicapped Children Act of 1975, guaranteeing a free and appropriate education for all SWD in the United States. After SWD entered the public schools, the court ruled on the issue of inclusive placement for SWD in Roncker $v$. Walter (1983), stipulating placement decisions for SWD should be made on an individual basis. The Court ruled that if the services that make a segregated program can be effectively delivered in an integrated setting, inclusive placement is favorable to selfcontained placement (Roncker v. Walter, 1983). The decision in Daniel R. R. v. State Board of Education (1989) took inclusive placement one step further, ruling that students must be included in the classroom to the full extent possible. The next year, Congress passed the Individuals with Disabilities Education Act (IDEA, 1990) and defined the Least Restrictive Environment (LRE) standard for SWD.

In 1992, cases involving SWD continued to define the meaning of LRE. The court ruled in favor of Rachel in Sacramento Unified School District v. Rachel H. (1992), concluding a full-time placement in regular education classrooms was more appropriate for Rachel than half-time placement in regular education and half-time placement in special education. The court arrived at its decision by developing a four-part test which determined the costs and benefits of including SWD in the general education classroom. 
The court examined the following criteria: (a) the educational benefits available to the student in the regular education classroom compared to the benefits available in the special education classroom; (b) the non-academic benefits of interacting with nondisabled peers; (c) the effect of the student's presence on the teacher and the other students in the general education classroom; and (d) the cost of including the student in a regular classroom. The same year, the court ruled "inclusion is a right, not a special privilege for a select few" in Rafael Oberti v. Clementon School District (1992). Given this strong support by the courts for inclusion of SWD subject to the four-point test outlined in Sacramento Unified School District v. Rachel H. (1992), states and school districts have shifted to more inclusive placements for SWD.

\section{Spectrum of Educational Settings for Students With Disabilities}

IDEIA requires SWD receive their education in the LRE, considering the severity of their disability (PL 105-17, IDEIA, U.S. Department of Education, 2004). Educational settings for SWD range from residential schools, which are the most restrictive, to full inclusion classes with no accommodations, which are the least restrictive (VDOE, 2011). Included on the spectrum are self-contained classes, inclusion with accommodations, and collaborative classes, which are the three educational settings that are available to SWD at Central Middle School (B. Haught, personal communication, October 18, 2013).

Self-contained instruction. Self-contained classrooms are commonly defined as smaller settings in which fewer SWD meet with a licensed special education teacher for their content instruction instead of receiving instruction in the general education classroom. Self-contained classrooms can supplement or replace general education instruction. In the mid-1900s, students in self-contained classrooms spent the entire day 
with the special education teacher, having little interaction with their non-disabled peers (Kauffman \& Hallahan, 1995). In the 1970s, the self-contained classroom evolved into the resource room, where students would spend most instructional hours of the day with the special educator and other parts of the day, recess, lunch, and elective classes, with their non-disabled peers in general education classrooms. The National Report to Congress (USDOE, 2007) stated that approximately $23 \%$ of students received most of their education in self-contained classrooms. Researchers report numerous benefits of self-contained instruction for both teachers and students that are discussed below.

According to Landrum, Tankersley, and Kauffman (2003), the self-contained setting provides the opportunity for the special education teacher to work more closely with fewer students than in a regular education classroom, allowing for more individualized instruction and fulfillment of the accommodations required in each student's Individualized Education Plan (IEP). Fuchs, Fuchs, and Fernstrom (1993) add that the general education setting may be unable to accommodate the diverse needs of SWD. In a position statement about the diversity of instructional groups, Kauffman, Landrum, Mock, Sayeski, and Sayeski (2005) argue homogenous grouping provides the best approach for educating heterogeneous student populations. Fuchs and Fuchs (1995) also maintain the self-contained environment may hold greater benefits for some SWD. Benefits depend on the type and severity of the disability, but special education teachers utilize a variety of instructional strategies, materials, grouping patterns, and systems of evaluation to meet the needs of individual students, rather than a "one-size-fits-all" approach that is more common in general education classrooms (Fuchs \& Fuchs, 1995). 
Self-contained classrooms not only benefit SWD, but also match the training of special education teachers.

Self-contained education is considered more suitable for special education teachers because of the nature of their training. According to Mock and Kauffman (2002), special educators are trained to work specifically with students who have certain disabilities, and special education training provides pre-service teachers with the strategies they will need to work with those students. To require a special educator to work with a diverse group of students, such as those found in the general education classroom, is expecting them to be a "jack of all trades" when they are really only prepared to master a specific subset of students (Mock \& Kauffman, p. 289).

Inclusion. Kilanowski-Press, Foote, and Rinaldo (2010) define inclusive education as bringing services and support to the student in the general education classroom, as opposed to removing students from learning experiences with their same age peers. Friend and Cook (2000) add that inclusion is "the educational application of the social belief that all individuals bring value to a situation and that no individuals should be excluded because they have disabilities" (p. 18). Inclusive education became more common after the signing of IDEA in 1990 and the requirement for students to be educated in the LRE.

Browder, Wakeman, and Flowers (2006) contend that access to general education for all students is critical for the academic progress of SWD. Not only do SWD benefit from inclusive education, some researchers have found academic and social benefits for general education students in an inclusive setting (Cole, Waldron, \& Majd, 2004; Fisher, Pumpian, \& Sax, 1998; Peterson \& Hittie, 2003). Cole, Waldron, and Majd (2004) found 
that students without disabilities who were educated in inclusive settings made significantly greater academic progress in math and reading compared to their nondisabled peers in traditional settings. Fisher, Pumpian, and Sax (1998) surveyed high school students and found those exposed to inclusive education also have more positive attitudes about SWD than the students in schools where self-contained is the predominant setting for SWD.

Furthermore, researchers have found substantial evidence that SWD sustain more academic benefits from inclusive education than their disabled peers in self-contained settings (Baker, Wang, \& Walberg, 1995; Freeman \& Alkin, 2000; Peterson \& Hittie, 2003; Waldron \& McLeskey, 1998). Baker, Wang, and Walberg (1995) completed a synthesis of meta-analyses on the most effective setting for SWD. The effect sizes generated from the study show a "small-to-moderate beneficial effect of inclusive education on the academic and social outcomes of special-needs children" (Baker, Wang, \& Walberg, 1995, p. 33). Freeman and Alkin (2000) also completed a synthesis of studies comparing academic and social gains of mentally retarded (MR) students and their non-disabled (ND) peers in integrated and segregated settings. Overall, the studies confirmed "higher academic gains are shown when children with mental retardation are more fully integrated into the general education classroom" (Freeman \& Alkin, 2000, p. 14). According to a study by Waldron and McLeskey (1998), students with Learning Disabilities (LD) who were educated in an inclusive setting made significantly more progress on a curriculum-based reading assessment than did the students who were educated in a non-inclusive setting. Although there is some disagreement among 
researchers, both SWD and their non-disabled peers have been found to benefit academically from inclusive education.

In addition to the academic gains in inclusive settings found for students with and without disabilities, many researchers focus on the social and developmental benefits of inclusion. In a two-year study of SWD in inclusive and self-contained classrooms, Fisher and Meyer (2002) found students in inclusive settings made statistically significant gains on measures of development and scored higher on measures of social competence than did their peers in self-contained classrooms. Researchers discovered students with severe disabilities in general education settings had greater social contact with their peers without disabilities, higher frequency of receiving and offering social support, and a larger network of friends (Fryxell \& Kennedy, 1995; Hunt, Alwell, Farron-Davis, \& Goetz, 1996; Hunt, Staub, Alwell, \& Goetz, 1994; Kennedy, Shulka, \& Fryxell, 1997). Inclusion also has positive attitudinal effects on non-disabled students. General education students who have access to inclusive classes have more positive attitudes about their classmates with disabilities than students in schools where only self-contained education is offered (Fisher, Pumpian, \& Sax, 1998).

Collaborative instruction. Collaboration has become a popular form of instruction for SWD because it combines the special education support from the selfcontained classroom with the academic and social benefits of the general education classroom in the LRE, required by IDEA. Friend and Cook (2002) define collaboration as "a style for direct interactions between at least two coequal parties voluntarily engaged in shared decision making as they work toward a common goal" (p. 6). Bauwens and Hourcade (1997), citing a previous study of their own, add to the definition by saying 
"two (or more) educators possessing distinct sets of skills work in a coordinated fashion to teach academically heterogeneous groups of students together in the general classroom" (Bauwens \& Hourcade, 1995, p. 81). Collaborative instruction may look different from one classroom to the next based on the specific model used, but the goal is for general educators and special educators to work together to accommodate the social and instructional needs of all students in a classroom with SWD and general education students.

Collaborative instruction provides the benefits of small student-teacher ratios, special educator expertise, and accommodations for SWD found in the self-contained classroom combined with the social interactions and general educator expertise of the inclusive classroom. Magiera and Zigmond (2005) claim the reduction of the studentteacher ratio that occurs because of the presence of two teachers allows the teachers to give one another professional support. Additionally, Dahlberg and Hoover (2003) found the presence of two teachers also decreases the number of disruptions in the classroom. The lower student-teacher ratio also has been found to have a positive impact on student achievement. In an observational study comparing SWD in co-taught classes with those in solo-taught classes, Magiera and Zigmond (2005) found SWD receive significantly more one-to-one instructional interactions in co-taught classes than in solo-taught classes. Austin (2001) cites a growing body of literature that supports collaborative instruction for improving affective and academic outcomes of disabled and non-disabled students (Boudah, Schumacher, \& Deschler, 1997; Dynak, Whitten, \& Dynak, 1997; King-Sears, 1995; Miller \& Savage, 1995; Minke, Bear, Deemer, \& Griffin, 1996; Pugach \& Seidl, 1995; Villa, Thousand, \& Chapple, 1996; Walther-Thomas, Bryant, \& Land, 1996). 


\section{Collaborative Models}

Recommended practices. Researchers suggest various models for successful implementation of collaborative instruction. Austin (2001) divides collaborative instruction into three approaches: the consultant model, the coaching model, and the teaming model. The teaming model has been most fully explored. Bauwens, Hourcade, and Friend (1989) suggest a combination of team teaching, supportive learning activities, and complementary instruction. More specifically, Vaughn, Schumm, and Arguelles (1997) describe five models for collaboration: "one teach, one assist," station teaching, parallel teaching, alternative teaching, and team teaching (co-teaching). In the research, two models of collaborative instruction are emphasized: consultative teaching and coteaching.

Consultative teaching. "Consultant," or "consultative," teaching includes services such as one-to-one instruction with students, small group instruction, and coteaching of academic material on an episodic basis (Scruggs, Mastropieri, \& McDuffie, 2007). In this model, the special educator does not consistently spend time in the general education classroom or work with general education students. The consultative model also features instructional support provided to general education teachers seeking guidance in their instruction to SWD (indirect support), while also allowing special educators to provide instruction to special education students within the general education classroom via one-to-one or small group formats providing direct support (Shulte, Osborne, \& Kauffman, 1993).

Co-teaching. "Co-teaching" can be defined as "two or more professionals delivering substantive instruction to a diverse, or blended, group of students in a single 
physical space" (Cook \& Friend, 1995, p. 1). Common among definitions of co-teaching is the "expectation that general and special education teachers work collaboratively within the general education setting to teach student with disabilities and those at risk for academic difficulty" (Bauwens, Hourcade, \& Friend, 1989; as cited in Solis, Vaughn, Swanson, \& McCulley, 2012, p. 499). According to some researchers (Friend \& Cook, 2004; Pugach \& Seidl, 1995), the equitable distribution of tasks and responsibilities is more efficient than the consultative approach. When teachers share the responsibilities of lesson planning, contacting parents, disciplining students, and instructing classes, students have the benefit of two teachers in the classroom, two perspectives from which to gain information, and two sets of eyes to monitor student behavior and engagement. Additionally, each teacher bears less weight for any one task because both are involved in preparation and instruction.

Implementation challenges. Teaching a classroom full of students of various learning strengths is challenging enough, and adding another teacher takes careful planning and coordination. While researchers highly recommend co-teaching as an instructional model for teaching SWD, some challenges must be faced in order to make this collaborative model successful for all students as well as teachers. Some of the greatest challenges addressed in the literature are special educator training, general educator training, and institutional constraints.

Training for special educators. Kennedy and Ihle (2012) discuss the uncertainty of the role of the special education teacher in the general education classroom. Most special educators are trained in individualized instruction, not whole class instruction (Deshler \& Shumaker, 2006). While special educators are well-prepared to serve the 
needs of SWD (Pressley \& Harris, 2006), they may not have learned the skills necessary to serve a more heterogeneous population of students (Brownell, Sindelar, Kiely, \& Danielson, 2010; Scruggs, Mastriopieri, \& McDuffie, 2007). During preservice coursework, special educators typically learn how to provide explicit instruction to students with disabilities in small groups (Brownell, Bishop, Gersten, Klingner, Penfield, Dimino, et al., 2009; Brownell et al., 2010). Collaborative instruction removes the special educator from the self-contained classroom and places them in the general education setting which requires a different skillset and training that needs to be provided to in-service teachers.

Training for general educators. Miller and Savage (1995) found when general education teachers are provided training and supportive services from a collaborative consultant, their attitudes, skills, and willingness to participate in collaborative interactions can be positively influenced. The success of collaborative instruction depends, in part, upon the preparedness of the general educators (Friend \& Cook, 2010). Specifically, general educators express a need for training in: flexible thinking (Buckley, 2005; as cited by Scruggs, Mastropieri, \& McDuffie, 2007); strategies and practical skill development (Curtin, 1998; as cited by Scruggs, Mastropieri, \& McDuffie, 2007); different co-teaching models (Feldman, 1998; as cited by Scruggs, Mastropieri, \& McDuffie, 2007); use of technology (Luckner, 1999; as cited by Scruggs, Mastropieri, \& McDuffie, 2007); characteristics of disabilities (Norris, 1997; as cited by Scruggs, Mastropieri, \& McDuffie, 2007); collaborative consultation skills (Rice \& Zigmond, 2000; as cited by Scruggs, Mastropieri, \& McDuffie, 2007); group interpersonal skills (Rosa, 1996; as cited by Scruggs, Mastropieri, \& McDuffie, 2007); and effective 
communication skills (Walther-Thomas, 1997; as cited by Scruggs, Mastropieri, \& McDuffie, 2007). Although research supports the importance of general educator training for successful collaboration, little evidence exists to indicate this training is occurring.

Institutional constraints. Even if special educators and general educators receive training to help them successfully implement collaborative instruction, other factors in the organization can hinder their success. "Policy changes and the organization of contemporary secondary schools often marginalize traditional practices mastered by special educators” (Brownell et al., 2010; Scruggs et al., 2007, as cited by Kennedy \& Ihle, 2012, p. 44). The lecture-style instruction of the secondary classroom discounts the special educator's expertise in small group instruction and learning skills. Kennedy and Ihle (2012) also cite other researchers who claim this large-group, whole-class instructional configuration can be problematic for special educators, specifically trained to work with small groups of students in a secluded setting, to meet the instructional needs of SWD (Edmonds, Vaughn, Wexler, Reutebuch, Cable, Tacket, et al., 2009; Faggella-Luby \& Deshler, 2008; Zigmond, 2003).

Criteria for optimal implementation. Researchers who support collaborative instruction as a model for teaching SWD in the general education classroom, advocate for three sets of conditions that lead to successful collaborative teams: supportive leadership, organizational structures (including classroom structure), and professional development.

Supportive leadership. School and division leaders must be supportive of collaborative education. Austin (2001) developed the Perceptions of Co-Teaching Survey and administered the survey to general education and special education teachers. 
Some responders participated in a semi-structured interview after completing the survey. Austin (2001) concluded a significant number of special educators and general educators place high importance on the value of administrative support, although administrative support is not specifically defined in this study. Carpenter and Dyal (2001) maintain collaborative instruction is most effective when principals establish models of effective co-teaching and recognize the need for manageable class sizes. Cook and Friend (1993) add that administrators must recognize the importance of shared planning time and provide it for co-teachers.

Cancio, Albrecht, and Johns (2013) created a survey delineating characteristics associated with administrative support for teachers. These characteristics fall under four categories: guidance and feedback, opportunity for growth, appreciation, and trust (Cancio, Albrecht, \& Johns, 2013). In the study, the mean ratings of the extent to which administrators supported teachers had a significant impact on teachers' intent to stay in the field of special education.

According to a report from the Donahue Institute at the University of Massachusetts (2004), researchers identified eleven practices that supported success with students in special education, most of which are wholly or mostly influenced by the building leader:

- emphasis on curriculum alignment with curriculum frameworks;

- effective systems to support curriculum alignment;

- emphasis on inclusion and access to the curriculum;

- culture and practices that support high standards and student achievement;

- a well-disciplined academic and social environment; 
- use of student assessment data to inform decision-making;

- unified practice supported by targeted professional development;

- access to resources to support key initiatives;

- effective staff recruitment, retention and deployment;

- flexible leaders and staff who work effectively in a dynamic environment; and

- effective leadership.

These criteria suggest building leaders who exemplify best practices for general educational leadership will also support successful collaborative instruction programs. Austin (2001) also reports on other organizational factors that impact successful implementation of collaborative instruction.

Organizational structures. Many teachers maintain the necessity for educators to volunteer to co-teach together (Thompson, 2001; Carlson, 1996; as cited by Scruggs, Mastropieri, \& McDuffie, 2007). Scruggs, Matropieri, and McDuffie (2007) cite earlier research from Vesay (2004) which found teachers' collaboration to have a positive effect on students' academic success and classroom behavior when they volunteered to work with each other. Once teachers volunteer to participate in a co-teaching relationship, there are school and classroom practices that contribute to success.

Cook and Friend (1995) suggest specific practices and topics for discussion to encourage a successful co-teaching relationship among general and special educators. Before beginning a co-teaching relationship, teachers should discuss their instructional beliefs, confidentiality, classroom routines, discipline, and pet peeves (Cook \& Friend, 1995). If co-teachers do not agree on the right and ability of all students to learn, their 
instructional practices will be very different, and co-teaching will be difficult (Cook \& Friend, 1995). Additionally, when co-teachers have a better understanding of each other's expectations in the classroom, the students will experience a more consistent learning environment (Cook \& Friend, 1995). Lastly, teachers must demonstrate equal responsibility for instruction (Cook \& Friend, 1995). Overall, there is a need for mutual understanding and commitment between general and special educators in a successful collaborative environment.

To build a strong collaborative team takes dedicated time. Austin (2001) found a substantial number of teachers place high value on scheduled planning time, but few have access to it. Researchers, Pugach and Johnson (1995) and Cook and Friend (1995), suggest regularly scheduled and frequent planning time is essential to the success of collaborative instruction (Cook \& Friend, 1995; Dieker, 2001, as cited in Scruggs, Mastropieri, \& McDuffie, 2007; Hazlett, 2001, as cited in Scruggs, Mastropieri, \& McDuffie, 2007; Murawski, 2009). This time also should be used for reviewing progress, discussing problems, and developing different instructional strategies (Cook \& Friend, 1995; Pugach \& Johnson, 1995). Co-planning also allows co-teachers time to give each other feedback on content and delivery (Cook \& Friend, 1995). Murawski and Lochner (2011) suggest collaboration and shared responsibility in lesson planning, instructional delivery, and student discipline increase the likelihood of a successful collaborative relationship. A lack of co-planning time may leave the general educator burdened with all the instructional responsibilities while the special educator becomes a less integral part of instruction (Cook \& Friend, 1995). 
Professional development. Special educators and general educators ranked "inservice training" as very important on the Perceptions of Co-Teaching Survey (Austin, 2001). Teachers who are trained to use evidence-based instructional practices are more likely to continue using those practices if they observe the frequent and positive impact of these practices on their students' learning and behavior (Klinger, Arguelles, Hughes, \& Vaughn, 2001). Additionally, research recommends teachers should choose their own evidence-based strategies and implement them in a systematic way (Lytle \& CochranSmith, 1992).

Both general educators and special educators require opportunities to prepare for collaborative teaching (Cook \& Friend, 1995). Scruggs, Mastropieri, and McDuffie (2007) cited studies in which general education teachers express specific needs for training in order to work with SWD (Buckley, 2005; Curtin, 1998; Feldman, 1998; Luckner, 1999; Norris, 1997; Rice \& Zigmond, 2000; Rosa, 1996; Walther-Thomas, 1997). Training should focus on communication skills, instructional strategies, and collaborative planning. Separately, special educators may need development in the content knowledge of the class, while general educators may need additional training on working with SWD (Cook \& Friend, 1995). Forcing teachers into a co-teaching relationship without providing appropriate training and support will, most likely, result in an ineffective collaborative relationship (Rosa, 1996; cited in Scruggs, Mastropieri, \& McDuffie, 2007).

\section{Conceptual Framework}

Researchers support the implementation of collaborative instruction as a form of inclusive education because of the academic and behavioral benefits to SWD and their 
non-disabled peers (Dahlberg \& Hoover, 2003; Magiera \& Zigmond, 2005). This study analyzed implementation of practices necessary for strong collaborative teams.

Additionally, the study analyzed the impact of two models of collaborative instruction on student engagement and student achievement. As depicted in Figure 3, if the conditions for strong collaborative teams were in place, students were more likely to be highly engaged in instruction, which presumably led to higher rates of student achievement (Brusca-Vega, Brown, \& Yasutake, 2011; Fontana, 2005).

\section{Conditions for Strong Collaborative Teams}

Strong collaborative teams have three overarching sets of characteristics in common: supportive leadership, organizational structures, and professional development. Strong collaborative teams have the support of a building leader who emphasizes inclusion and access to the curriculum, establishes models of effective co-teaching, creates manageable class sizes, schedules co-planning time for collaborative partners, and allows teachers the opportunity to choose to be collaborative educators (Cancio, Albrecht, \& Johns, 2013; UMASS Donahue Institute, 2004). Organizational structures that support strong collaborative teams include co-teachers who are compatible and effectively use available co-planning time (Redditt, 1991, cited in Cook \& Friend, 1995). Strong collaborative teams are supported with professional development opportunities that hone knowledge and skills for working with SWD, communication skills, and effective use of collaborative planning time (Austin, 2001; Scruggs, Mastropieri, \& McDuffie, 2007). 


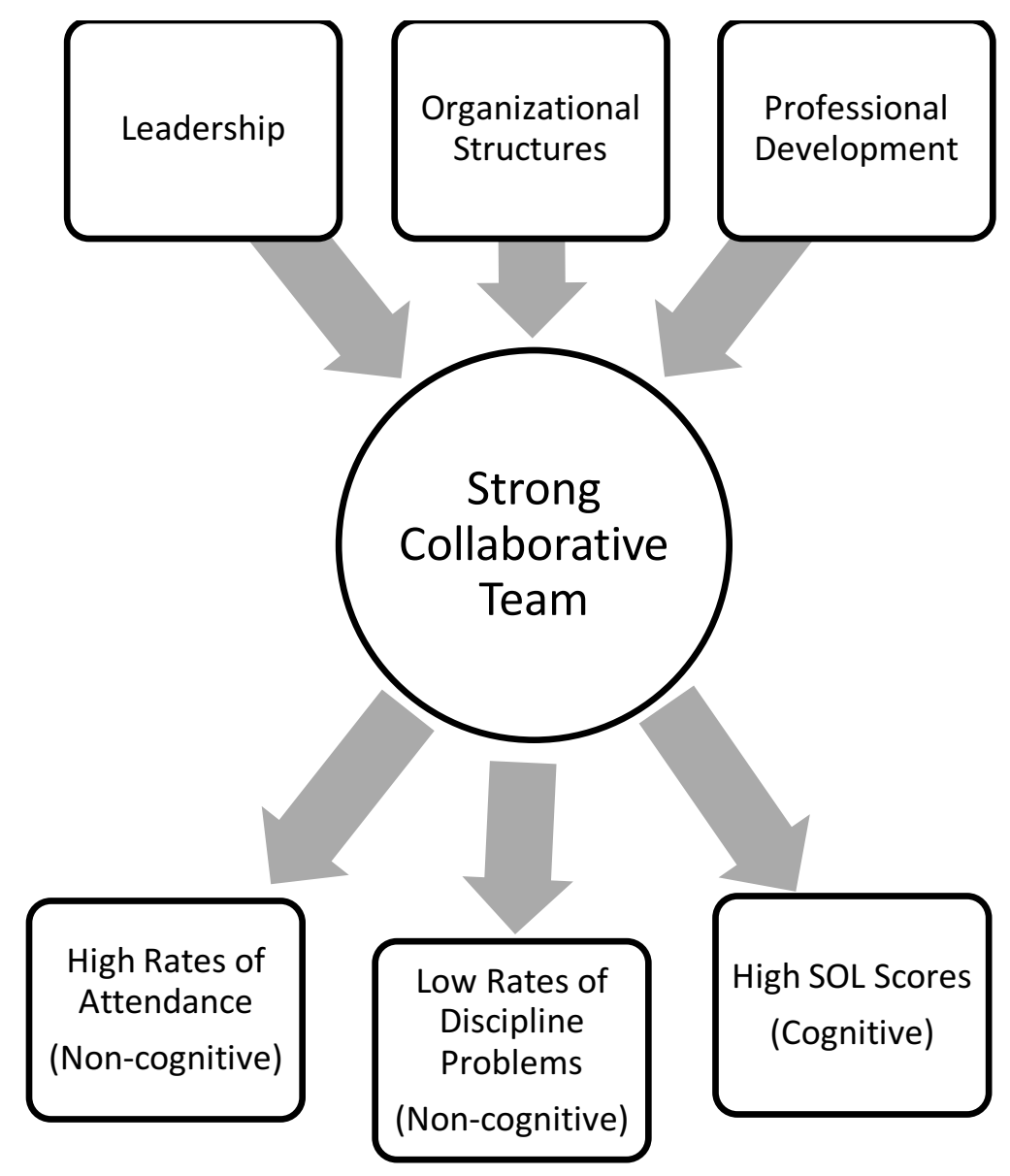

Figure 3. Conceptual framework for studying the instruction of Students With Disabilities. If the conditions for a strong collaborative team are in place, students will be more engaged in instruction. Higher engagement will lead to higher student achievement.

\section{Non-cognitive Indicators}

Students cannot be engaged in learning, regardless of the educational configuration of teachers, if they are not physically present. Research from Allensworth and Easton (2007) showed poor daily attendance among middle and high school students in Chicago Public Schools was related to academic decline, course failure, and dropout. Neild and Balfanz (2006) found similar results among middle and high school students in 
Philadelphia, where the number of absences in ninth grade was the greatest predictor for students dropping out of high school. In order for collaborative instruction to be successful, students must be present to receive instruction. Therefore, attendance was used as one non-cognitive indicator of student engagement in this study.

In addition to attendance, student misbehavior is also a predictor of course failure and delayed graduation rates (Balfanz, Herzog, \& MacIver, 2007). Student misbehavior affects not only the perpetrator, but also everyone in the learning environment. Often, student misbehavior is a product of boredom or low self-efficacy as a student (Beyda, Zentall, \& Ferko, 2002). A more successful collaborative classroom will generate fewer student discipline issues because students are more likely to be engaged in learning. Student discipline infractions were used as a second non-cognitive indicator of student engagement.

\section{Cognitive Indicators}

In Virginia, the Standards of Learning (SOL) are the educational guidelines in public schools establishing learning and achievement expectations for students in grades K-12. Students begin taking core SOL assessments in grade three and continue through high school; although, they do not take all core SOL assessments every year. The majority of the SOL assessments, with the exception of the short paper portion of the writing test, contain multiple choice and technology-enhanced items by which students demonstrate mastery of the skills and content for that subject area. A score of 300-399 is Fail/Basic, 400-499 is Pass/Proficient, and 500-600 is Pass/Advanced. In grades three through eight, students take reading and mathematics SOL assessments every spring. Students take science SOL assessments in fifth grade and eighth grade and social studies 
SOL assessments at the end of Virginia Studies and Civics and Economics (grade levels vary in each school system). Additionally, students must pass six end-of-course SOL assessments in high school to achieve a standard diploma (nine for an advanced diploma). High school students must pass reading, writing, one math (Algebra I, Geometry, or Algebra II), one science (Earth Science, Biology, or Chemistry), one history (Virginia/U.S. History, World History I, World History II, or World Geography), and one test of their choice from those three content areas.

In Virginia, these tests are the most objective measures of student achievement available for this population of students and were used in this study. Recent findings suggest that the Virginia SOL test scores are most accurately predicted by socioeconomic status (Lehr, 2013), but they remain the assessment used by the Virginia Department of Education and the public for drawing conclusions about the "learning" of students in our public schools. 


\section{CHAPTER THREE: METHODOLOGY}

This study used mixed methods to answer the four research questions regarding the collaborative environment at a rural middle school. Qualitative and quantitative data were collected and analyzed for trends relating student cognitive and non-cognitive indicators to the implementation of the two collaborative models used at Central Middle School from 2011 to 2016.

\section{Data Sources}

The researcher used archived student achievement data to compare mean achievement scores and pass rates between groups of students in the Full Content Collaboration and the Math/English Collaboration models. Some of the student groups took social studies tests in $6^{\text {th }}$ and $7^{\text {th }}$ grade, but the test was removed at those levels after the Spring 2015 test administration. The tests for writing and science are only administered in $8^{\text {th }}$ grade, so the researcher chose to include writing only because it is more closely related to reading (measured by the English SOL). The researcher also used archived student attendance data to compare mean attendance rates between groups of students in the two collaborative models. The researcher used student discipline data to identify trends in student behavior based on the use of each collaborative model and describe the prevalence of discipline issues. The researcher also included descriptions of teacher interview and survey data regarding the presence of criteria for strong 
collaborative teams as well as teacher perceptions of the Full Content Collaboration and the Math/English Collaboration models.

Using survey methodology, the researcher solicited teachers' perceptions of the school and classroom practices that support strong collaborative teams: supportive building leaders that provide guidance and feedback and opportunities for growth (Cancio, Albrecht, \& Johns, 2013); an emphasis on inclusion (UMASS Donahue Institute, 2004); optional participation in collaborative education (Cook \& Friend, 1995; Thompson, 2001, cited in Scruggs, Mastropieri, \& McDuffie, 2007); strong professional relationships among collaborating teachers (Cook \& Friend, 1995); opportunity for and efficient use of co-planning time (Cook \& Friend, 1995; Scruggs, Mastropieri, and McDuffie, 2007); shared responsibility for planning, instructional delivery, and student discipline among collaborating teachers (Murawski \& Lochner, 2010). Survey questions also addressed the predominate structure of the collaborative classroom (Friend \& Cook, 2010), and the amount and focus of professional development (Austin, 2001; Scruggs, Mastropieri, \& McDuffie, 2007).

Following survey administration, the researcher conducted semi-structured, faceto-face interviews with six middle school teachers, three of whom were special educators and three of whom were either math or English teachers, who taught during both iterations of the collaborative models. Interview questions addressed the teacher's role in the classroom, instructional philosophy and how that includes SWD, and perceptions of the school environment and how it impacted collaborative instruction and SWD during the time of the study. 


\section{Research Questions}

This study analyzed measures of student engagement, student achievement, and teacher perceptions to answer the following research questions:

1. How did the Collaborative Instruction environment change in the identified school from Fall 2011 to Spring 2016?

2. What were the teachers' perceptions of the Collaborative Instruction environment from 2011-2016?

3. What patterns of student achievement emerged from 2011-2016?

4. What patterns emerged among non-cognitive indicators from 2011-2016?

\section{Context}

Central Middle School is a rural school in Central Virginia. The middle school serves approximately 550 students in grades 6-8. The student population is about 77 percent white, 20 percent African-American, with the remainder registered as Asian or mixed-race. Forty-nine percent of the students in Central County qualify for free or reduced lunch rates. Approximately eleven percent of the student population is labeled as Students With Disabilities (B. Haught, personal communication, October 18, 2013).

Each grade level has two teachers in each of the four content areas: math, English, science, and social studies. Three special educators, one at each grade level, serve the SWD in and out of the collaborative classrooms. Students also attend encore (elective classes) in grade-level groups.

During the 2011-2012 school year, SWD in each grade level attended their four core classes as a group, joining five to seven general education students in each class. The special educator attended each core class with the SWD as part of the Full Content 
Collaboration model. During the 2012-2014 school years, SWD in each grade level were divided into two groups and split among two collaborative math and two collaborative English classes. The special educator collaborated with the general education teacher during the Math/English Collaboration. In this model, SWD attended science and social studies classes in groups of three or four. Although the special educator was not present in these classes, SWD still received classroom and testing accommodations according to their IEP's.

Table 2 shows the SOL pass rates for SWD at CMS as reported by the Virginia Department of Education on the school report card. These are data from both collaboration models.

Table 2

SOL Pass Rates for SWD at Central Middle School

\begin{tabular}{lcccccccc}
\hline Subject Area & 2009 & 2010 & 2011 & 2012 & 2013 & 2014 & 2015 & 2016 \\
\hline English & 80 & 79 & 44 & 40 & 39 & 37 & 32 & 52 \\
Math & $\mathrm{X}$ & 86 & 31 & 17 & 33 & 36 & 41 & 49 \\
Writing & $\mathrm{X}$ & $\mathrm{X}$ & 59 & 76 & 19 & 8 & 35 & 17 \\
History & 46 & 71 & 55 & 67 & 41 & 44 & 50 & 43 \\
Science & $\mathrm{X}$ & 53 & 80 & 88 & 25 & 23 & 33 & 31
\end{tabular}

Note. Writing and Science SOL tests are only administered at the end of the $8^{\text {th }}$ grade year. Tests are cumulative, including content from $6^{\text {th }}, 7^{\text {th }}$, and $8^{\text {th }}$ grade SOLs. Some early data are unavailable. (VDOE, 2016) 


\section{Participants}

The researcher collected data on three cohorts of students. Cohort A consisted of SWD who entered $6^{\text {th }}$ grade in the 2011-2012 school year; Cohort B entered $6^{\text {th }}$ grade in the 2012-2013 school year; and Cohort C entered $6^{\text {th }}$ grade in the 2013-2014 school year. Including the general population, each grade level contains approximately 175 students, with equal numbers of male and female, and demographic characteristics representative of the school's population. Student achievement ranges from very advanced learners to students with learning disabilities. The cohort groups of Students With Disabilities are smaller, and demographics are not representative of the school's population. Three years-worth of SOL test scores, attendance reports, and discipline reports were used for each of the three cohorts. Student data from the time of the study are archived, and no students were contacted by the researcher.

Middle level teachers who taught in 2015-2016 were asked to complete a survey about presence of conditions that support strong collaborative teams during the 20152016 school year. Six additional teachers, three of whom had already completed the survey and three of whom had moved to different schools, were interviewed regarding their perceptions of collaborative instruction at CMS.

\section{Data Collection}

All data were obtained from students and teachers at one rural middle school. The researcher analyzed archived student academic data from the 2011-2012, 2012-2013, 2013-2014, 2014-2015, and 2015-2016 school years. After collecting survey data from all teachers regarding their perceptions of the school conditions surrounding collaborative education in the 2015-2016 school year, the researcher interviewed six middle school 
educators. The researcher focused on the implementation of collaborative instruction in each model in an effort to inform future instruction for Students With Disabilities. A description of the specific data collection procedures is located in Appendix E.

Student data. The researcher obtained four categories of student data: demographics, achievement, attendance, and discipline.

1. Demographic data includes gender, ethnicity, and coded disability where applicable.

2. Achievement data includes state test scores for Spring 2012, Spring 2013, Spring 2014, Spring 2015, and Spring 2016. Sixth and seventh grade state test reports include math and English (reading) scores, with a maximum score of 600. Eighth grade state test reports include math, English (reading), and writing, with a maximum score of 600 .

3. Attendance reports for each student include the number of days absent each school year.

4. Student discipline data include the number of infractions for each student per school year.

The Central High School guidance department had electronic files of student demographic information, attendance, and state test scores that were generated in a report. The researcher had to gather discipline data from student files at CMS.

Teacher survey data. Teacher survey responses regarding the presence of criteria for optimal implementation of collaborative instruction were used in conjunction with the student achievement, attendance, and discipline data. In a report about webbased surveys, Gunn (2002) cites research from Frary (1996), Gaddis (1998), and 
Dillman, Tortora, and Bowker (1998), all of whom provide suggestions for a userfriendly, web-based survey that is cost effective and promotes a high response rate. Therefore, teachers involved in collaborative instruction in 2015-2016 completed a selfadministered, Web-based survey (see Appendix A) developed by the researcher to report the presence of the conditions and practices supportive of strong collaborative teams at Central Middle School. Survey questions addressed practices in the following categories: leadership/administrative support, professional development, and organizational structures. The survey had a "respondent-friendly design," according to a description by Dillman, Sinclair, and Clark (1993), meaning the survey was easy to complete, minimized confusion about what or how to answer, and contained no objectionable questions. Additionally, scales were arranged horizontally to enhance accuracy of responses (Dillman \& Christian, 2002). Likert-style responses were entered into the spreadsheet on a scale of 1-5, and remaining question results were coded according to the specific numbers or words in the answer choices.

Teacher interview data. The researcher developed a set interview protocol (see Appendix B) with suggested prompts in case interviewees needed more specific guidance. Because of a previous professional placement, the researcher already had some rapport with interviewees that encouraged open and honest interaction (Fontana \& Frey, 2005). Although the protocol was set, the researcher sought to establish a conversational tone to help participants feel more comfortable and respond more freely (Oakley, 1981; Reinharz, 1992). The semi-structured format of the interview allowed for follow-up questions and more detailed answers that clarified data from the survey (Patton, 2008). 


\section{Data Analysis}

The researcher used multiple methods to analyze data collected through interviews, surveys, and student records. Qualitative data from the interviews were analyzed to clarify information from the surveys and further explain quantitative data from the surveys (Remler \& Van Ryzin, 2011). Survey data were analyzed with descriptive statistics: means and standard deviations (Ravid, 2011). Interview and survey data were analyzed to address Research Questions 1 and 2 regarding the Collaborative Instruction environment from 2011 to 2016.

The researcher compared achievement scores, attendance rates, and discipline trends from each cohort to the same reports from the overall population at that same level. (see Figure 4). The researcher also aggregated data by gender to determine patterns of student cognitive and non-cognitive indicators in Full Content Collaboration and Math/English Collaboration. 


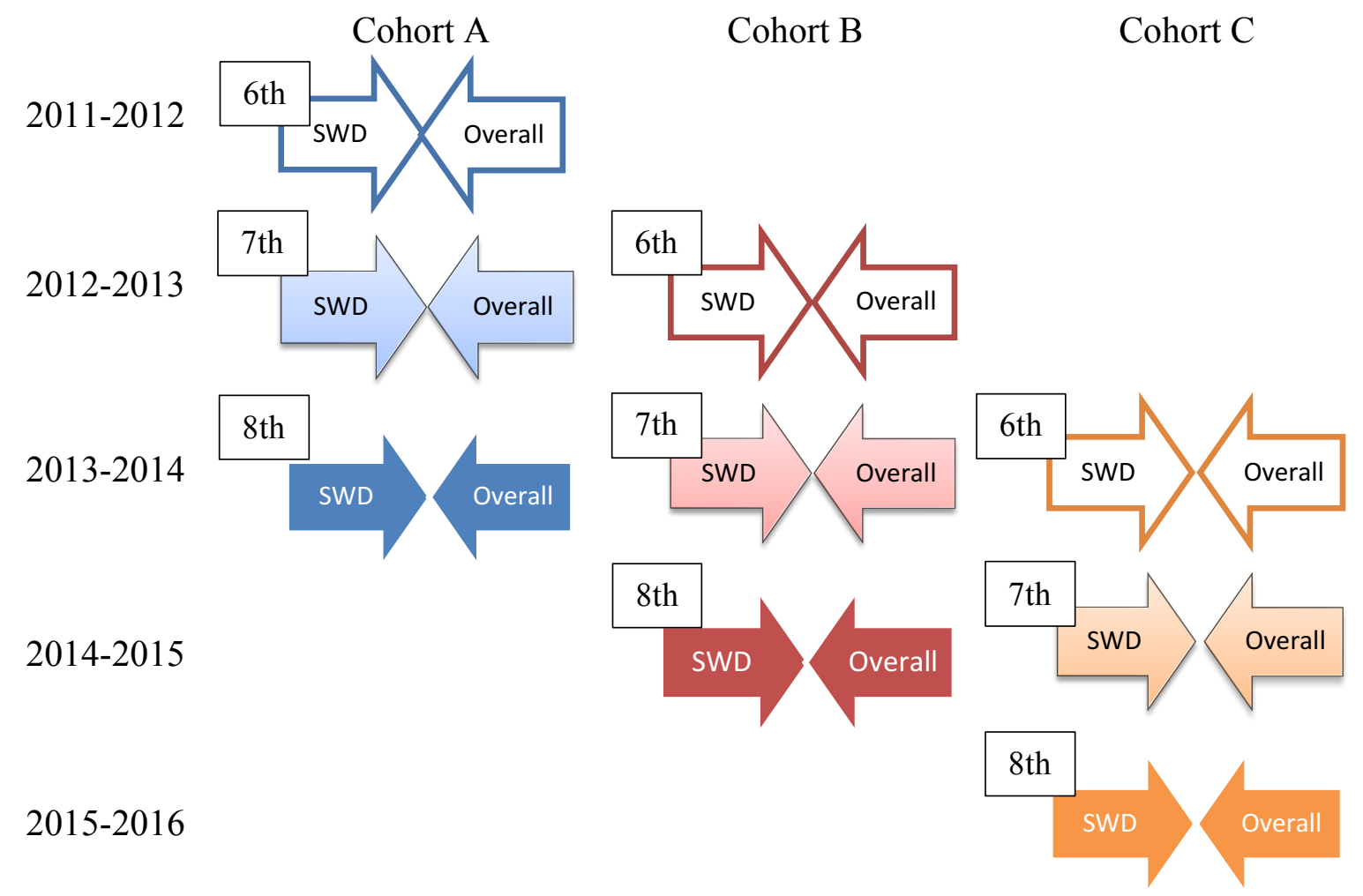

Figure 4. Comparison groups for data analysis. Data from Cohort A, Cohort B, and Cohort $\mathrm{C}$ (SWD) were compared to data from the overall population of students in the same grade level.

The researcher determined pass rates of each achievement measure for each cohort of students. For example, Cohort A had pass rates for math and reading for $6^{\text {th }}$, $7^{\text {th }}$, and $8^{\text {th }}$ grades. Each pass rate was compared with the corresponding pass rate for all students who were tested in that grade level.

The researcher also determined average number of absences for each cohort for each year and performed the same comparisons to determine if any cohort attained higher attendance rates compared to their peers. Discipline infractions were totaled per student and means of the number of infractions were compared to determine the frequency of discipline problems. 
The researcher used average daily attendance comparisons and measures of discipline frequency to describe the impact of Full Content Collaboration and Math/English Collaboration on student engagement.

Graphs and descriptions of student achievement, attendance, and discipline trends were used to answer Research Questions 3 and 4.

Survey responses from the Fall of 2016 were analyzed to determine the presence of the three criteria for optimal collaborative teams: leadership support, organizational structures, and professional development. Interview responses were used to enhance the description of the collaborative environment, provide information about how collaboration changed from 2011 to 2016 , and determine teachers' perceptions of collaboration and how it may have affected student cognitive and non-cognitive indicators from 2011 to 2016.

The researcher provided a description of teacher interview and survey data regarding the collaborative education environment and its perceived impact on SWD. The results of these analyses were compared to the results of the student cognitive and non-cognitive indicator data to determine trends in student achievement and engagement measures during the implementation of different collaborative instructional models.

\section{Summary}

To ensure all students are afforded the most appropriate, high-quality education for their needs, and because of increased accountability measures for educating and assessing SWD, Central Public Schools must determine the most effective methods for instructing SWD while still meeting requirements of the LRE. Two iterations of collaborative instruction, Full Content Collaboration and Math/English Collaboration, 
have been implemented. In Chapter 4, the researcher compares student achievement, student attendance rates, and student discipline rates in each model. Additionally, the researcher provides descriptions of the conditions for strong collaborative teams that were present during Full Content Collaboration and Math/English Collaboration, as well as teacher perceptions of each model. 


\section{CHAPTER FOUR: FINDINGS}

The purpose of this research was to provide a description of the Collaborative Instruction environment at one rural middle school from 2011 to 2016 . This study explored the perceptions of teachers who have been involved in the program in the past as well as teachers currently involved in Collaborative Instruction. In addition, the study examined information regarding the academic achievement and other non-cognitive measures of the SWD served by the Collaborative Instruction program. The data collection for this research included three sources: (a) archived student data for SOL scores, discipline, and attendance, (b) survey of current teachers at CMS about the current Collaborative Instruction program, and (c) interviews of current and former CMS teachers about the past Collaborative Instruction program.

These findings provide an analysis of the data collected. Quantitative data were collected from the Collaborative Instruction Survey and student files. The interviews were conducted with six teachers from the middle school. The general education and special education teachers who participated in the individual interviews allowed the researcher to collect qualitative data pertaining to the perceptions of the Collaborative Instruction program.

\section{Participants}

Teachers. Central Middle School employs 27 teachers in the core content areas and special education. The response rate for the study was 66.7 percent, 18 responses 
were received from 27 invitations. There was an equal response rate among general educators and special educators with 16 general educators and 2 special educators responding.

Teachers were evenly distributed among the three grade levels $\left(6^{\text {th }}, 7^{\text {th }}\right.$, and $\left.8^{\text {th }}\right)$. Six of the general educators taught English, six taught math, two taught science, and two taught social studies; the two special educators were responsible for teaching multiple subjects (see Table 3). 
Table 3

Demographic Characteristics of Teachers

\begin{tabular}{|c|c|c|c|}
\hline Characteristic & & $n$ & $\%$ \\
\hline \multicolumn{4}{|l|}{ Years Teaching } \\
\hline & $0-5$ years & 7 & $38.9 \%$ \\
\hline & $6-10$ years & 7 & $38.9 \%$ \\
\hline & $11-20$ years & 2 & $11.1 \%$ \\
\hline & over 20 years & 2 & $11.1 \%$ \\
\hline \multicolumn{4}{|c|}{$\begin{array}{l}\text { Years Teaching at } \\
\text { CMS }\end{array}$} \\
\hline & $0-5$ years & 11 & $61.1 \%$ \\
\hline & $6-10$ years & 4 & $22.2 \%$ \\
\hline & $11-20$ years & 3 & $16.7 \%$ \\
\hline & over 20 years & - & - \\
\hline \multicolumn{4}{|l|}{ Certification } \\
\hline & Special & 2 & $11.1 \%$ \\
\hline & Education & & \\
\hline & General & 16 & $88.9 \%$ \\
\hline & Education & & \\
\hline \multicolumn{4}{|l|}{ Grade Level } \\
\hline & $7^{\text {th }}$ Grade & 6 & $\begin{array}{l}53.5 \% \\
33.3 \% \\
-10\end{array}$ \\
\hline & $8^{\text {th }}$ Grade & 6 & $33.3 \%$ \\
\hline & Multiple Grades & - & - \\
\hline \multicolumn{4}{|l|}{ Subject Area } \\
\hline & English & 6 & $33.3 \%$ \\
\hline & Math & 6 & $33.3 \%$ \\
\hline & Science & 2 & $11.1 \%$ \\
\hline & Social Studies & 2 & $11.1 \%$ \\
\hline & Multiple & 2 & $11.1 \%$ \\
\hline & Subjects & & \\
\hline
\end{tabular}

Note: $n=18$

The researcher also conducted interviews with six teachers, three who were still teaching at CMS at the time of interviews and three who had moved to other positions, either in the district or elsewhere. Of the six interviewees, three had special education certification and three had general education certification. The three special educators were each responsible for one grade level at CMS during the time of the study; the 
general educators taught $6^{\text {th }}$ grade English, $6^{\text {th }}$ grade math, and $7^{\text {th }}$ grade math during the time of the study.

Students. The researcher collected archival data for three cohorts of students, each cohort having three years of data for achievement and non-cognitive indicators. Cohort A had 14 students, Cohort B had 12 students, and Cohort C had 11 students. All three groups of students had more males than females, with males making up 57-75 percent of each group (See Figure 5). The majority of students in each group were white, ranging from 58-73 percent (See Figure 6).

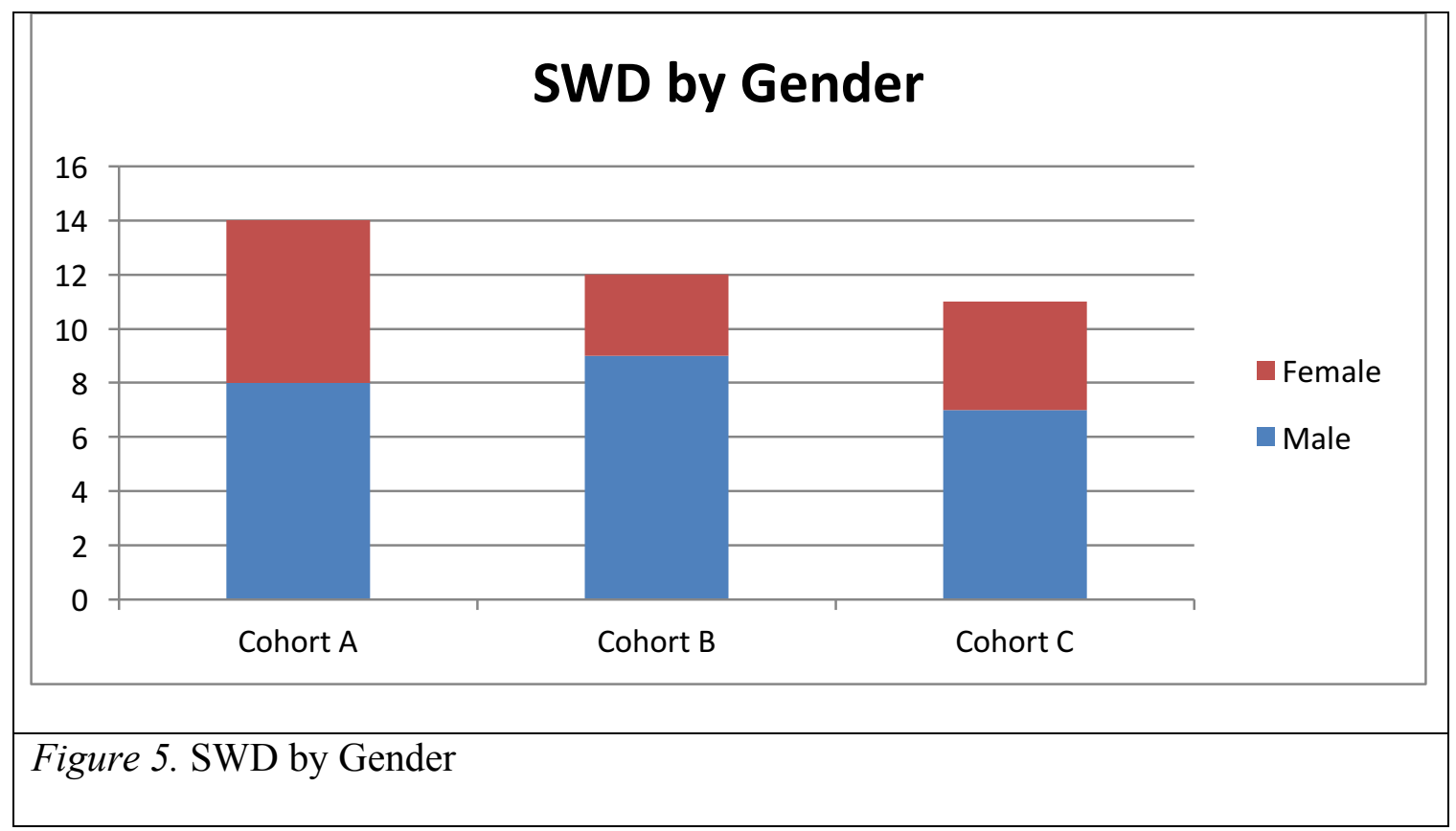




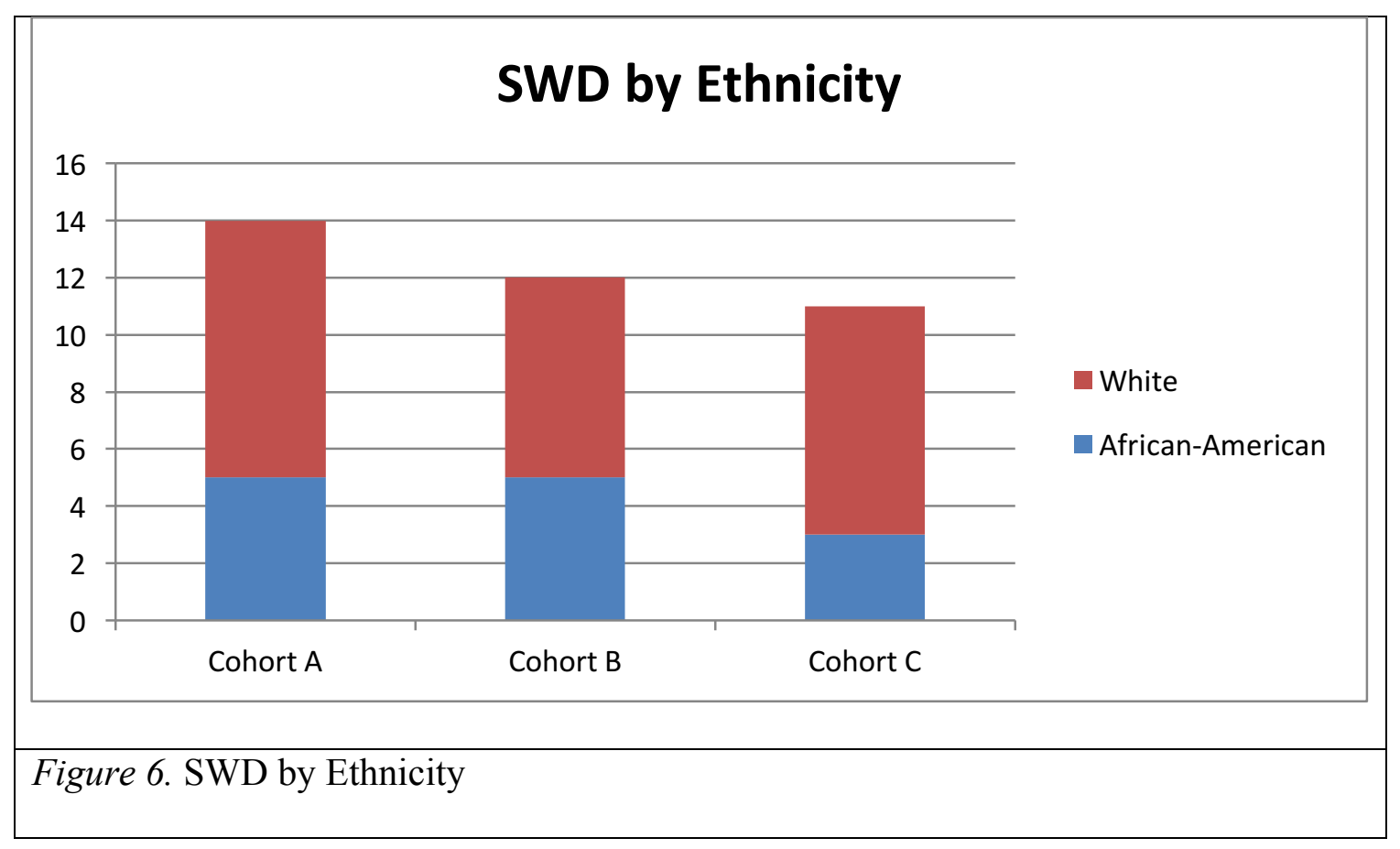

Within each group, disabilities varied, but IEPs and 504 Plans carried the following labels: Specific Learning Disability (SLD), Other Health Impairment (OHI), Emotional Disability (ED), Intellectual Disability (ID), and 504. Out of the 37 SWD, 12 were labeled SLD, 10 were labeled OHI, 5 were labeled ED, 9 had 504 Plans, and the remaining student was labeled ID (See Figure 7). 


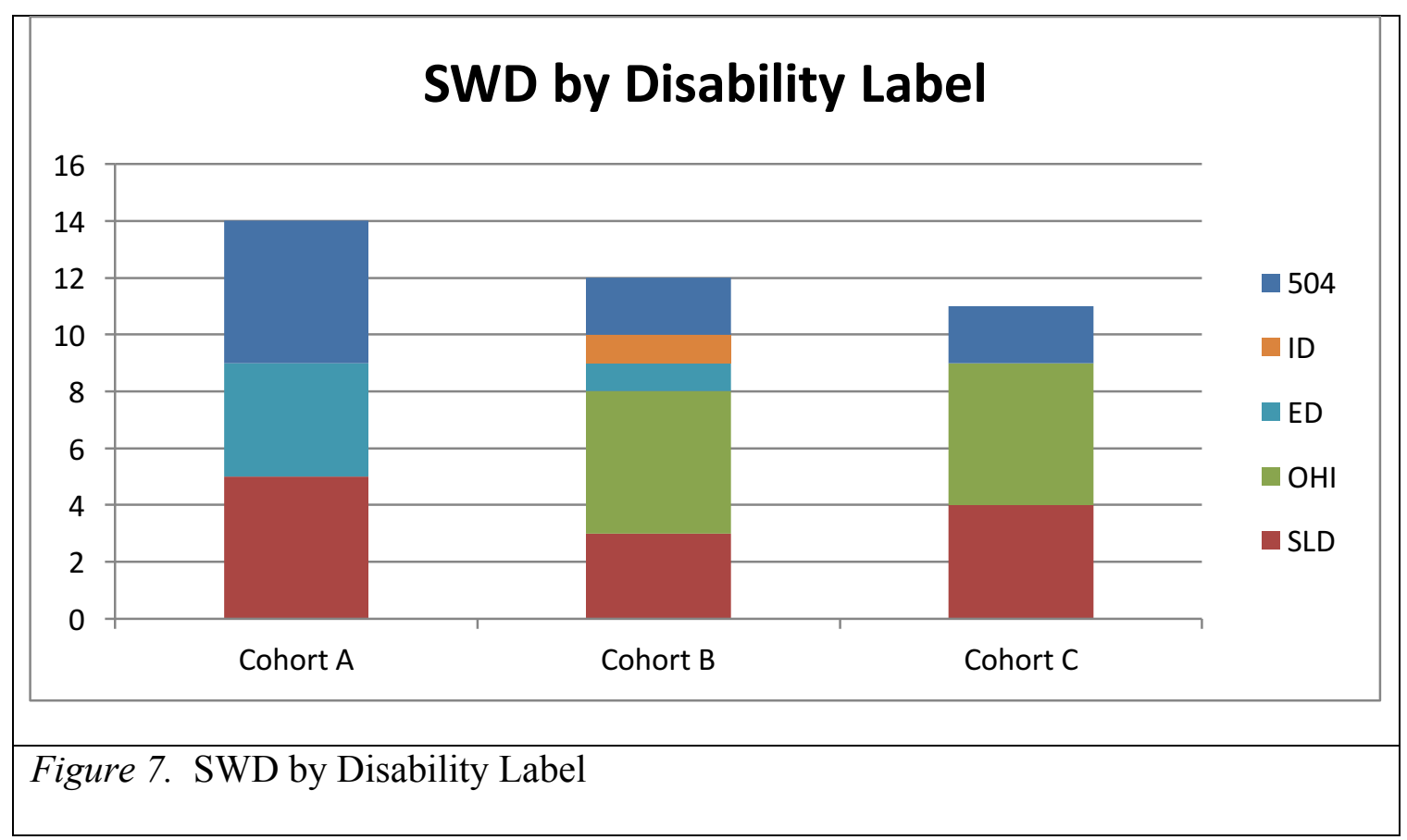

\section{Findings}

The following section presents the findings for each research question. This analysis draws upon data collected from students' files, the teacher survey, and teacher interviews. The survey instrument provided quantitative data, while the interviews provided qualitative data to support data from the survey. For the purpose of understanding means and standard deviations for the survey data, the number of participants was 18 .

\section{Research question 1: How did the Collaborative Instruction environment} change in the identified school from Fall 2011 to Spring 2016? To answer Research Question 1, the researcher relied on qualitative data from teacher interviews to describe the change in collaborative instruction over time. All six interviewees discussed the transition from Full Collaboration to Math/English Collaboration, citing the number of 
SWD in each core class in 2011-2012 as the possible cause for evidence of the observed decline in student achievement.

Leadership support. When asked about leadership support surrounding Collaborative Education, all six interviewees cited a change in building leadership as having a positive impact on Collaborative Education because of the new administrator's understanding of collaborative instruction and her expectations for co-teaching. The current leadership is able to provide teachers with more constructive feedback after observations and supports teachers with resources about co-teaching. The previous building leader, serving 2010-2015, had little understanding of collaborative education and how to support teachers in the collaborative classroom. According to one teacher, "When he came to observe, he expected us to be co-teaching the whole class period, and that's hard to do when you are responsible for knowing the content in four different subjects." The same teacher added, "The current administration has a much better understanding of [special education teachers], and our roles and abilities in a collaborative classroom."

When asked about leadership and how that may have impacted student discipline rates among SWD, teachers agreed the makeup of the group and their individual needs (especially those who are labeled ED) have more to do with discipline rates than building leadership. One teacher did point out the rate of discipline referrals increased the year students transitioned to Math/English Collaboration and suggested not having the support of the special educator in the science and social studies classrooms may have been a cause for that increase. 
Teachers agreed leadership has little to no impact on student attendance rates.

One teacher said, "If the parents don't value education and don't make the child come to school, that has much less to do with school than it does with home."

Organizational structures. All six interviewees agreed the CMS schedule allowed for little time to plan collaboratively. None of the special education teachers had a common planning time with their collaborative general education partners. For collaborative partners that have been working together for several years, this presented less of a challenge than for new teachers. In one instance, the general education teacher was not informed she was teaching a collaborative class until the special education teacher showed up in her classroom on the first day of school. The teacher cited this lack of information and time to prepare as a possible cause of low student achievement in her collaborative classroom.

Of the six interviewees, three were still teaching at CMS and suggested a change in the schedule in the 2014-2015 school year, moving from six periods to four blocks, had a positive impact on student achievement, especially in the collaborative classroom. Because students have math and English for 84 minutes every day all year, teachers have more opportunity to help students individually and in small groups. All three special educators said when they pull students from the classroom, it is never the same group of students, and is always inclusive of both SWD and general education students who may be struggling with a particular concept. Before this schedule change, SWD went to the special educator for that grade level during a daily "directed study" period, where they were able to get support for science and social studies (non-collaborative classes). In the Math/English Collaboration model, SWD receive less support in those classes, but 
because there are no longer SOL tests for those subjects in $6^{\text {th }}$ and $7^{\text {th }}$ grade, student achievement is not monitored in a standardized manner.

Regarding student discipline, one special educator suggested the reduction in transitions because of the new block schedule may have had a positive impact on student discipline, but reiterated that discipline among students varies from year to year and had more to do with the particular students and less to do with the schedule. Another special educator claimed student discipline issues would increase because of students' frustration in the classes where they no longer have the support of a special educator. The four other interviewees agreed student discipline was variable according to the group of students.

Five of the six interviewees believed student attendance is unrelated to the organizational structures of the school, but one special educator disagreed. She claimed students are more likely to attend class when they feel supported, but not isolated. The current Collaborative Instruction program seeks to include SWD without isolating them in the collaborative classroom. All the special educators work with all the students in their collaborative classrooms, not just the SWD.

Professional development. All six interviewees claimed professional development has been lacking for Collaborative Instruction at CMS. One general educator said, "The only professional development I had was what I found online combined with the advice my collaborative partner offered." Although she feels confident as a collaborative teacher now, “I didn't know what I was doing when I first started, and there was no one except [the special educator] to offer any advice about working with those students." 
All three special educators expressed their frustration in being expected to teach content when their certifications deal more with supporting students with learning disabilities. "I really would have liked the opportunity to meet with my collaborative partner before school started and talk with them about what their expectations were for me in their classroom," said one special educator. While some teacher preparation programs provide some information about the different types of collaborative instruction, many current educators are still unaware of what collaborative instruction can look like in a classroom. One general educator said, "It would have been nice to at least have a session where we learned about the different models of collaborative instruction. I honestly think your survey was the first time I've seen some of the different models explained in a way that makes sense to me."

The six interviewees did agree that the years of professional development focusing on differentiation of instruction had a positive impact on student achievement. The division's professional development focus from 2012 to 2014 was on how to differentiate instruction to meet the needs of individual learners. By providing students with learning resources on their level, allowing them to experience information in different ways (auditory, kinesthetic, visual), and providing options for the ways students show their learning, teachers have been better able to meet the needs of all learners. Because all teachers learned how to differentiate in their classrooms to meet the needs of a wide variety of students, SWD benefit as well as the general population. "Many of the differentiation practices work well in a collaborative classroom, so I think that has been really helpful," said one special educator. She went on to say, "Because the regular 
ed[ucation] teachers were exposed to strategies for meeting the learning needs of all students, everyone gets what they need in the classroom."

While the special educators feel they received enough training in student discipline as part of their certification, the general educators agreed some professional development focused on classroom management with SWD, especially those with emotional disabilities, would be helpful.

All interviewees were unsure if there would be any professional development that would help increase student attendance rates.

\section{Research question 2: What were the teachers' perceptions of the}

Collaborative Instruction environment from 2011-2016? To answer Research

Question 2, means and standard deviations were calculated for the survey items associated with leadership support and professional development contributing to Collaborative Instruction. Because a different scale was used with the Organization Structures section of the survey, these finding are reported in percentages. The key findings for Research Question 2 were:

- Building leadership was supportive of Collaborative Instruction with a $M=3.70$ and $\mathrm{SD}=.98$ on a scale of 1 to 5 with 5 indicating leadership was "always" supportive.

- The most frequently used model for Collaborative Instruction was One Teach, One Assist (40\%), closely followed by Team Teaching (30\%).

- Most collaborative teachers (70\%) reported having an excellent relationship with their collaborative partner. 
- Most collaborative teachers $(90 \%)$ reported equally shared responsibility for student discipline in the collaborative classroom, while only $60 \%$ reported equally shared responsibility for instruction.

- Professional development weakly supported Collaborative Instruction with a $\mathrm{M}=$ 2.23 and $\mathrm{SD}=1.17$ on a scale of 1 to 5 with 5 indicating "all" professional development focused on collaborative instruction skills.

Survey data. The researcher collected 18 responses from the 27 survey

invitations. Survey items were divided into four sections: educational experience and role (see Table 3), leadership support for collaborative instruction, organizational structures supporting collaborative instruction, and professional development for collaborative instruction.

Leadership and administrative support. Table 4 summarizes the five items that addressed the teachers' perceptions of the Leadership and Administrative Support for Collaborative Instruction from 2015-2016. Two of the items required teachers to rate the amount of information they receive from the administration about collaborative instruction; two of the items asked about time for planning and other non-classroom responsibilities; and the fifth item asked about the administration's advocacy of inclusive practices. A majority of the teachers surveyed felt the administration at CMS provided support for collaborative instruction, with no teachers reporting "never" on the items. A majority of teachers (78-94\%) responded "some," "often," or "always" to all five items. Teachers felt most positively about the administration's support of inclusion practices (39\% reported "always"), but also felt they did not receive the time they needed for nonteaching responsibilities (44\% reported "rarely" or "some"). 
Table 4

Teacher Perceptions of Leadership and Administrative Support Supporting Collaborative Education

\begin{tabular}{|c|c|c|c|c|c|c|}
\hline $\begin{array}{l}\text { Please rate the } \\
\text { following statements } \\
\text { about your building } \\
\text { principal during the } \\
\text { 2015-2016 school year: }\end{array}$ & Never & Rarely & Some & Often & Always & $\mathrm{M}(\mathrm{SD})$ \\
\hline $\begin{array}{l}\text { Provided suggestions } \\
\text { for me to improve } \\
\text { instruction }\end{array}$ & - & $\begin{array}{l}6 \% \\
(1)\end{array}$ & $\begin{array}{l}39 \% \\
(7)\end{array}$ & $\begin{array}{l}33 \% \\
(6)\end{array}$ & $\begin{array}{l}22 \% \\
(4)\end{array}$ & $\begin{array}{l}3.72 \\
(.90)\end{array}$ \\
\hline $\begin{array}{l}\text { Provided information } \\
\text { on up-to-date } \\
\text { instructional and } \\
\text { behavioral techniques }\end{array}$ & - & $\begin{array}{l}11 \% \\
(2)\end{array}$ & $\begin{array}{l}33 \% \\
(6)\end{array}$ & $\begin{array}{l}44 \% \\
(8)\end{array}$ & $\begin{array}{l}11 \% \\
(2)\end{array}$ & $\begin{array}{l}3.50 \\
(.92)\end{array}$ \\
\hline $\begin{array}{l}\text { Provided time for } \\
\text { various non-teaching } \\
\text { responsibilities (e.g. } \\
\text { IEPs, meetings) }\end{array}$ & - & $\begin{array}{l}22 \% \\
(4)\end{array}$ & $\begin{array}{l}22 \% \\
(4)\end{array}$ & $\begin{array}{l}39 \% \\
(7)\end{array}$ & $\begin{array}{l}17 \% \\
(3)\end{array}$ & $\begin{array}{l}3.50 \\
(1.04)\end{array}$ \\
\hline $\begin{array}{l}\text { Provided adequate } \\
\text { planning time }\end{array}$ & - & $\begin{array}{l}11 \% \\
(2)\end{array}$ & $\begin{array}{l}28 \% \\
(5)\end{array}$ & $\begin{array}{l}33 \% \\
(6)\end{array}$ & $\begin{array}{l}28 \% \\
(5)\end{array}$ & $\begin{array}{l}3.83 \\
(1.0)\end{array}$ \\
\hline $\begin{array}{l}\text { Emphasized inclusion } \\
\text { and access to the } \\
\text { curriculum for Students } \\
\text { With Disabilities }\end{array}$ & - & $\begin{array}{l}11 \% \\
(2)\end{array}$ & $\begin{array}{l}28 \% \\
(5)\end{array}$ & $\begin{array}{l}22 \% \\
(4)\end{array}$ & $\begin{array}{l}39 \% \\
(7)\end{array}$ & $\begin{array}{l}3.94 \\
(1.06)\end{array}$ \\
\hline \multicolumn{6}{|c|}{ Overall Leadership Support } & $\begin{array}{l}3.70 \\
(.98) \\
\end{array}$ \\
\hline
\end{tabular}

Note: $n=18$

Organizational structures. Table 5 summarizes the teachers' responses regarding the Organizational Structures at the school and how they supported collaborative instruction. These six items asked teachers to identify the most-used model of collaborative instruction in their classrooms, rate the relationship with their collaborative partner, rate the amount of collaborative planning time they have, and rate the amount of 
responsibility taken by the general educator and special educator for planning, discipline, and instruction.

Of the 18 survey respondents, only 10 were teaching a collaborative education class during the 2015-2016 school year. On this section of the survey, teachers were asked to read a brief description of five collaborative instruction models and identify the one most used in their classrooms. Of the 10 collaborative teachers, four responded that "one teach, one assist" is most used, and three responded that "team teaching" is most used. No teachers reported "parallel teaching" as a model for their collaborative instruction.

The majority of teachers $(90 \%)$ reported a "good" or "excellent" relationship with their collaborative partner, with only one teacher reporting a "poor" relationship. Interview responses supported the position that most collaborative teachers at CMS have a positive professional relationship with their partners.

The ten responses varied regarding the amount of planning time spent with their collaborative partners. Seven of the ten respondents collaborate on lesson plans "some," "often," or "always," with only one teacher saying the general educator and special educator "never" collaborated on lesson plans.

While most (90\%) teachers reported the general and special educator "equally" responsible for student discipline, only $60 \%$ reported the teachers being "equally" responsible for instruction. In both discipline and instruction, where responsibilities are not "equally" shared, they fall to the general educator, not the special educator. 
Table 5

Teacher Perceptions of Organizational Structures Supporting Collaborative Education Question

\begin{tabular}{|c|c|c|c|c|c|}
\hline & $\begin{array}{l}\text { One teach, } \\
\text { one assist }\end{array}$ & $\begin{array}{l}\text { Station } \\
\text { teaching }\end{array}$ & $\begin{array}{l}\text { Parallel } \\
\text { teaching }\end{array}$ & $\begin{array}{l}\text { Alternative } \\
\text { teaching }\end{array}$ & $\begin{array}{l}\text { Team } \\
\text { teaching }\end{array}$ \\
\hline \multirow{2}{*}{$\begin{array}{l}\text { Which of the collaborative } \\
\text { models best describes } \\
\text { your experience? }\end{array}$} & $4(40 \%)$ & $2(20 \%)$ & - & $1(10 \%)$ & $3(30 \%)$ \\
\hline & Poor & Fair & Average & Good & Excellent \\
\hline \multirow{2}{*}{$\begin{array}{l}\text { Please rate your } \\
\text { professional relationship } \\
\text { with your collaborative } \\
\text { partner }\end{array}$} & $1(10 \%)$ & - & - & $2(20 \%)$ & $7(70 \%)$ \\
\hline & 0 hours & 0.5 hour & 1 hour & 2 hours & $3+$ hours \\
\hline \multirow{2}{*}{$\begin{array}{l}\text { Average weekly planning } \\
\text { time spent with } \\
\text { collaborative partner }\end{array}$} & $2(20 \%)$ & $2(20 \%)$ & $2(20 \%)$ & $2(20 \%)$ & $2(20 \%)$ \\
\hline & Never & Rarely & Some & Often & Always \\
\hline \multirow{2}{*}{$\begin{array}{l}\text { Extent to which special } \\
\text { educator and general } \\
\text { educator collaborate on } \\
\text { lesson plans }\end{array}$} & $1(10 \%)$ & $2(20 \%)$ & $2(20 \%)$ & $2(20 \%)$ & $3(30 \%)$ \\
\hline & $\begin{array}{l}\text { Entirely } \\
\text { general } \\
\text { educator }\end{array}$ & $\begin{array}{l}\text { Mostly } \\
\text { general } \\
\text { educator }\end{array}$ & Equally & $\begin{array}{l}\text { Mostly } \\
\text { special } \\
\text { educator }\end{array}$ & $\begin{array}{l}\text { Entirely } \\
\text { special } \\
\text { educator }\end{array}$ \\
\hline $\begin{array}{l}\text { Extent to which both } \\
\text { teachers share } \\
\text { responsibility for student } \\
\text { discipline }\end{array}$ & $1(10 \%)$ & - & $9(90 \%)$ & - & - \\
\hline $\begin{array}{l}\text { Extent to which both } \\
\text { teachers share } \\
\text { responsibility for student } \\
\text { instruction }\end{array}$ & $2(20 \%)$ & $2(20 \%)$ & $6(60 \%)$ & - & - \\
\hline
\end{tabular}

Professional Development. Table 6 summarizes the survey results for the seven items related to Professional Development supporting Collaborative Education. Two of the items focused on the amount of time spent in professional development targeted for 
collaborative instruction before and during the school year, while the other five items focused on the content of the training.

Of the ten respondents who taught a collaborative class during the 2015-2016 school year, four reported spending no time in training for collaborative instruction before the school year, and four reported spending one to three hours in training before the school year. Only two teachers reported spending more than nine hours in training before the school year began. Five teachers claimed to have no training for collaborative instruction during the school year, while three said they had one to three hours during the year, and two said they had four to eight hours. No teachers reported more than eight hours of training for collaborative instruction during the school year.

When asked to rate the topics of focus for professional development, five teachers said "none" of the training focused on different collaborative models, and four teachers said "none" of the training focused on characteristics of various disabilities. Half of the respondents (five) said "some" professional development focused on strategies and skill development in collaborative instruction, while four of the teachers said "much" of the training focused on communicating more effectively. All teachers reported "none," "little," or "some" training focused on collaborative consultation skills, and no teachers responded "all" to any of the items. 
Table 6

Teacher Perceptions of Professional Development Supporting Collaborative Education

\begin{tabular}{|c|c|c|c|c|c|c|}
\hline & None & $1-3$ & $4-8$ & $9-12$ & $13+$ & $\mathrm{M}(\mathrm{SD})$ \\
\hline $\begin{array}{l}\text { How many hours of } \\
\text { training before the } \\
\text { school year in } \\
\text { preparation for } \\
\text { collaborative } \\
\text { instruction? }\end{array}$ & $\begin{array}{l}40 \% \\
(4)\end{array}$ & $\begin{array}{l}40 \% \\
(4)\end{array}$ & - & $\begin{array}{l}10 \% \\
(1)\end{array}$ & $\begin{array}{l}10 \% \\
(1)\end{array}$ & $\begin{array}{l}2.1 \\
(1.370)\end{array}$ \\
\hline $\begin{array}{l}\text { How many hours of } \\
\text { training during the } \\
\text { school year to support } \\
\text { collaborative } \\
\text { instruction? }\end{array}$ & $\begin{array}{l}50 \% \\
(5)\end{array}$ & $\begin{array}{l}30 \% \\
(30)\end{array}$ & $\begin{array}{l}20 \% \\
(2)\end{array}$ & - & - & $\begin{array}{l}1.70 \\
(.823)\end{array}$ \\
\hline $\begin{array}{l}\text { Amount of teacher } \\
\text { training focused on the } \\
\text { following: }\end{array}$ & None & Little & Some & Much & All & $\mathrm{M}(\mathrm{SD})$ \\
\hline $\begin{array}{l}\text { Strategies and skill } \\
\text { development }\end{array}$ & $\begin{array}{l}30 \% \\
(3)\end{array}$ & - & $\begin{array}{l}50 \% \\
(5)\end{array}$ & $\begin{array}{l}20 \% \\
(2)\end{array}$ & - & $\begin{array}{l}2.60 \\
(1.174)\end{array}$ \\
\hline $\begin{array}{l}\text { Different collaborative } \\
\text { models }\end{array}$ & $\begin{array}{l}50 \% \\
(5)\end{array}$ & $\begin{array}{l}20 \% \\
(2)\end{array}$ & $\begin{array}{l}10 \% \\
(1)\end{array}$ & $\begin{array}{l}20 \% \\
(2)\end{array}$ & - & $\begin{array}{l}2.00 \\
(1.247)\end{array}$ \\
\hline $\begin{array}{l}\text { Characteristics of } \\
\text { disabilities }\end{array}$ & $\begin{array}{l}40 \% \\
(4)\end{array}$ & - & $\begin{array}{l}40 \% \\
(4)\end{array}$ & $\begin{array}{l}20 \% \\
(2)\end{array}$ & - & $\begin{array}{l}2.40 \\
(1.265)\end{array}$ \\
\hline $\begin{array}{l}\text { Collaborative } \\
\text { consultation skills }\end{array}$ & $\begin{array}{l}30 \% \\
(3)\end{array}$ & $\begin{array}{l}40 \% \\
(4)\end{array}$ & $\begin{array}{l}30 \% \\
(3)\end{array}$ & - & - & $\begin{array}{l}2.00 \\
(.816)\end{array}$ \\
\hline $\begin{array}{l}\text { Communicating more } \\
\text { effectively }\end{array}$ & $\begin{array}{l}30 \% \\
(3)\end{array}$ & - & $\begin{array}{l}30 \% \\
(3)\end{array}$ & $\begin{array}{l}40 \% \\
(4)\end{array}$ & - & $\begin{array}{l}2.80 \\
(1.317)\end{array}$ \\
\hline \multicolumn{6}{|c|}{ Overall Professional Development } & $\begin{array}{l}2.23 \\
(1.203)\end{array}$ \\
\hline
\end{tabular}

Note: $n=10$

Summary. Most teachers felt positively about the leadership at CMS and perceived they were supported in collaborative instruction $(\mathrm{M}=3.70, \mathrm{SD}=.977)$. While some of the teachers did not feel responsibilities for discipline and instruction were shared in the collaborative classroom (10-40\%), a majority of the respondents $(60-90 \%)$ 
were "equally" involved in student discipline and instruction. The lack of perceived support for collaborative instruction was based on the absence of professional development, with a majority of teachers $(80 \%)$ reporting less than three hours of professional development before and during the school year that was targeted to collaborative instruction.

\section{Research question 3: What patterns of SWD achievement emerged from}

2011-2016? To answer Research Question 3, the researcher collected archived data on three groups of SWD $(n=37)$ as well as data reported by the state for overall pass rates for Central Middle School. For the purpose of this study, student achievement was measured using scores on the Virginia Standards of Learning (SOL) assessments in English, mathematics, and writing ( $8^{\text {th }}$ grade only). The key findings for Research Question 3 were:

- Writing SOL pass rates trended downward over time for SWD, with $21 \%$ of students in Cohort A passing the writing SOL in Spring 2014 and 0\% of students in Cohort C passing the writing SOL in Spring 2016; however, the overall population pass rates for the Writing SOL increased from 2014 to 2016.

- English SOL pass rates remained under 50\% for SWD.

- All groups of SWD maintained pass rates under 50\% in math.

- While Cohort B Math pass rates stayed the same from $6^{\text {th }}$ grade to $7^{\text {th }}$ grade, the pass rates of the overall population of students at that level decreased by 36 percentage points. 
- While Cohort C pass rates for Math and English SOL tests remained 45 to 72 percentage points below the overall population pass rates, both groups followed the same trends from $6^{\text {th }}$ grade to $8^{\text {th }}$ grade.

English SOL test. The English SOL test is administered at the end of $6^{\text {th }}, 7^{\text {th }}$, and $8^{\text {th }}$ grades at CMS. Figures 8, 9, and 10 compare three different cohorts of SWD to their general education peers during the same time period on SOL performance. Figure 8 shows an increase in pass rates among SWD in Cohort A from $6^{\text {th }}$ grade to $8^{\text {th }}$ grade, while the overall population's pass rates decreased in that time.

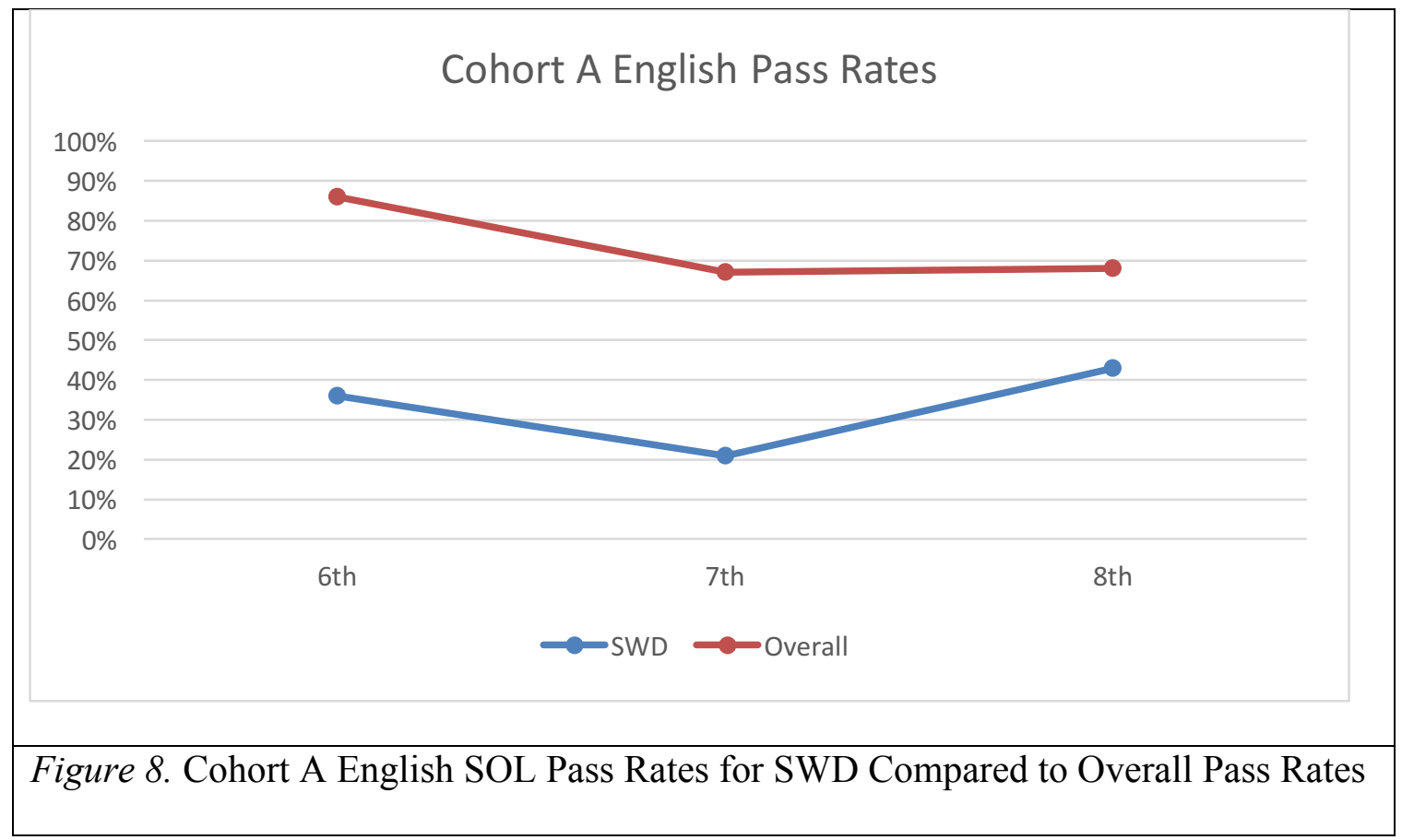

Figure 9 shows Cohort B pass rates among SWD increased from $6^{\text {th }}$ grade to $7^{\text {th }}$ grade while the overall population pass rates decreased. From $7^{\text {th }}$ grade to $8^{\text {th }}$ grade, however, SWD pass rates decreased seventeen percentage points while the overall population increased three percentage points. 


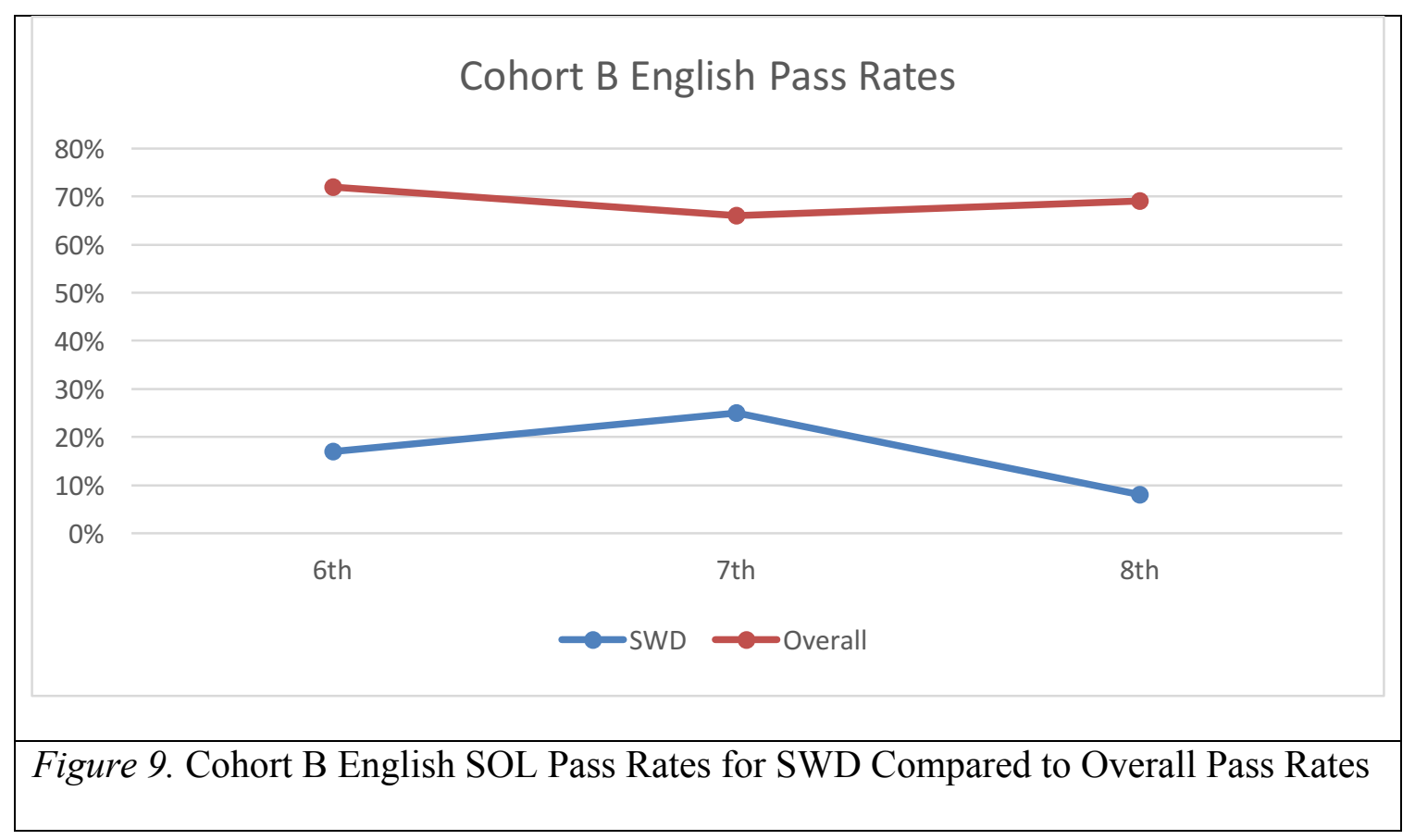

Figure 10 shows an increase in Cohort C pass rates for SWD and the overall population from $6^{\text {th }}$ grade to $7^{\text {th }}$ grade followed by a decrease among both groups from $7^{\text {th }}$ grade to $8^{\text {th }}$ grade.

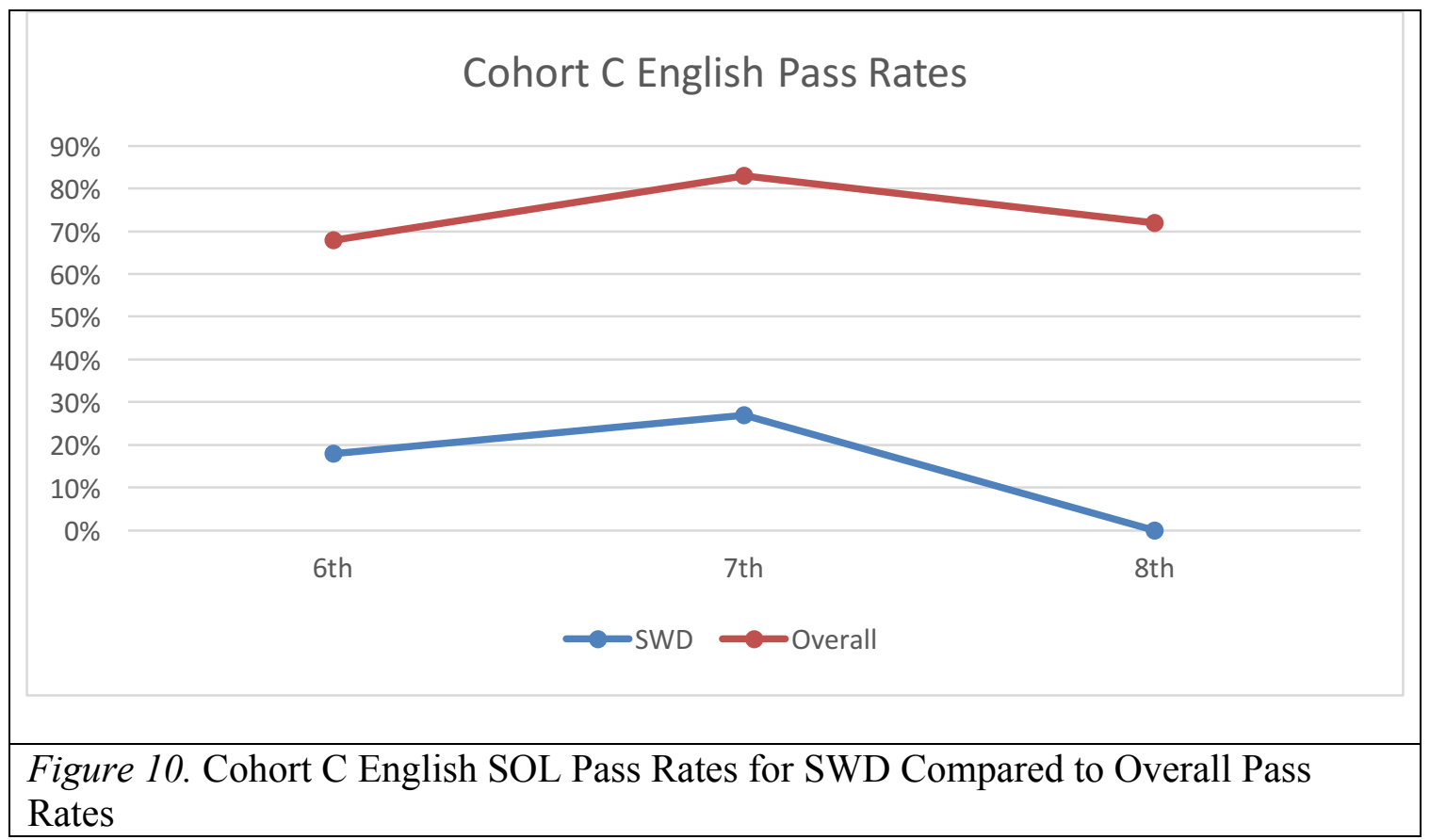


Writing SOL test. The writing SOL test is only administered in $8^{\text {th }}$ grade at CMS based on state policy for all public middle schools. Figure 11 shows the writing pass rates trended downward from 2014 (Cohort A) to 2016 (Cohort C), with Cohort A having a pass rate of $21 \%$ and Cohort $\mathrm{C}$ having a pass rate of $0 \%$.

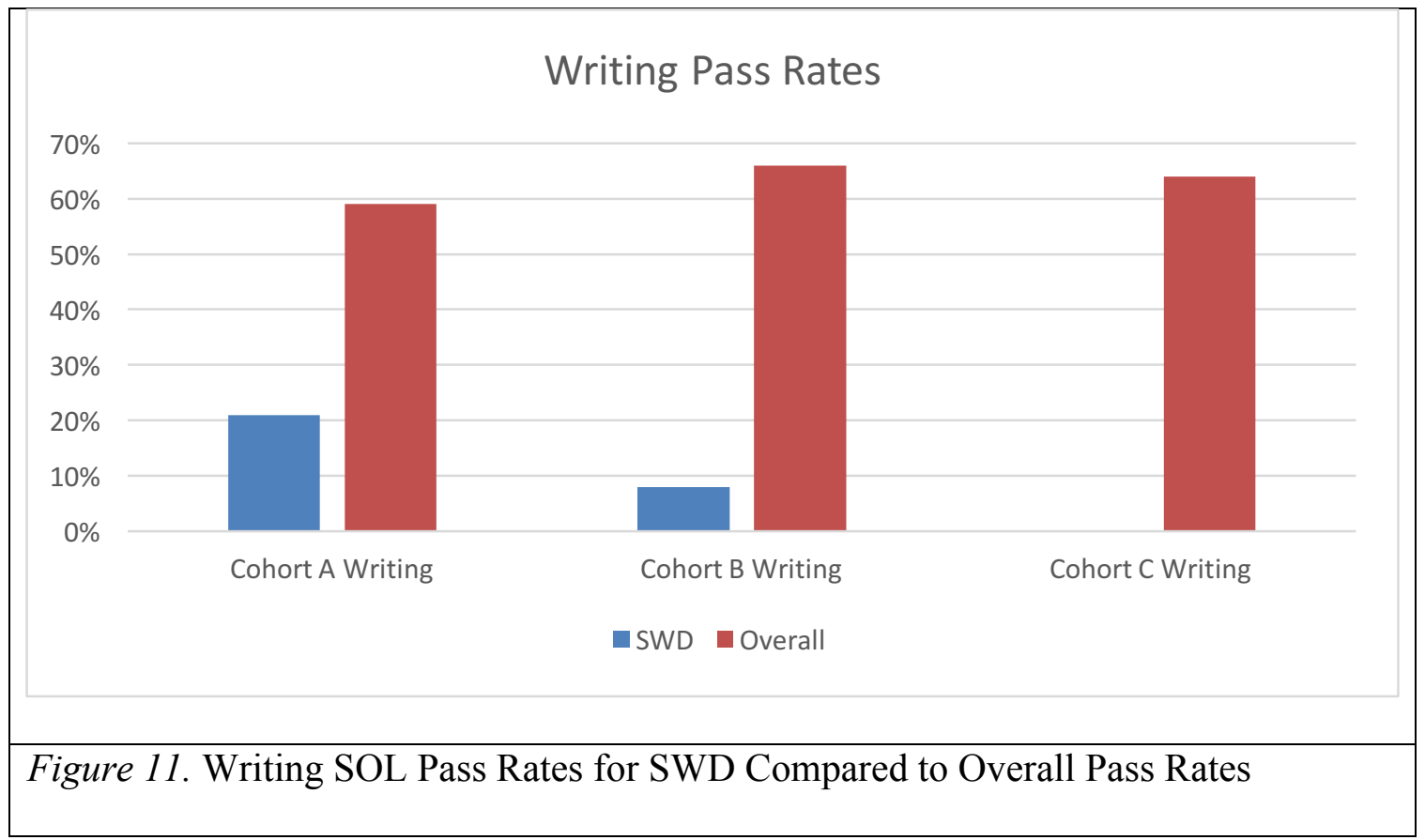

Math SOL test. Students take the math SOL test in $6^{\text {th }}, 7^{\text {th }}$, and $8^{\text {th }}$ grades at CMS. Figures 12, 13, and 14 compare three different cohorts of SWD to their general education peers during the same time period on SOL performance. Figure 12 shows a general increase in pass rates for SWD in Cohort A, while the overall population experienced a sharp decline (36 percentage points) from $6^{\text {th }}$ grade to $7^{\text {th }}$ grade. 


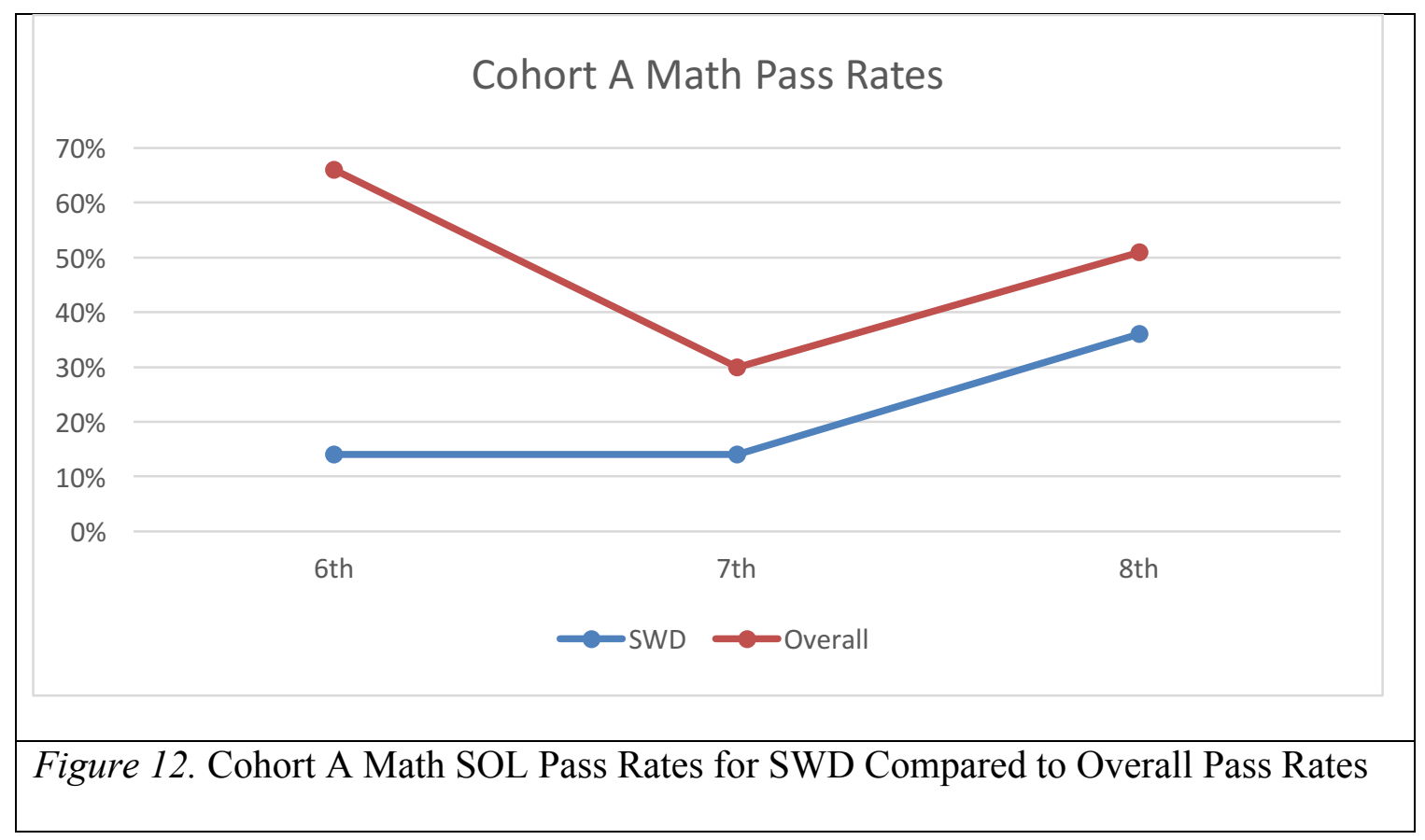

Figure 13 shows a similar decline among SWD in Cohort B and the overall population in that grade level. From $7^{\text {th }}$ grade to $8^{\text {th }}$ grade, however, SWD pass rates continued to decline while the overall population pass rates increased.

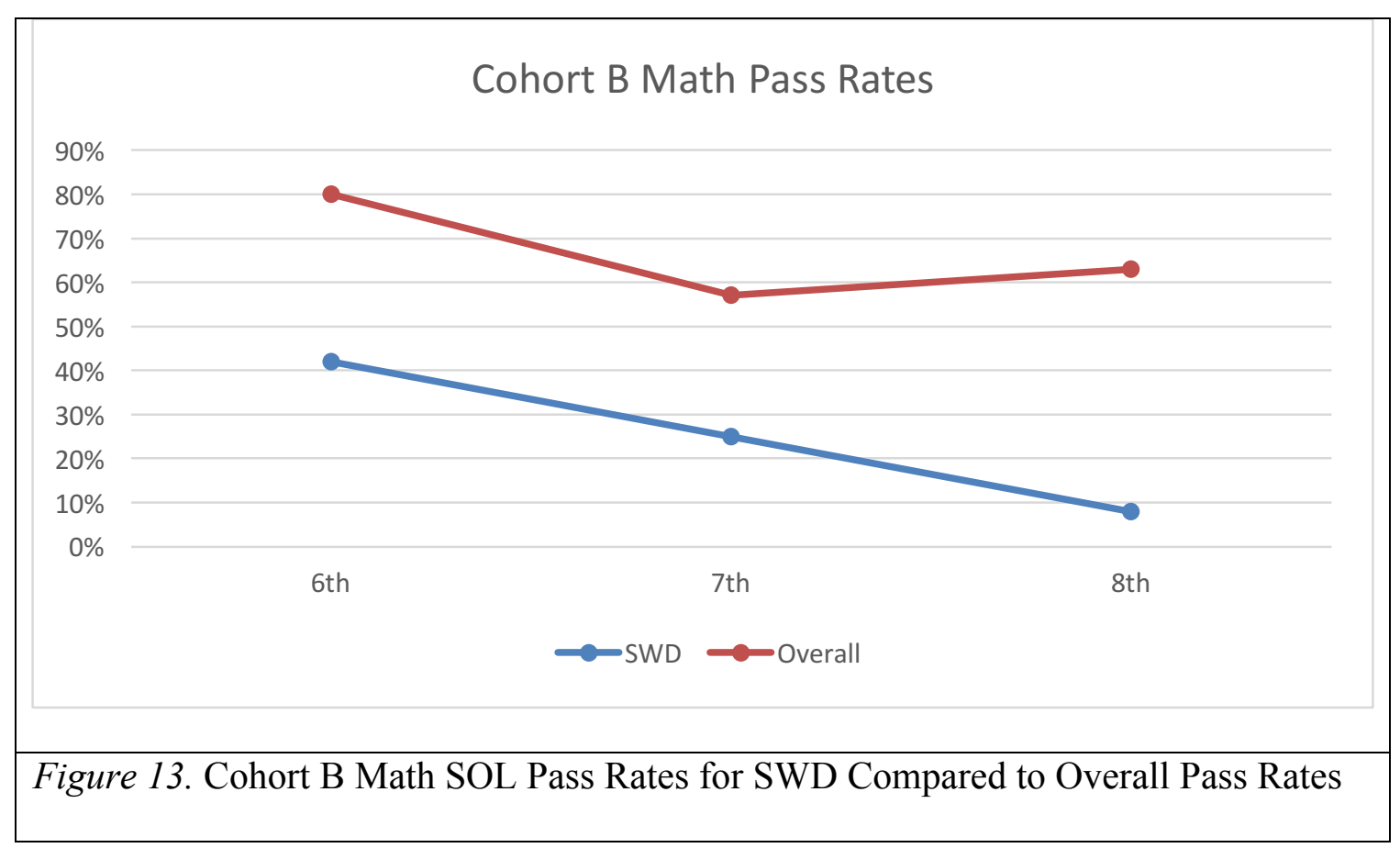


Figure 14 shows the SWD in Cohort $\mathrm{C}$ and the overall population pass rates decreased in $7^{\text {th }}$ grade and increased in $8^{\text {th }}$ grade, although the overall population pass rates remained 45 to 52 percentage points above SWD.

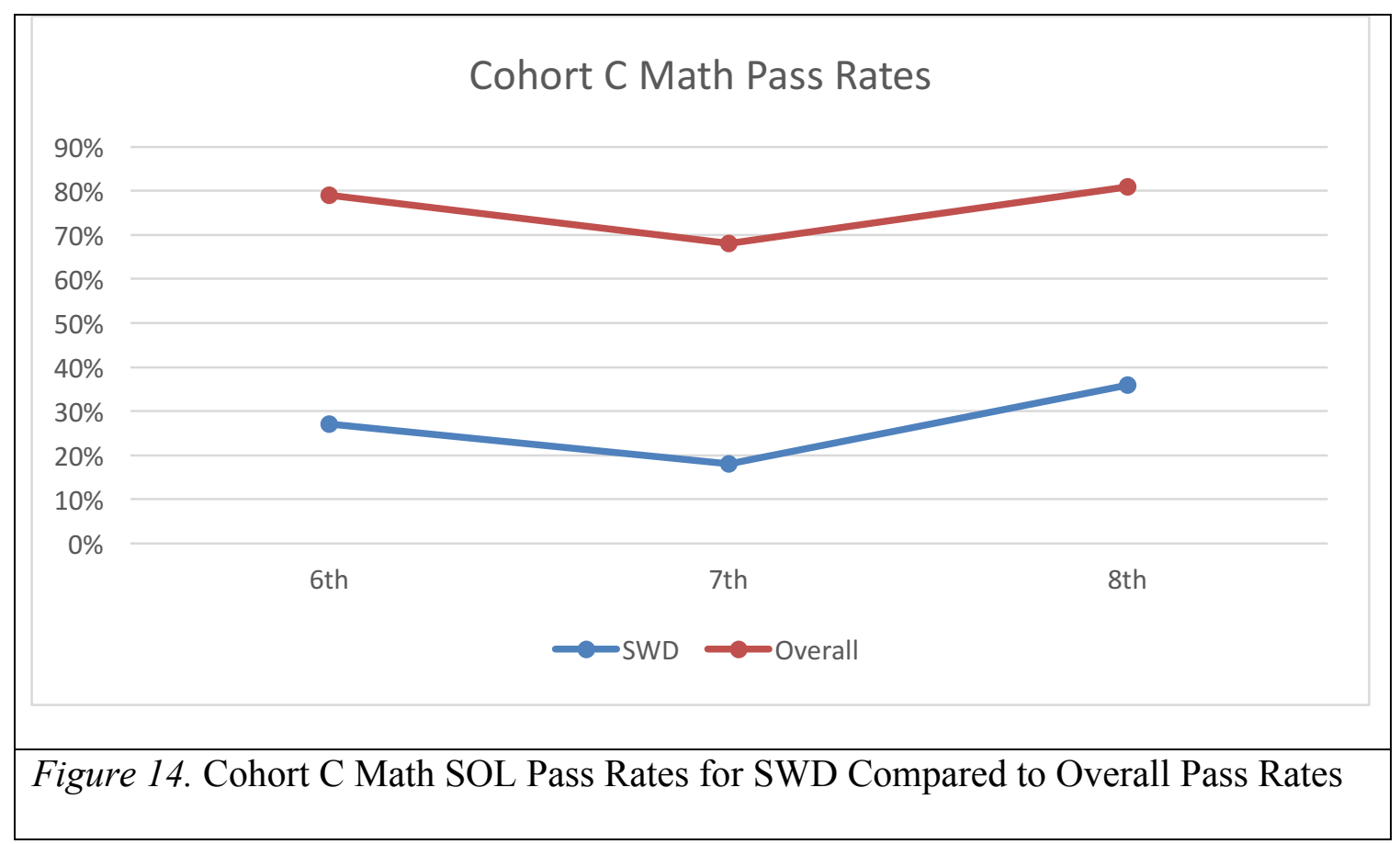

Summary. Over the course of five school years (2011-2016) SOL scores for SWD in English, writing, and math exhibited a downward trend. English and writing pass rates dropped from $21 \%$ (Cohort $\mathrm{A}, 8^{\text {th }}$ grade) to $0 \%$ (Cohort $\mathrm{C}, 8^{\text {th }}$ grade). Math pass rates were consistently low, with no group having a pass rate higher than $42 \%$ (Cohort B, $6^{\text {th }}$ grade). That same group, Cohort B, had a sharp decline in pass rates, ending their $8^{\text {th }}$ grade year with a pass rate of $8 \%$.

In some cases, the SWD pass rates followed the same trends as the overall population pass rates for the students who tested at that same level (ie. Cohort A English pass rates, Cohort $\mathrm{C}$ English and math pass rates); however, overall population pass rates remained fifteen to 72 percentage points higher than SWD pass rates. 


\section{Research question 4: What patterns emerged among SWD non-cognitive}

indicators from 2011-2016? To answer Research Question 4, the researcher retrieved archived student data for student attendance and discipline. The researcher looked at overall absences, not discriminating between excused and unexcused absences.

Originally, discipline data was to be coded according to the school's coding system; however, discipline offenses were so similar, the researcher chose to use the number of offenses without coding them. The key findings for Research Question 4 were:

- For the years 2011-2016, there was a small change in the average number of absences per student and was similar to the overall population.

- SWD were disproportionately represented in the overall number of discipline offenses compared to the general population.

- Males had higher numbers of absences and discipline offenses on average than females.

Attendance. Attendance rates were used as a non-cognitive indicator for student engagement in the collaborative classrooms. Figure 15 shows a comparison of the average number of absences per school year among SWD and the total population of the school. While there was a general trend downward for both groups of students, showing a decrease in the number of absences per year, the SWD did not show greater or fewer average absences than the general population in any given year. 


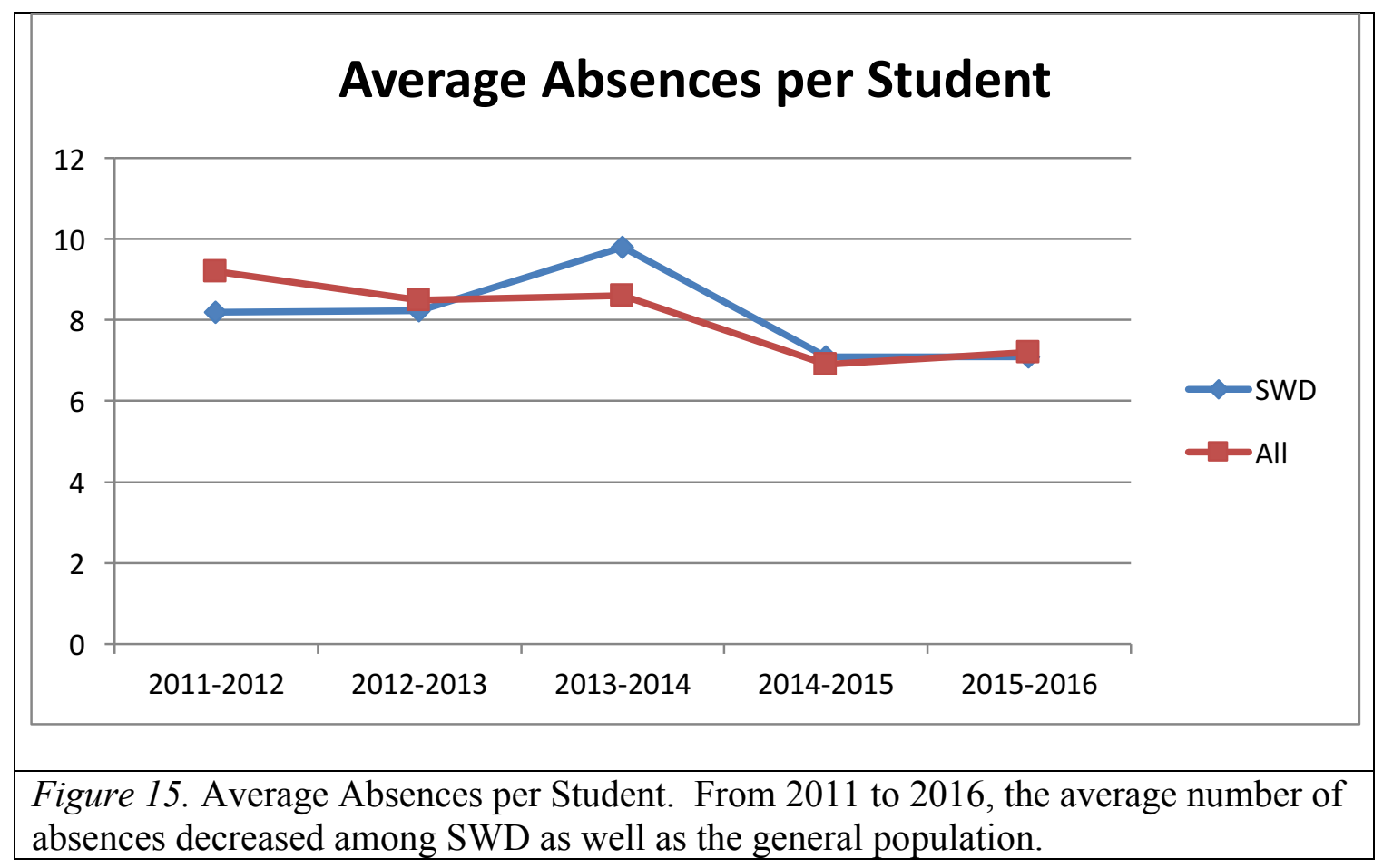

Discipline. Discipline offenses were also used as a non-cognitive indicator for student engagement in the collaborative classroom. Although the total number of discipline offenses per school year was reported online via the school report card (VDOE), the researcher had to sort through all the student files to find the number and type of discipline offenses for each of the SWDs.

The average number of discipline offenses for the general population increased for each group from $6^{\text {th }}$ to $8^{\text {th }}$ grade, but the total number of discipline offenses among SWD trended downward from 2011 to 2016 (see Figure 16). The males had an overall higher average of discipline offenses $\mathrm{M}=1.74(\mathrm{SD}=1.212)$ than females $\mathrm{M}=0.67(\mathrm{SD}=$ 0.647), and males had more average discipline offenses in every group, every year with only two exceptions (Cohort A girls earned more average referrals than boys during $8^{\text {th }}$ grade; Cohort B girls earned more average referrals than boys during $7^{\text {th }}$ grade). 
Despite the downward trend of discipline referrals, SWD continued to incur a disproportionate number of referrals based on their percent of the school population (eleven percent).

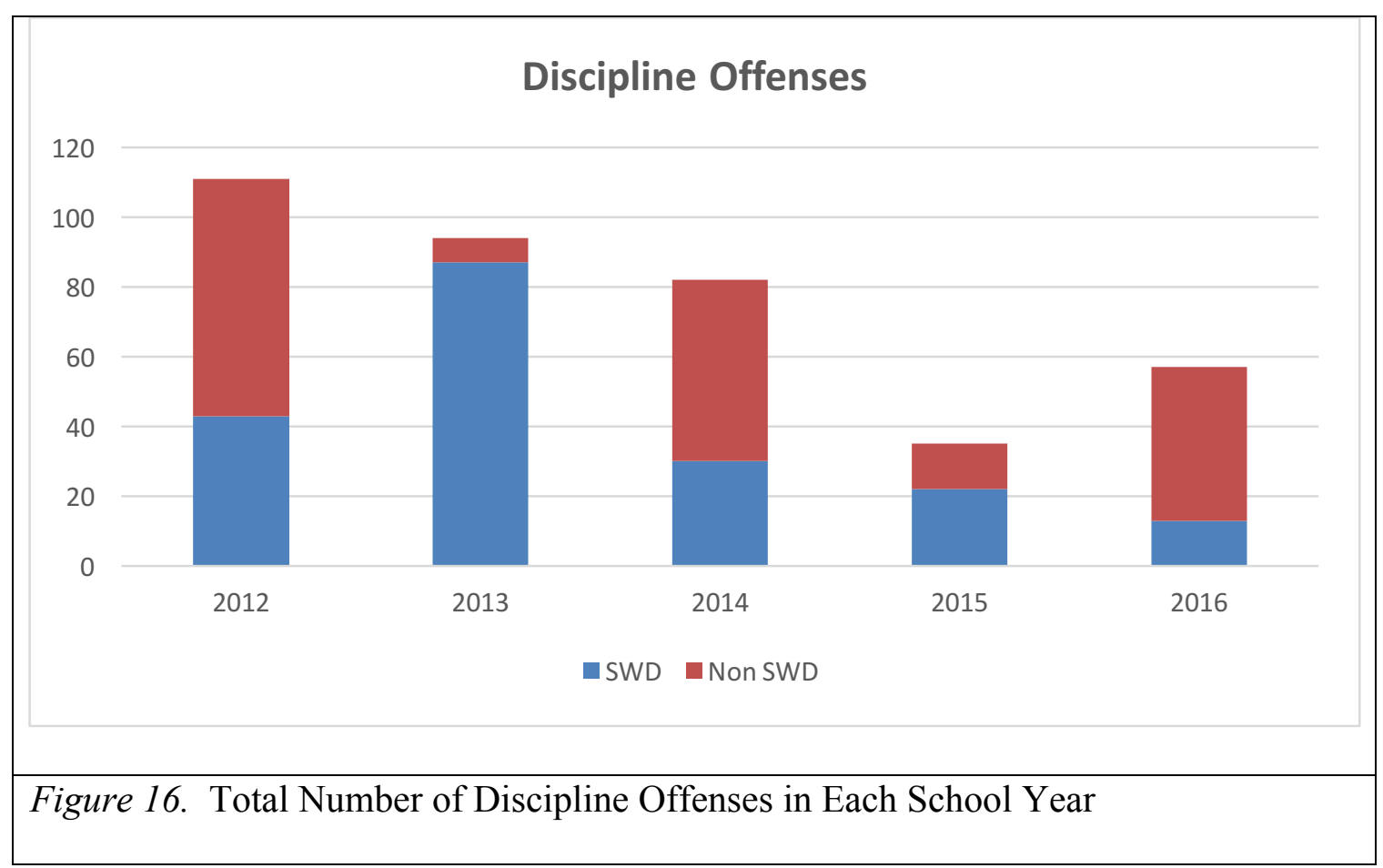

Summary. While there were some fluctuations among each group of SWD, absences and discipline offenses both trended downward over time. These changes possibly could be related to the students' level of engagement in their collaborative classrooms. 


\section{CHAPTER FIVE: DISCUSSION AND ACTION COMMUNICATIONS \\ Purpose of the Research}

This study investigated the problem of practice, instruction for Students With Disabilities (SWD), and how collaborative education may impact student achievement, discipline, and attendance. Specifically, I investigated the presence of three criteria that support optimal implementation of collaborative instruction: Leadership and Administrative Support, Organizational Structures (schedule, planning time, instructional models), and Professional Development. Along with those criteria, I analyzed student achievement data as well as data for discipline and attendance to describe student performance throughout the implementation of collaborative instruction from 2011 to 2016. All core teachers at the middle school were invited to participate in the survey, and eighteen teachers responded. Furthermore, six teachers, current and former, participated in individual semi-structured interviews to supplement survey and student data.

\section{Research Questions}

\section{Research question 1: How did the collaborative instruction environment} change in the identified school from Fall 2011 to Spring 2016? Qualitative responses from the six teacher interviews revealed changes in the collaborative instruction environment at CMS from 2011-2016. In each interview, teachers discussed changes in leadership, organizational structures, and professional development and their perceived impact on student achievement, attendance rates, and discipline offenses. All six 
interviewees agreed that changes in leadership were positive for teachers in collaborative classrooms, with the current administration having a greater understanding of the roles of the special and general educators in that environment and an ability to offer information and suggestions for improvement without having unrealistic expectations of each teacher. According to the interviewees, the current administrators meet most of the criteria established by the Donahue Institute at the University of Massachusetts (2004) as practices supporting students in special education. The six teachers also agreed that while the change in leadership may have impacted student achievement and discipline rates, attendance is perceived to be unrelated to leadership and administration.

Teachers' responses varied regarding changes in organizational structures and their perceived impact on SWD. Three of the six teachers were still teaching at CMS during the 2015-2016 school year and suggested a change in schedule, from six periods to four blocks, should have had an overall positive impact for students, especially in math and English where students received more than 50\% more instructional time than they did in the previous schedule. Research shows block schedules provide more instruction time for students, reducing the amount of time dedicated to organizational tasks such as taking attendance and bringing the class to order (Northeast, 1998). Researchers also found block scheduling allows students and teachers to have deeper learning experiences, enhancing students' understanding of the content (Northeast, 1998).

According to Pugach and Johnson (1995) and Cook and Friend (1995), coteachers need regularly scheduled planning time, but all six teachers agreed the amount of time they have to collaborate and prepare for lessons was minimal (.5-1 hour weekly). Without time to prepare lessons together, the general educator becomes burdened with all 
the instructional responsibilities while the special educator becomes a passive observer (Cook \& Friend, 1995).

Four teachers also said working with the same collaborative partner each year was more impactful for students than having the special educator work with different general education teachers each year. Of the three general educators, none of them was initially asked if they wanted to teach a collaborative class, but two of the three have requested collaboration in the years since they were first introduced to it; however, the third preferred not to have a collaborative classroom. All teachers agreed that the desire to teach collaborative education and the type of relationship a collaborative team has are very important to their success in a collaborative classroom, supporting conclusions from Thompson (2001) and Carlson (1996; as cited by Scruggs, Mastropieri, \& McDuffie, 2007).

There was a lack of professional development supporting teachers who were in collaborative classrooms. Of the six teachers interviewed, none of them had received training specific to collaborative instruction since they began teaching; although, all agreed the division's focus on differentiation was helpful for all teachers. The five teachers who were still teaching in collaborative classrooms expressed the need for training related to the different models of collaborative instruction as well as classroom management techniques for students with emotional disorders.

The collaborative learning environment at CMS did change from 2011 to 2016. The change in administration in 2015 provided teachers with more leadership support in the form of feedback and resources. The change in schedule in 2015 from six periods to four blocks gave co-teaching teams more instructional time in math and English classes, 
where SOL pass rates were decreasing. Allowing teachers to volunteer for collaborative instruction led to greater teacher satisfaction, and having teachers co-teach for multiple years contributes to stronger co-teaching relationships, leading to student success, according to the research (Cook \& Friend, 1995). The only aspect of the collaborative learning environment that showed little change was the amount of professional development for co-teachers: There was none. Without professional development specifically targeted to co-teaching in a collaborative environment, the co-teaching relationship could fail (Rosa, 1996; cited in Scruggs, Matropieri, \& McDuffie, 2007). Going forward, this is an area where teachers would like to see increased support.

\section{Research question 2: What were the teachers' perceptions of the}

\section{Collaborative Instruction environment from 2011-2016? For Research Question 2,} there were three criteria, identified by researchers as criteria optimal for collaborative instruction, that made up the categories for the survey about collaborative instruction. Leadership and Administrative Support had an overall mean above three, indicating teachers feel supported by administration in their collaborative classrooms. The current administration was able to provide information about collaborative instruction as well as suggestions for improvement, and most teachers felt they had the time they needed to plan and complete other non-classroom responsibilities. In particular, the administration was supportive of inclusive practices and encouraged the placement of SWD in classrooms with their non-disabled peers.

Survey data revealed the majority of collaborative classrooms at CMS employed two models of instruction: "one teach, one assist" and "team teaching." Most teachers (90 percent) had a positive relationship with their collaborative partner, a characteristic 
the interviewees felt was strongly instrumental in the collaborative team's success. Most of the collaborative teachers felt they were equally responsible for student discipline and instruction, although more felt the general educator is the main instructor in the classroom. While the three special educators who were interviewed discussed pulling groups of students occasionally for extra support or separate instruction, the groups of students varied so SWD did not feel singled out.

Professional Development received a low rating $(\mathrm{M}=2.23)$, and interview responses supported the conclusion that teachers in collaborative classrooms feel they have not received the training and development opportunities they need to be successful collaborative teachers.

According to survey results, some of the criteria for optimal implementation of collaborative instruction were present at CMS during 2015-2016. Supportive leadership (Austin, 2001; Carpenter \& Dyal, 2001) and organizational structures (Thompson, 2001; Vesay, 2004; as cited by Scruggs, Mastropieri, and McDuffie, 2007) received high ratings, suggesting teachers felt supported by administration in their co-teaching classrooms, and certain organizational structures (schedule, collaborative planning time) were in place to increase the effectiveness of collaborative instruction. Professional development targeted specifically to co-teaching teams working with SWD, a necessary component of collaborative instruction (Austin, 2001), was lacking according to survey responses. In order to continue to support teachers, professional development will need to be provided.

\section{Research question 3: What patterns of SWD achievement emerged from}

2011-2016? The researcher began the study after observing an overall decline in SOL 
scores among SWD according to the school's report card (VDOE). After analyzing data from three groups of SWD, despite the positive perceptions teachers have about the collaborative education at CMS, student achievement scores continue to decline, especially in the areas of English (reading) and writing. There are, however, other factors in the educational environment that could have caused this decline in achievement.

One issue, not identified by the survey but mentioned by two of the special educators who were interviewed, is the amount of teacher turnover at CMS since 2011. Not only has the administration changed (both the current principal and assistant principal were teachers at the beginning of the study), but the English and math departments had some positions filled with a different teacher each year. When Cohort B was in $8^{\text {th }}$ grade and students took two SOL tests, the English classroom had a teacher who left mid-year, followed by a long-term substitute before the position was filled on a permanent basis. For the special educator, this turnover makes developing a good professional relationship difficult. In addition, the inconsistency in instruction can lead to a decline in achievement.

Another issue not directly addressed in the teacher survey, but a possible cause for students' decline in achievement in English and writing, was the school's status as “in school improvement" from 2012 to 2016, with an emphasis on improving math scores. The school developed a plan for math remediation; however, the English teacher, one of the interviewees for this study, felt English, especially writing instruction, was deemphasized as a result.

The dip in each cohort's seventh grade math achievement scores could also be the result of multiple teacher transitions that occurred from 2011-2015. Most of the cohorts 
(except Cohort B) were able to recover on the $8^{\text {th }}$ grade test, performing as well as or better than they did in $6^{\text {th }}$ grade.

\section{Research question 4: What patterns emerged among SWD non-cognitive}

indicators from 2011-2016? To determine whether students were engaged in instruction, the researcher used the measurable data from students' attendance and discipline records, even though five of the six teachers interviewed for this study believe students' attendance is unrelated to classroom instruction. Researchers agree, however, that students who are engaged in instruction in the classroom will have higher rates of attendance (Allensworth \& Easton, 2007; Neild \& Balfanz, 2006).

Over time, the average number of absences decreased for SWD. This is also true to the general population of the school. One of the interviewed teachers attributed this decline to a local "crack-down" on student attendance, which is being supported by the local court system. Another interviewee did believe attendance was related to students' desire to be in class and claimed if their attendance rates were increasing, it must be because they either like the content or have developed a good relationship with the teacher.

The "average number of absences" may be misleading because of the substantial variance in the number of days absent. For example, in Cohort B, one SWD missed 52 days in three years while another missed three days in three years. There are some students who are habitually absent, although most students only miss a few days each year; the outliers skew the overall averages.

Discipline offenses also declined over time; however, the percentage of discipline referrals received by SWD was not proportional to the percentage of SWD in the school. 
According to research by Leone, Mayer, Malmgren, and Meisel (2000), SWD represent about twenty percent of students who are suspended, but only make up eleven percent of the population. Even so, CMS's SWD represented, at the very least, 23 percent of discipline offenses from 2011 to 2016. When asked about this, the teachers who were interviewed responded with two explanations: (a) students with disabilities are easily frustrated in class because, by nature of their disability, they struggle with learning, or have an emotional disability, which causes them to act out, or (b) teachers who have not been trained in working with SWD do not have the skillset to recognize the students' frustration or manage their outbursts and, therefore, write a discipline referral because they do not know how else to deal with the student. Each cohort group consisted of more boys than girls, and studies show boys are more likely to be referred to the principal's office for discipline issues (Gurian, 2006; Skiba, Peterson, \& Williams, 1997). Even with those trends, Cohort B had a female who received more discipline referrals than any of the males in the group. The interviewed teachers concurred that, in any classroom, the combination of students, both SWD and their non-disabled peers, can have a significant impact on the number of disruptions and discipline referrals.

\section{Emergent Patterns}

Five emergent patterns became apparent in the student and survey data and were supported by information from the interviews.

Teacher preference. In interviews, teachers who were involved in both collaborative models expressed a preference for the second model of collaborative instruction in which SWD had collaborative math and English classes but attended 
science and social studies classes without a special educator. These teachers gave two main reasons to support their preference.

The second model distributed SWD among multiple collaborative classes for math and English, allowing for fewer SWD in one class. Research is unclear about an ideal number or percentage of SWD in a co-taught classroom, but the literature supports the "principle of natural proportions" (Brown et al., 1989), maintaining a similar percentage of SWD in the classroom that is represented in the school. Other authors claim anywhere from $25-50 \%$ of the classroom is an acceptable ratio for learners with special needs, including students who are at-risk for failing (Knackendoffel, 2005; Nowacek, 1992; Walther-Thomas et al., 1996; Zigmond \& Magiera). With fewer SWD in the classroom, those students may have received more one-on-one time with each teacher, meeting their individual special learning needs, while allowing them the opportunity to meet the high expectations of a general education classroom. One teacher said, 'I don't feel like I'm running around the classroom the whole time answering each student's questions. There are only a few students who need my individual attention, so now I have a bigger role in whole-class teaching."

While the second model of collaborative instruction was implemented before a change in administration, teachers claimed the change was positive for collaborative classrooms. Teachers felt the administrative team was supportive of collaborative education, especially regarding the administration's ability to provide information on upto-date instructional practices and an emphasis on inclusion and access to the curriculum for SWD. Research indicates that teachers who feel supported by their administration and involved in decision-making are generally more satisfied in their positions (Blase \& 
Roberts, 1994; Darling-Hammond, 1995). Teachers' preference for the Math/English Collaboration model may be enhanced by their overall satisfaction under the current administration.

Collaboration improved over time. As with any new program or strategy, practice improves over time. Likewise, the collaborative education program at Central Middle School improved from 2011 to 2016. As teacher teams continued to work together, they developed more parity in planning, instruction, and discipline in their cotaught classrooms. In a report of research-based practices that support co-teaching teams, Nierengarten (2013) suggested that maintaining co-teaching teams from year to year allows teams to improve their practice. Jung (1998) reported co-teaching teams could still be in a trial stage after four years of teaching together. As teachers became more familiar with co-teaching practices, the classroom likely became less restrictive for SWD, allowing them to experience a more mainstream education.

In addition to a less restrictive environment, a change in the master schedule likely contributed to the improvement of the collaborative model. The block schedule, implemented in 2015, offered many possible benefits to the collaborative environment: more time on task, greater depth in subject matter, stronger student-teacher relationships, and reduced discipline problems (Farbman \& Kaplan, 2005; Freeman, 2001; Northeast, 1998; O’Neil, 1995). With fewer transitions during the school day, teachers and students were able to spend more time with the content and less time getting organized and moving from one class to the next. Additionally, because there were fewer classes during the day, teachers were able to develop closer relationships with their students because they had fewer students with more face time. These deeper student-teacher relationships 
have been found to lead to greater teacher satisfaction and fewer discipline problems (Farbman \& Kaplan, 2005; O'Neil, 1995). The block schedule appeared to have a positive impact on collaborative instruction at Central Middle School as it relates to teacher perceptions of the collaborative environment.

Student non-cognitive indicators improved. From 2011 to 2016, absences and discipline referrals decreased among SWD. Teachers who were interviewed gave some possible explanations for these trends:

1. In the Full Content Collaboration model, SWD traveled as a group with the special educator to all four of their core classes. Teachers involved in this model believed the students being together almost all day created tension among students as well as between the students and the special educator who was with them. Because these students and their grade level special educator were together all day, teachers believed students were more likely to get in petty disputes or disrupt class as a result of "getting on each other's nerves." With the change to the Math/English Collaboration model, the special educator had fewer SWD in each class and only saw them twice each day. Also, the students were less likely to be in the same classes, creating less tension, and therefore, less disruption, than when they were together all day.

2. In the second model, Math/English Collaboration, SWD were distributed in smaller numbers among their general education peers. This can create less of a stigma on the collaborative classes as being "low level." When the SWD traveled as a group to all four core classes, students may have felt targeted as the "low" or "dumb" group, making them feel less capable or welcome in the classroom. If 
these students felt stigmatized, it is possible they would have acted out and caused discipline issues or simply chosen to not attend school. When the SWD made up a smaller percentage of the class, they may have felt less targeted as a student with special learning needs, leading to greater comfort in the classroom, less disruptive behavior, and higher attendance rates.

3. The change to a block schedule in 2015 reduced the number of transitions between classes. Teachers felt this reduction in transition time was directly related to the reduction in discipline referrals. One teacher commented, "Students are more likely to do something stupid when they're in the hallway, and they think no one is paying attention." Additional research supports a reduction in discipline referrals as well as increased attendance when students are on a block schedule (Brandenburg, 1995; Buckman et al., 1995; Carroll, 1994; Hackmann, 1995).

4. Teachers felt the change in leadership in 2015 also had a positive impact on discipline rates, if not also attendance. The administrative team sought to establish a positive learning environment with high expectations for all students, and teachers were empowered to do the same in their classrooms. As these high expectations were enforced, discipline incidences declined and attendance rates increased.

All of the teachers interviewed expressed high academic and behavioral expectations for all students, but research on tracking shows that teachers speak and think differently about students who are in lower-level classes (Allington, 1983; Gambrell et al., 1981; Gamoran, 1986; Goodlad, 1984; Rosenbaum, 1976). These researchers found 
that teachers described their low-level students as having discipline problems, being unmotivated to learn, and having uninvolved parents. When the SWD at Central Middle School traveled as a large group in the Full Content Collaboration model, they made up a majority of the class, possibly creating the perception of a "low level" class, even though there were general education students in the class as well. Even though these teachers voiced high expectations for all students, the perception of ability grouping may have impacted their expectations of the students' behavior and attendance. When the SWD were more evenly distributed among classes in Math/English Collaboration, the perception of the "low level" class disappeared, possibly leading to higher behavioral and academic expectations for the SWD in those classes.

Model follows research-based practices. The Math/English Collaboration model incorporated many of the research-based criteria introduced in Chapter 2 as components of a successful collaborative environment. The leadership provided feedback and resources for collaborative teachers and supported the strategies they used in the classroom. The environment was organized in a way that condoned higher student engagement, greater student-teacher relationships, reduced discipline, and greater attendance. A block schedule also allowed teachers to have more planning time, possibly providing common planning opportunities for co-teachers. The only identified criteria for collaborative success missing from the Math/English Collaboration model is professional development. Teachers in the Central Public Schools have often attended professional development as whole schools, or even as a whole division, due possibly to a lack of time or resources. While many of the collaborative teachers were veteran 
teachers, professional development specific to collaborative education could improve their practice.

In one interview, the special educator revealed that while Central Middle School was under review by the Virginia Department of Education, professionals from Virginia's Training and Technical Assistance Centers (T/TAC) observed and collected data on the special education program at CMS. At the end of the review, the T/TAC professionals said the CMS teachers were "doing a great job," and did not offer any suggestions for improvement. The Math/English collaborative model was being implemented well, despite academic decline.

\section{Student achievement performance declined in Math/English Collaboration.}

Despite improvement in non-cognitive indicators, increased teacher satisfaction, and improved research-based collaborative practices, student achievement declined from 2011 to 2016. Teachers who were interviewed offered a couple of possible reasons regarding this trend:

1. Each group of students is different. The nature and severity of their disabilities vary, and the relationships they have with each other can impact their behavior and performance.

2. Changes in faculty may have negatively impacted student achievement. According to the teachers who were interviewed, teacher turnover, especially in core subjects, was an issue for several years in a row. Not only did the special educator have to work with a new partner, but often the new teacher had not been trained in collaborative instruction or how to work with SWD in a general education setting. There were several new teachers who had classroom 
management issues which also impacts instruction and achievement. DarlingHammond and Young (2002) reported a direct relationship between quality of teaching and student learning. If the SWD in Full Content Collaboration had more experienced, more effective teachers, their scores would have been higher, regardless of the collaborative model change.

Other factors may have impacted the decline in student achievement among SWD from 2011 to 2016. With a high percentage of SWD in the Full Content Collaboration classrooms, instruction may have reflected lower expectations for students while still providing the content and skills they needed to pass the SOL assessments. In the Math/English Collaboration, SWD might have felt overwhelmed by higher educational expectations and given up rather than attempting to meet those higher expectations. According to the School Improvement Plan, while Central Middle School was under review by the Department of Education, there was an enhanced focus on math instruction and remediation. Accordingly, most groups in the study had higher pass rates on the Math SOL from sixth grade to eighth grade. Because of the increased emphasis on mathematics instruction and remediation, reading and writing instruction may have suffered as an unintended consequence, leading to decreased pass rates on both the English SOL and Writing SOL assessments.

Because of the small numbers of students included in the study, and the exclusion of some students based on incomplete data, achievement data may be skewed. The researcher acknowledges this as a limitation of the study. 


\section{Limitations}

The researcher would like to acknowledge several limitations that may have impacted the accuracy of data in the study. First, because many of the teachers completing the survey had not worked at CMS for the entirety of the study, the survey was only applicable to the 2015-2016 school year, limiting the data used for Research Question 2 regarding teachers' perceptions of the Collaborative Instruction model from 2011-2016. Additionally, although interviewed teachers were chosen because of their presence during the transition from the Full Collaboration model to Math/English Collaboration, the amount of time that has passed required teachers to remember information from four years prior to the time of the interviews. This time delay in gathering data could have resulted in inaccurate information about that transition.

Without observation data on of the quality of teacher instruction in the different collaborative classroom models, the researcher cannot accurately determine the relative effectiveness of the collaborative models for teaching SWD. This study merely determined the presence of research-based criteria that contribute to a successful collaborative learning environment.

\section{Recommendations for Future Implementation}

The main purpose of this research was to provide a descriptive evaluation of the collaborative practices in one rural middle school in addition to identifying trends in the academic and non-cognitive performance of SWD at that middle school. The study explored the perceptions of teachers who are involved in collaborative education, and identified areas of strength and weakness in the current implementation.

The recommendations for future implementation are as follows: 
- Provide professional development opportunities targeted to teachers who have collaborative classrooms, including training specific to: the different models of collaborative instruction, classroom management for SWD, and collaborative consultation skills. Cook and Friend (1995) report both general educators and special educators require opportunities to prepare for collaborative teaching. Special educators may need content-specific professional development, while general educators may need more training to work with SWD (Cook \& Friend, 1995). Additionally, the co-teaching team needs support for developing a positive, productive relationship that will benefit students (Rosa, 1996; cited in Scruggs, Mastropieri, \& McDuffie, 2007).

- Provide more feedback to collaborative instructors, especially general educators, to help them improve their instruction for SWD and their relationships with co-teaching partners. Research on clinical supervision as a form of professional development suggests principals and other instructional supervisors should observe classrooms, collect measurable data, and provide feedback for improved practice in a non-evaluative manner, encouraging improved practice without fear of judgement (Alger, 2005; Deppeler, 2007, Reed \& Bergemann, 2005; Smith \& Richards, 1989).

- Provide teachers with the opportunity to volunteer to teach collaborative classes, rather than assigning this responsibility without consulting the teacher. Scruggs, Mastropieri, and McDuffie (2007) cite research from Vesay (2004) and Carlson (1996) that maintained teacher teams should volunteer to 
co-teach together; this leads to improved student achievement and behavior outcomes.

- Provide extra time for collaborative teachers to plan together, either by allowing them to have a common planning time, or reducing some of their other non-classroom responsibilities (like after-school or lunch duties). Pugach and Johnson (1995) and Cook and Friend (1995) suggest regularly scheduled and frequent planning time for a successful collaborative team.

\section{Future Research}

The purpose of this study was to provide a description of the collaborative education environment at one rural middle school through the lens of three criteria: Leadership and Administrative Support, Organizational Structures, and Professional Development. Future research of collaborative education should involve a more in-depth study of the characteristics of the collaborative environment, including classroom observations to document student-teacher interactions and student on-task behavior, and more teacher interviews detailing presence of the optimal criteria for collaborative instruction.

Additionally, future research on the impact of collaborative education should include observational data on teacher instruction. Adnot, Dee, Katz, and Wyckoff (2017) cite other researchers (Aaronson, Barrow, \& Sander, 2007; Chetty, Friedman, \& Rockoff, 2014; Jackson, 2012; Rivkin, Hanushek, \& Kain, 2005; Rockoff, 2004) that support "the variance in teacher effectiveness is qualitatively large, and more effective teachers can dramatically improve students' short- and long-run life outcomes” (p. 56). 


\section{Action Communication}

The following report was developed to provide the Superintendent of Central Public Schools and the Director of Special Education with the key findings and recommendations for future implementation of the collaborative instruction program at Central Middle School.

\section{Report for the Superintendent and the Director of Special Education: Key Findings and Recommendations for Future Implementation}

Thank you for the opportunity to share the findings of my study of collaborative instruction at Central Middle School. I appreciate your support, and I thank you for allowing me to have access to the teachers who participated as well as student data needed to complete the study. Because of these multiple data sources, I was able to develop a good understanding of the implementation of collaborative education at CMS from 2011 to 2016. The purpose of this communication is to provide you with the key findings and recommendations for future implementation of collaborative instruction. If you have any further questions, please contact me.

\section{Purpose of the Research}

This study investigated the problem of practice, instruction for Students With Disabilities (SWD), and how collaborative education may impact student achievement, discipline, and attendance. Specifically, I investigated the presence of three criteria that support optimal implementation of collaborative instruction: Leadership and Administrative Support, Organizational Structures (schedule, planning time, instructional models), and Professional Development. In addition, I analyzed student achievement data as well as data for discipline and attendance to describe student performance 
throughout the implementation of collaborative instruction from 2011 to 2016 . All core teachers at the middle school were invited to participate in the survey, and eighteen teachers responded. Furthermore, six teachers, current and former, participated in individual semi-structured interviews to supplement survey and student data.

This study, Understanding the Decline of Academic Indicators for Students with Disabilities at a Rural Middle School, focused on four research questions:

1. How did the Collaborative Instruction environment change in the identified school from Fall 2011 to Spring 2016 ?

2. What were the teachers' perceptions of the Collaborative Instruction environment from 2011-2016?

3. What patterns of SWD achievement emerged from 2011-2016?

4. What patterns emerged among non-cognitive indicators for SWD from 2011-2016?

\section{Key Findings and Recommendations for Future Implementation}

The accompanying graphic identifies the key findings identified in the study along with recommendations for future implementation of the collaborative instruction program at CMS.

Overall, teachers prefer the current model of collaborative instruction, which has improved over time and incorporates research-based practices for collaborative education. In the past five years, although student achievement (measured by SOL pass rates) has declined, attendance and discipline rates among SWD have improved.

Major recommendations for continuing collaborative instruction include maintaining a block schedule where SWD are distributed equally among collaborative 
and general education classes, hiring and keeping highly qualified and effective teachers, and providing targeted professional development for teachers working with SWD. 


\section{Key Collaboration Findings}

Teachers Prefer

Math/English

Collaboration

- Fewer SWD in each class

- Supportive leadership
- Recommendation for Future Implementation
- Evenly distribute SWD among core classes

- Provide feedback and resources about collaborative instruction

\section{Collaboration Improved}

Over Time

- Consistent teacher

teams improved practice

- Less restrictive

environment for SWD

- Block schedule provides more instructional time
- Allow co-teachers to volunteer to work together

- Provide common planning time for co-teaching teams

- Provide professional development to enhance collaborative practice

- Evenly distribute SWD among core classes

- Maintain a block schedule

\section{Math/English}

Collaboration follows research-based practices

- Supportive leadership

- Organizational

structures

- Professional development is limited
- Maintain a block schedule

- Provide professional development for teachers working with SWD before and during the school year

- Provide formative, non-evaluative feedback to improve practice 


\section{Key Student Findings}

Student Non-cognitive

Indicators Improved

- SWD more dispersed

- Smaller numbers of

SWD in class

- Block schedule allows deeper student-teacher relationships

- Leadership supports positive learning environment

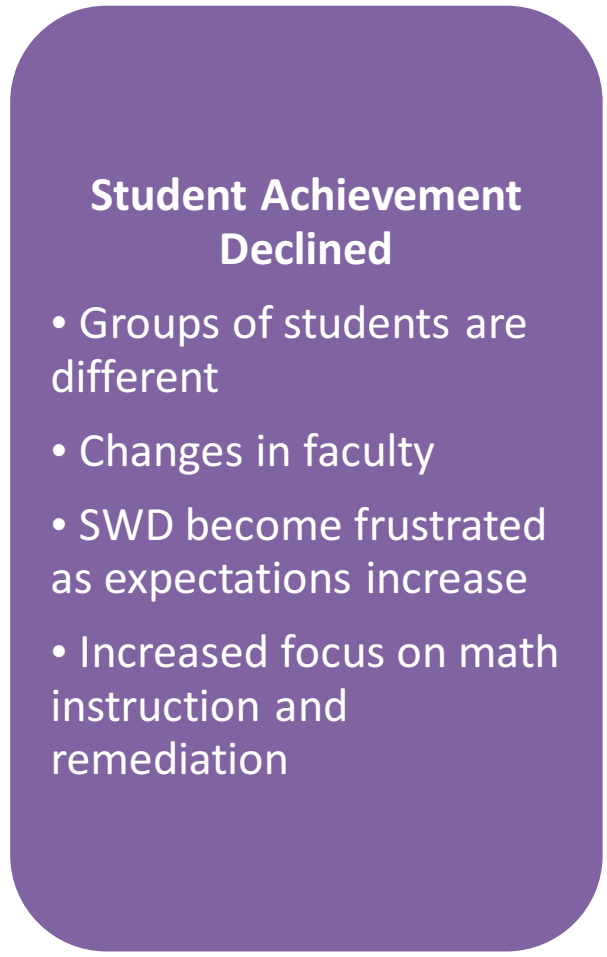

- Recommendations for Future Implementation
- Evenly distribute SWD among core classes

- Maintain a block schedule

- Maintain positive learning environment with high expectations for all
- Distribute SWD among classes to avoid known conflicts

- Continue to hire highly qualified teachers and train them to work with SWD

- Mentor new teachers to provide feedback and improve practice

- Maintain high and reasonable expectations for SWD

- Scaffold instruction to help SWD reach high expectations

- Increase focus on English and writing instruction 


\section{References}

Adnot, M., Dee, T., Katz, V., \& Wyckoff, J. (2017). Teacher turnover, teacher quality, and student achievement in DCPS. Educational Evaluation and Policy Analysis, 39(1), 54-76.

Akey, T. (2006). School context, student attitudes and behavior, and academic achievement: An exploratory analysis (MDRC Report). New York, NY: MDRC. Retrieved from http://inpathways.net/school_context.pdf

Allensworth, E., \& Easton, J. (2007). What matters for staying on track and graduating in Chicago Public Schools. Chicago, IL: Consortium on Chicago School Research at the University of Chicago.

Allington, R. L. (1983). The reading instruction provided readers of differing reading abilities. The Elementary School Journal, 83, 548-559.

Alger, G. (2005). Literacy teacher's interactions with instructional leaders: students reap the benefits. Current Issues in Education, 8(13), 1-24.

Austin, V. L. (2001). Teachers' beliefs about co-teaching. Remedial and Special Education, 22(4), 245-255.

Baker, E. T., Wang, M. C., \& Walberg, H. J. (1994). The effects of inclusion on learning. Educational Leadership, 52(4), 33-35.

Bauwens, J., \& Hourcade, J. J. (1995). Cooperative teaching: Rebuilding the schoolhouse for all students. Austin, TX: PRO-ED. 
Bauwens, J., \& Hourcade, J. J. (1997). Cooperative teaching: Pictures of possibilities. Intervention in School and Clinic, 33(2), 81-85, 89.

Bauwens, J., Hourcade, J. J., \& Friend, M. P. (1989). Cooperative teaching: A model for general and special education integration. Remedial and Special Education, 10, $17-22$.

Balfanz, R., Herzog, L., \& MacIver, D. (2007). Preventing student disengagement and keeping students on the graduation path in urban middle-grades schools: Early identification and effective interventions. Educational Psychology, 223-235.

Beyda, S. D., Zentall, S. S., \& Ferko, D. J. K. (2002). The relationship between teacher practices and the task-appropriate and social behavior of students with behavioral disorders. Behavioral Disorders, 27, 236-255.

Bolling v. Sharpe, 347 U.S. 497 (1954)

Boudah, D. J., Schumacher, J. B., \& Deschler, D. D. (1997). Collaborative instruction: Is it an effective option for inclusion in secondary classrooms? Learning Disability Quarterly, 20, 293-316.

Bradenburg, A.O. (1996). An analysis of block scheduling models and their impact on a positive school climate. Dissertation Abstracts International - A 57(01), 40.

Browder, D. M., Wakeman, S. Y., \& Flowers, C. (2006). Assessment of progress in the general curriculum for students with disabilities. Theory Into Practice, 45(3), 249259.

Brown v. the Board of Education of Topeka, Kansas, 347 U.S. 483 (1954). 
Brownell, M. T., Bishop, A. G., Gersten, R., Klingner, J. K., Penfield, R. D., Dimino, J., et al. (2009). The role of domain expertise in beginning special education teacher quality. Exceptional Children, 75(4), 391-411.

Brusca-Vega, R., Brown, K., \& Yasutake, D. (2011). Science achievement of students in co-taught, inquiry-based classrooms. Learning Disabilities: A Multidisciplinary Journal, 17(1), 23-31.

Buckman, D.C., B.B. King, and S. Ryan. (1995). Block scheduling: A means to improve school climate. NASSP Bulletin (May): 9-18.

Cancio, E. J., Albrecht, S. F., \& Johns, B. H. (2013). Defining administrative support and its relationship to the attrition of teachers of students with emotional and behavioral disorders. Education and Treatment of Children, 36(4), 71-94.

Carroll, J. M. (1994). The Copernican plan evaluated. The evolution of a revolution. Phi Delta Kappan (Oct.): 105-113.

Cole, C. M., Waldron, N., \& Majd, M. (2004). Academic progress of students across inclusive and traditional settings. Mental Retardation, 42(2), 136-144.

Cook, L., \& Friend, M. (1995). Co-teaching: Guidelines for creating effective practices. Focus on Exceptional Children, 28, 1-16

Dahlberg, K. A., \& Hoover, J. (2003). The effects of coteaching on K-6 student discipline and attendance. St. Cloud, MN: St. Cloud University.

Daniel R. R. v. State Board of Education, 874 F.2d 1036 ( $5^{\text {th }}$ Circuit Court, 1989).

Darling-Hammond, L., \& Young, P. (2002). Defining "highly qualified teachers": What does "scientifically based research" actually tell us? Educational Researcher, 31(9), 13-25. 
Deppeler, J. (2007). Leading Inquiry: Inquiry and Collaboration. Redesigning Pedagogy: Culture, Knowledge and Understanding. Singapore: National Institute of Education.

Deshler, D. D., \& Shumaker, J. B. (2006). High school students with disabilities: Strategies for accessing the curriculum. New York, NY: Corwin Press.

Dillman, D. A. (2002). Presidential address: Navigating the rapids of change: Some observations on survey methodology in the early twenty-first century. Public Opinion Quarterly, 66, 473-494.

Dillman, D. A. (2006). Why choice of survey mode makes a difference. Public Health Reports, 121(1), 11-13.

Dillman, D. A. \& Christian, L. (2002). The influence of words, symbols, numbers, and graphics on answers to self-administered questionnaires: Results from 18 experimental comparisons. Retrieved from http://sesrc.wsu.edu/dillman/papers/2002/theinfluencewords.pdf

Dillman, D. A., Sinclair, M. D., \& Clark, J. R. (1993). Effects of questionnaire length, respondent-friendly design and a difficult question on the response rates for occupant-addressed census mail surveys. Public Opinion Quarterly, 57(3), 289304.

Dynak, J., Whitten, E., \& Dynak, D. (1997). Refining the general education student teaching experience through the use of special education collaborative teaching models. Action in Teacher Education, 19, 64-75.

Edmonds, M., Vaughn, S., Wexler, J., Reutebuch, C., Cable, A., Tackett, K., et al. (2009). A synthesis of reading interventions and effects on reading 
comprehension outcomes for older struggling readers. Review of Educational Research, 79(1), 262-300.

Faggella-Luby, M. N., \& Deshler, D. D. (2008). Reading comprehension in adolescents with LD: What we know; what we need to learn. Learning Disabilities Research \& Practice, 23(2), 70-78.

Farbman, D., \& Kaplan, C. (2005). Time for a change: The promise of extended-time schools for promoting student achievement. Boston, MA: Massachusetts 2020.

Finn, J. D. (1989). Withdrawing from school. Review of Educational Research, 59, $117-$ 142.

Fisher, M., \& Meyer, L. (2002). Development and social competence after two years for students enrolled in inclusive and self-contained educational programs. Research \& Practice for Persons with Severe Disabilities, 27(3), 165-174.

Fisher, D., Pumpian, I., \& Sax, C. (1998). High school students' attitudes about and recommendations for their peers with significant disabilities. Journal of the Association of Persons with Severe Handicaps, 23, 272-280.

Freeman, C. (2001, November). Blocking the school schedule: Potential for instructional change. Paper presented at the Annual Meeting of the University Council for Educational Administration. Retrieved April 13, 2017 from http://cehd.umn.edu/CAREI/Reports/docs/BlockingSchedules.pdf

Freeman, S., \& Alkin, M. (2000). Academic and social attainments of children with mental retardation in general education and special education settings. Remedial and Special Education, 21(1), 3-18. 
Friend, M., \& Cook, L. (2000). Interactions: Collaboration skills for school professionals. New York, NY: Addison Wesley Longman, Inc.

Friend, M., \& Cook, L. (2010). Interactions: Collaboration skills for school professionals ( $6^{\text {th }}$ ed.). Columbus, OH: Merrill.

Fryxell, D., \& Kennedy, C. H. (1995). Placement along the continuum of services and its impact on students' social relationships. Journal of the Association of Persons With Severe Handicaps, 20(4), 259-269.

Fuchs, D., \& Fuchs, L. (1995). Sometimes separate is better. Educational Leadership, $52(4), 22-26$.

Fuchs, L. S., \& Fuchs, D. (2001). Principles for the prevention and intervention of mathematics difficulties. Learning Disabilities Research \& Practice, 16(2), 8695.

Fuchs, D., Fuchs, L. S., \& Fernstrom, P. (1993) A conservative approach to special education reform: Mainstreaming through transenvironmental programming and curriculum-based measurement. American Educational Research Journal, 30(1), $149-177$.

Gambrell, L., Wilson, R. M., \& Walter, N. (1981). Classroom observations of taskattending behaviors of good and poor readers. Journal of Educational Research, $74,400-404$.

Gamoran, A. (1986). Instructional and institutional effects of ability grouping. Sociology of Education, 59, 185-199. 
Garcia-Reid, P., Reid, R. J., \& Peterson, N. A. (2005). School engagement among Latino youth in an urban middle school context: Valuing the role of social support. Education \& Urban Society, 37(3), 257-275. doi: 10.1177/0013124505275534

Goodlad, J. (1984). A place called school: Prospects for the future. New York: McGrawHill.

Gunn, H. (2002). Web-based surveys: Changing the survey process. First Monday, 7(12), n. pag. doi: http://dx.doi.org/10.5210/fm.v7i12.1014

Gurian, M. (2006). Learning and gender. American School Board Journal, 193(10), 1922.

Hackmann, D.G. 1995. 'Fen guidelines for implementing block scheduling. Educational Leadership (Nov.): 24-27.

Heller, R., Calderon, S., \& Medrich, E. (2003). Academic achievement in the middle grades: What does research tell us? A review of the literature (SREB Report). Atlanta, GA: Southern Regional Educational Board. Retrieved from http://eric.ed.gov/?id=ED478009

Hunt, P., Alwell, M., Farron-Davis, F., \& Goetz, L. (1996). Creating socially supportive environments for fully included students who experience multiple disabilities. The Journal of the Association for Persons with Severe Handicaps, 21, 53-71.

Hunt, P., \& Goetz, L. (1997). Research on inclusive educational programs, practices, and outcomes for students with severe disabilities. The Journal of Special Education, 31(1), 3-29. 
Hunt, P., Staub, D., Alwell, M., \& Goetz, L. (1994). Achievement by all students within the context of cooperative learning groups. Journal of the Association for Persons with Severe Handicaps, 19, 290-301.

Individuals With Disabilities Education Act, 20 U.S.C. § 1400 (1990).

Individuals With Disabilities Education Act, 20 U.S.C. $§ 1400$ (2004).

Kauffman, J., \& Hallahan, D. (1995). The illusion of full inclusion. Austin, TX: Pro-Ed, Inc.

Kauffman, J. M., Landrum, T. J., Mock, D. R., Sayeski, B., \& Sayeski, K. L. (2005). Diverse knowledge and skills require diversity of instructional groups: A position statement. Remedial and Special Education, 26(1), 2-6.

Kennedy, M. J., \& Ihle, F. M. (2012). The old man and the sea: Navigating the gulf between special educators and the content area classroom. Learning Disabilities Research \& Practice, 27(1), 44-54.

Kennedy, C., Shulka, S., \& Fryxell, D. (1997). Comparing the effects of educational placement on the social relationships of intermediate school students with severe disabilities. Exceptional Children, 64(1), 31-48.

King-Sears, M. E. (1995). Teamwork toward inclusion: A school system and university partnership for practicing educators. Action in Teacher Education, 17, 54-66.

Kilanowski-Press, L., Foote, C. J., \& Rinaldo, V. J. (2010). Inclusion classrooms and teachers: A survey of current practices. International Journal of Special Education, 25(3), 43-56. 
Klingner, J. K., Arguelles, M. E., Hughes, M. T., \& Vaughn, S. (2001). Examining the schoolwide "spread" of research-based practices. Learning Disability Quarterly, $24,221-234$.

Landrum, T. J., Tankersley, M., \& Kauffman, J. M. (2003). What's special about special education for students with emotional and behavioral disorders? The Journal of Special Education, 37, 148-156.

Leone, P. E., Mayer, M. J., Malmgren, K., \& Meisel, S. M. (2000). School violence and disruption: Rhetoric, reality, and reasonable balance. Focus on Exceptional Children, 33(1), 1-20.

Lytle, S. L., \& Cochran-Smith, M. (1992). Teacher research as a way of knowing. Harvard Educational Review, 62, 447-474.

Magiera, K., \& Zigmond, N. (2005). Co-teaching in middle school classrooms under routine conditions: Does the instructional experience differ for students with disabilities in co-taught and solo-taught classes? Learning Disabilities Research and Practice, 20(2), 79-85.

McLaurin v. Oklahoma State Regents, 339 U.S. 637 (1950).

Miller, K. J., \& Savage, L. B. (1995). (1995, March). Including general educators in inclusion. Paper presented at the meeting of the American Council on Rural Special Education, Las Vegas, NV.

Minke, K. M., Bear, G. G., Deemer, S. A., \& Griffin, S. M. (1996). Teachers' experiences with inclusive classrooms: Implications for special education reform. The Journal of Special Education, 30, 152-186.

Missouri ex rel. Gaines v. Canada, 305 U.S. 337 (1938). 
Mock, D. R., \& Kauffman, J. M. (2002). Preparing teachers for full inclusion: Is it possible? The Teacher Educator, 37, 202-215.

Murawski, W. (2009). Collaborative teaching in secondary schools: Making the coteaching marriage work! Thousand Oaks, CA: Corwin Press.

Murawski, W. W. \& Lochner, W. W. (2011). Observing co-teaching: What to ask for, look for, and listen for. Intervention in School and Clinic, 46(3), 174-183.

Neild, R. C., \& Balfanz, R. (2006). Unfulfilled promise: the dimensions and characteristics of Philadelphia's droupout crisis. Philadelphia: Philadelphia Youth Network, Johns Hopkins University \& the University of Pennsylvania.

No Child Left Behind Act (NCLB). (2001). P.L. 107-110, 115 Stat. 1425 (2002).

Northeast and Islands Regional Educational Laboratory. (1998). Block scheduling: Innovations with time. LAB at Brown University.

Oberti v. Clementon School District, 995 F.2d 1204 (3rd Cir., 1993)

O’Neil, J. (1995). Finding time to learn. Educational Leadership. 53(3), 11-15.

Patton, M. Q. (2008). Utilization focused evaluation (4 ${ }^{\text {th }}$ Ed.). Thousand Oaks, CA: SAGE Publications.

Pennsylvania Association for Retarded Children (PARC) v. Commonwealth of Pennsylvania, 343 Fed. Supp. 279 (1972).

Peterson, J. M., \& Hittie, M. M. (2003). Inclusive teaching: Creating effective schools for all children. Boston, MA: Allyn \& Bacon.

Pressley, M., \& Harris, K. L. (2006). Cognitive strategies instruction: From basic research to classroom instruction. In P. A. Alexander \& P. H. Winne (Eds.), 
Handbook of Educational Psychology (2 ${ }^{\text {nd }}$ ed., pp. 265-286). Mahweh, MJ: Lawrence Erlbaum.

Pugach, M. C., \& Johnson, L. J. (1995). Collaborative practitioners, collaborative schools. Denver, CO: Love.

Pugach, M. C., \& Seidl, B. L. (1995). From exclusion to inclusion in urban schools: A new case for teacher education reform. Education and Urban Society, 27, 379395.

Ravid, R. (2011). Practical statistics for educators (4 ${ }^{\text {th }}$ ed.). Lanham, MD: Rowman \& Littlefield.

Reed, A. J., \& Bergemann, V. E. (2005). A Guide to Observation, Participation, and Reflection in the Classroom (5th ed.). New York: McGraw- Hill.

Remler, D. R., \& Van Ryzin, G. G. (2011). Research methods in practice: Strategies for description and causation. Thousand Oaks, CA: SAGE Publications.

Roncker v. Walter, 700 F2d. 1058 (6 $6^{\text {th }}$ Circuit Court, 1993)

Rosenbaum, J. (1976). Making inequality: The hidden curriculum of high school tracking. New York: Wiley.

Sacramento Unified School District v. Rachel H., 14 F.3d 1398 (9th Cir., 1994)

Scruggs, T. E., Mastropieri, M. A., \& McDuffie, K. A. (2007). Co-teaching in inclusive classrooms: A metasynthesis of qualitative research. Council for Exceptional Children, 73(4), 392-416.

Schulte, A. C., Osborne, S. S., \& Kauffman, J. M. (1993). Teacher responses to two types of consultative special education services. Journal of Educational and Psychological Consultation, 4(1), 1-27. 
Skiba, R. J., Peterson, R. L., \& Williams, T. (1997). Office referrals and suspension: Disciplinary intervention in middle schools. Education and Treatment of Children, 20(3), 295-315.

Smith, W. F., \& Richards, A. L. (1989). Instructional Leadership: How Principals Make a Difference. Alexandria: Association for Supervision and Curriculum.

Solis, M., Vaughn, S., Swanson, E., \& McCulley, L. (2012). Collaborative models of instruction: The empirical foundations of inclusion and co-teaching. Psychology in the Schools, 49(5), 498-510.

Thurlow, M. L., \& Wiley, H. I. (2004). Almost there in public reporting of assessment results for students with disabilities (Technical Report 39). Minneapolis, MN: University of Minnesota, National Center on Educational Outcomes

United States Department of Education. (2007). Twenty-seventh annual report to congress on the implementation of the Individuals With Disabilities Education Act, 2005 (Vol. 1). Washington, DC: Westat.

Snyder, T. D., \& Dillow, S. A. (2011). Digest of education statistics. Washington, DC: United States Department of Education, Institute of Education Services, National Center for Education Statistics. Retrieved from http://nces.ed.gov/programs/digest/d11/tables/dt11_046.asp

United States Department of Education. (2012). Virginia state snapshot. Washington, DC: Author Retrieved from http://eddataexpress.ed.gov/statereport.cfm/state/VA/

University of Massachusetts Donahue Institute. (2004). Report of field research findings: Case studies and cross-case analysis of promising practices in selected urban 
public school districts in Massachusetts. Hadley, MA: Research and Evaluation Group.

Vaughn, S., Schumm, J. S., \& Arguelles, M. E. (1997). The abcdes of co-teaching. Teaching Exceptional Children, 30(2), 4-10.

Villa, R. A., Thousand, J. S., \& Chapple, J. W. (1996). Preparing teachers to support inclusion: Preservice and inservice programs. Theory Into Practice, 35, 42-50.

Pyle, C. B. (2010, April 22). State superintendent announces start of phaseout of VGLA: New online reading and math tests for students with disabilities. Richmond, VA: Virginia Department of Education News. Retrieved from http://www.doe.virginia.gov/news/news_releases/2010/apr22.pdf

Virginia Department of Education. (2011). Regulations governing special education programs for children with disabilities in Virginia. Richmond, VA.

Virginia Department of Education. (2012). Graduation requirements. Richmond, VA: Author. Retrieved from http://www.doe.virginia.gob/instruction/graduation/index.shtml

Waldron, N., \& McLeskey, J. (1998). The effects of an inclusive school program on students with mild and severe learning disabilities. Exceptional Children, 64(2), $395-405$.

Walther-Thomas, C., Bryant, M., \& Land, S. (1996). Planning for effective co-teaching: The key to successful inclusion. Remedial and Special Education, 17, 255-265. Zigmond, N. (2003). Where should students with disabilities receive special education services? Is one place better than another? The Journal of Special Education, 37, 193-199. 


\section{Appendix A}

\section{Collaborative Instruction Survey}

Note from the Researcher: The following survey questions will address the implementation of collaborative instruction during the 2015-2016 school year.

Directions: Please answer the following questions by checking the boxes that most accurately represent the 2015-2016 school year. All answers will be collected and analyzed anonymously.

\section{General Information}

1. I have been teaching for:

2. I have been teaching at Central Middle School:

\begin{tabular}{|c|c|c|c|}
\hline $\begin{array}{c}0-5 \\
\text { years }\end{array}$ & $6-10$ years & $\begin{array}{c}11-20 \\
\text { years }\end{array}$ & $\begin{array}{c}\text { over } 20 \\
\text { years }\end{array}$ \\
\hline & & & \\
\hline & & & \\
\hline
\end{tabular}

3. During the 2015-2016 school year, I taught:
a. grade level
b. general education or special education
c. subject
d. collaborative classes

\begin{tabular}{|c|c|c|c|}
\hline & $6^{\text {th }}$ & $7^{\text {th }}$ & $8^{\text {th }}$ \\
\hline & $\begin{array}{c}\text { general } \\
\text { education }\end{array}$ & & $\begin{array}{c}\text { special } \\
\text { education }\end{array}$ \\
\hline Math & English & Science & $\begin{array}{c}\text { Social } \\
\text { Studies }\end{array}$ \\
\hline & $\begin{array}{c}\text { no } \\
\text { collaborative } \\
\text { classes }\end{array}$ & $\begin{array}{c}\text { one } \\
\text { collaborative } \\
\text { class }\end{array}$ \\
\hline
\end{tabular}

\section{Leadership/Administrative Support}

4. Was collaborative education offered as an optional role for the 2015-2016 school year?

5. How many times were you observed by a supervisor during a collaborative class?

6. Please rate the following statements about your building principal during the 2015-2016 school year:

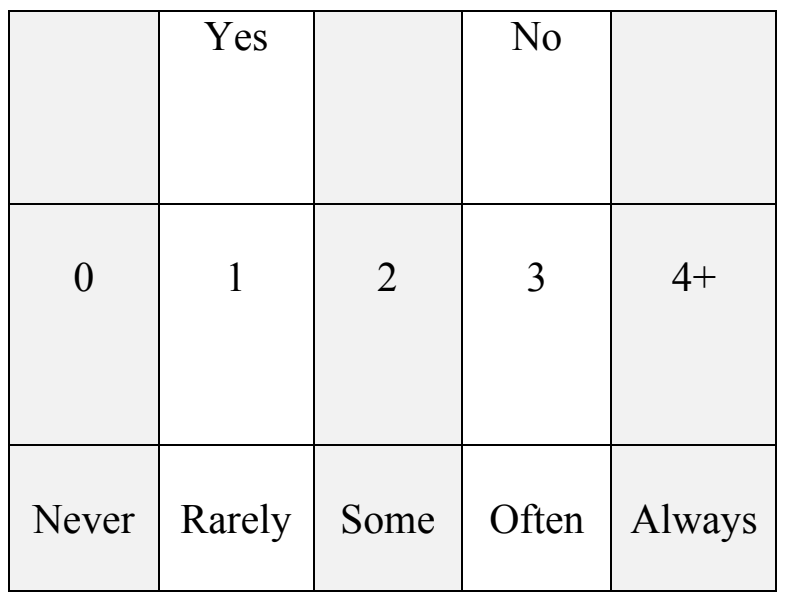


a. Provided suggestions for me to improve instruction

b. Provided information on up-to-date instructional and behavioral techniques

c. Provided time for various nonteaching responsibilities (e.g. IEP's, meetings)

d. Provided adequate planning time

e. Emphasized inclusion and access to the curriculum

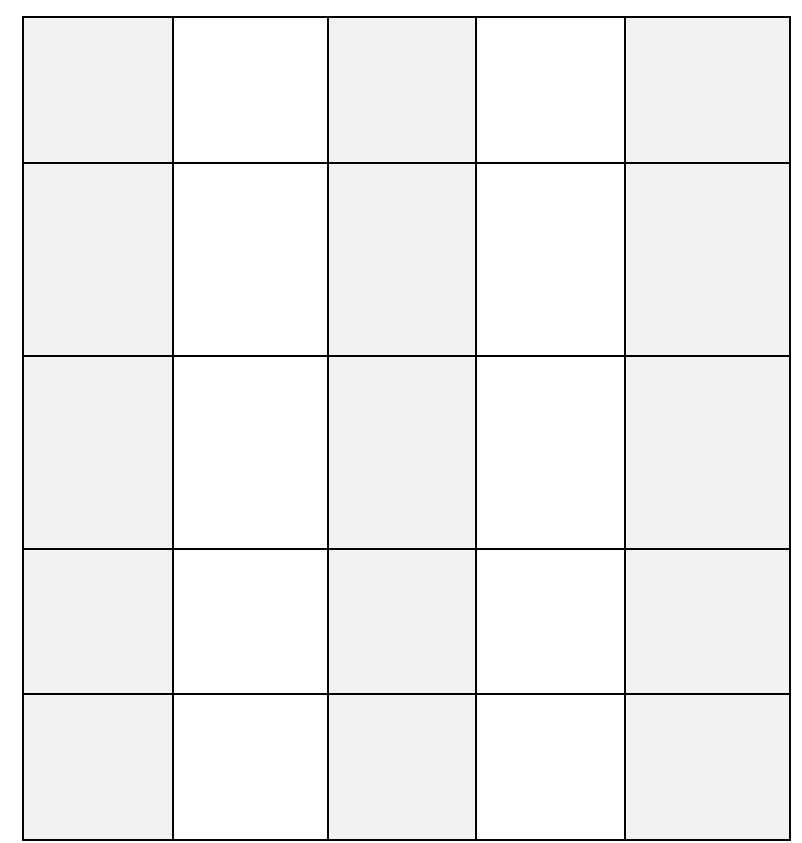

\section{Organizational Structures}

Please take a moment to read the following descriptions of various types of collaborative instruction models:

A. One teach, one assist: One teacher, usually the general educator, assumes teaching responsibilities, and the special education teacher provides individual support as needed. B. Station teaching: Various learning stations are created, and the co-teachers provide individual support at the different stations.

C. Parallel teaching: Teachers teach the same or similar content in different classroom groupings.

D. Alternative teaching: One teacher may take a smaller group of students to a different location for a limited period of time for specialized instruction.

E. Team teaching: Both co-teachers share teaching responsibilities equally and are equally involved in leading instructional activities.

7. Based on the explanations of the five models of collaborative instruction, which model best describes your experience?

8. Please rate the professional relationship between you and your collaborative partner?

\begin{tabular}{|c|c|c|c|c|}
\hline 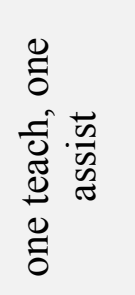 & 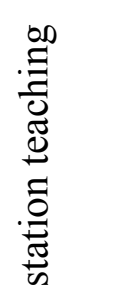 & 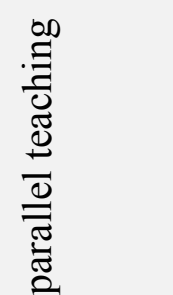 & 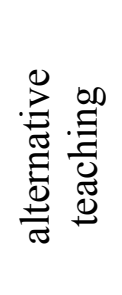 & 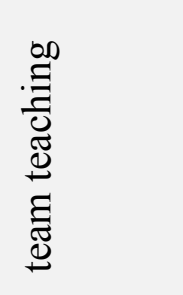 \\
\hline Poor & Fair & Average & Good & Excellent \\
\hline 0 & 0.5 & 1 & 2 & $3+$ \\
\hline
\end{tabular}

9. How much weekly planning time (in hours) did you spend on average with your collaborative partner? 
10. To what extent did the general educator and special educator collaborate together on lesson plans?

11. To what extent did both teachers share the responsibility for student discipline?

12. To what extent did both teachers share the responsibility for instructing students?

\begin{tabular}{|c|c|c|c|c|}
\hline Never & Rarely & Some & Often & Always \\
& & & & \\
\hline Entirely & Mostly & Evenly & Mostly & Entirely \\
Gen. & Gen. & & Sp. & Sp. Ed. \\
Ed. & Ed. & & Ed. & \\
\hline Entirely & Mostly & Evenly & Mostly & Entirely \\
Gen. & Gen. & & Sp. & Sp. Ed. \\
Ed. & Ed. & & Ed. & \\
\hline
\end{tabular}

\section{Professional Development}

13. How many hours of training did you receive before the school year began in preparation for collaborative instruction?

14. How many hours of training did you receive during the school year to support your collaborative instruction?

15. How much, if any, teacher training focused on the following topics:
a. strategies and skill development
b. different collaborative models
c. characteristics of disabilities
d. collaborative consultation skills
e. communicating more effectively

\begin{tabular}{|l|l|l|l|l|}
\hline None & $1-3$ & $4-8$ & $9-12$ & $13+$ \\
\hline & & & & \\
\hline None & Little & Some & Much & All \\
\hline & & & & \\
\hline & & & & \\
\hline & & & & \\
\hline & & & & \\
\hline
\end{tabular}

This concludes the Collaborative Instruction Survey.

Thank you for your time. 
Appendix B

\section{Teacher Interview Protocol}

1. Please tell me about your role at Central Middle School from 2011-2016.

a. What subject did you teach?

b. Are you a general educator or special educator?

2. Describe your instructional philosophy.

a. What does this mean for Students With Disabilities?

b. How do you structure your classroom for Students With Disabilities?

3. Please take a look at these SOL data from the past 6 years for Students With

Disabilities at CMS and the student body as a whole. What sense do you make of these data?

a. What has changed that may have contributed to these patterns in student achievement?

Prompts:

- Nature of collaborative instruction?

- Administrative support?

- Organizational structures?

- Professional development?

4. Please take a look at these attendance data from the past 5 years for Students With Disabilities. What sense do you make of these data?

a. What has changed that may have contributed to these patterns in student attendance? 
Prompts:

- Nature of collaborative instruction?

- Administrative support?

- Organizational structures?

- Professional development?

5. Please take a look at these discipline data from the past 5 years for Students With Disabilities at CMS and the student body as a whole. What sense do you make of these data?

a. What has changed that may have contributed to these patterns in student achievement, discipline, and attendance?

Prompts:

- Nature of collaborative instruction?

- Administrative support?

- Organizational structures?

- Professional development?

More questions based on responses above.

\section{Collaborative Education:}

a. Describe collaborative education and how it has changed over this time period.

b. How might these changes have affected student achievement?

c. How might these changes have affected student discipline?

d. How might these changes have affected student attendance? 


\section{Administrative support:}

a. What can you tell me about the administrative support for collaborative education at CMS?

b. How might this administrative support have affected student achievement?

c. How might this administrative support have affected student discipline?

d. How might this administrative support have affected student attendance?

\section{Organizational Structures:}

a. What can you tell me about the organizational structures (such as schedule) at CMS that might have affected collaborative education?

b. How might these structures have affected student achievement?

c. How might these structures have affected student discipline?

d. How might these structures have affected student attendance?

\section{Professional Development:}

a. What can you tell me about professional development at CMS and its relationship to collaborative education?

b. How might professional development have affected student achievement?

c. How might professional development have affected student discipline?

d. How might professional development have affected student attendance? 


\section{Appendix C}

\section{Initial E-mail to Potential Interviewees}

\section{Dear Colleague,}

I am currently working on my doctoral research regarding the implementation of collaborative instruction at your school and its perceived effects. If you are willing, I would like to sit with you and ask some questions about your experiences in collaborative classrooms at the middle school and how those experiences may have impacted students. The interview will last 20-30 minutes.

I can assure you, there will be no information used that will identify you as a teacher at_Middle School. The name and exact location of the school will not be published, and no names of students or teachers will be reported.

If you are willing to be interviewed, please respond with a selection of dates and times that suit your schedule. I look forward to talking with you.

Sincerely,

Bethany Hunter 
Appendix D

Transcript of After-School Faculty Meeting Address

Over the past few years I have been researching Collaborative Instruction and its potential benefits for students, especially Students With Disabilities. As part of this research, I need teacher input about the Collaborative Instruction environment here at your school and how you think it impacts your students.

This afternoon, you will receive an e-mail with a link to a survey at Survey Monkey. The survey is completely anonymous and will only take you 5-10 minutes to complete.

To further ensure your anonymity, the name of the school and its location will not be published. A pseudonym and general location will be used in the publication to protect the identities of the students and teachers involved.

I have been working on this research for several years, and I do hope that you will take a few minutes to contribute information about your experiences in an effort to complete this work.

Thank you so much for your time! 


\section{Appendix E}

\section{Procedures for Data Collection}

\section{Student Data}

The researcher requested a school-generated report of student demographics, attendance, discipline, and SOL scores, from Central High School. In the absence of some data, the researcher searched student files to find information that was not reported electronically. The researcher kept all student identification confidential by assigning each student a number for data collection.

\section{Interviews}

The researcher sent an e-mail invitation (see Appendix C) to six teachers who taught collaborative education at the middle school during the time of the study (three special educators, two English teachers, and one math teacher); the initial e-mail explained the study, assured confidentiality, and requested an interview. The interviewer met with each interviewee privately, outside of school hours, in a location of the interviewee's choosing. The interview protocol allowed the interviewer to prompt interviewees if they did not answer initial questions completely. The interviewer used the "Voice Memo" application available on iPhones to record each interview for transcription. Data from the interview was used to clarify descriptions of the survey data.

\section{Survey}

To obtain teacher perception data, the researcher addressed the middle school faculty after school in the Fall of 2016 to discuss the purpose and importance of the Collaborative Instruction Survey (see Appendix D). Teachers received the link to the web-based survey in an e-mail after the faculty meeting. According to Remler and Van 
Ryzin (2011), computer-assisted personal interviewing (CAPI) allows for confidentiality and easily accessible data. The researcher entered data into a spreadsheet to be analyzed with descriptive statistics. The combined interview and survey data provided a clear description of the learning environment at the middle school during the time of the study, answering Research Questions 1 and 2. 